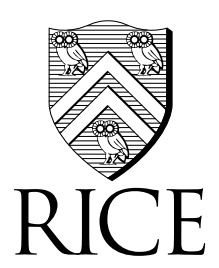

\title{
MECHANISMS AND OPTIMIZATION OF COAL COMBUSTION
}

\author{
Final Technical Report \\ Performance Period: 11/1/1996 -10/31/2000
}

Submitted to the

Department of Energy

Grant Number DE-FG22-96PC96214

PRINCIPAL INVESTIGATOR

Kyriacos Zygourakis

Department of Chemical Engineering

Rice University

Houston, Texas 77251-1892 


\section{TABLE OF CONTENTS}

SECTION 1: OBJECTIVES AND SIGNIFICANCE ..................................................

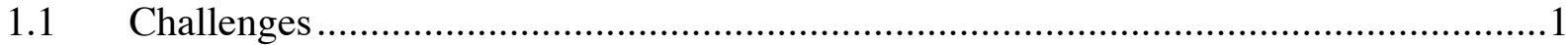

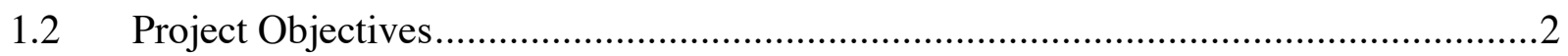

SECTION 2 EXPERIMENTAL EQUIPMENT AND PROCEDURES …...................... 4

2.1 TGA Reactor with in-situ Video Microscopy System (TGA/VMI)...........................4

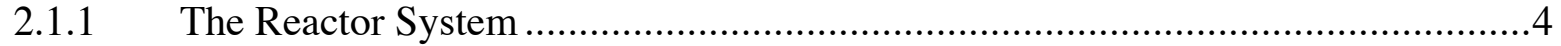

2.1.2 Video Microscopy System ..................................................................

2.2 Experimental Conditions and Procedures .........................................................6

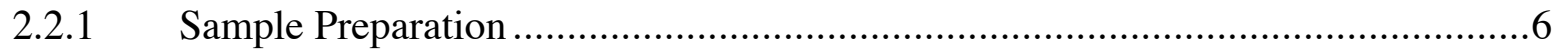

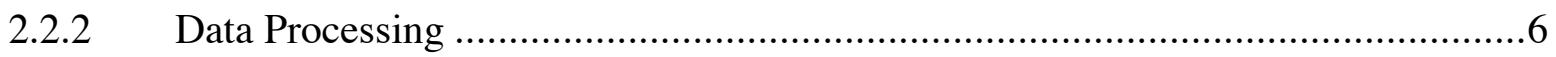

2.2.3. Staged and Sequential Combustion Protocol .................................................8

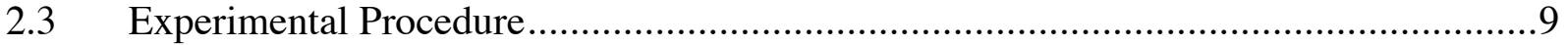

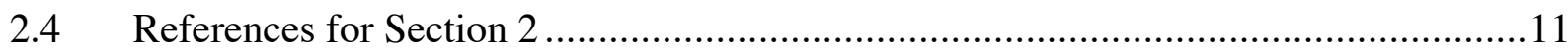

\section{SECTION 3: PYROLYSIS AND THE EFFECT OF HEATING RATE} ON CHAR MACROPORE STRUCTURE ......................................... 20

3.1 Many coals soften and become plastic during pyrolysis ......................................20

3.2 Pyrolysis conditions affect the devolatilization rates .......................................2 21

3.3 Pyrolysis heating rates affect the macropore structure of produced chars .................23

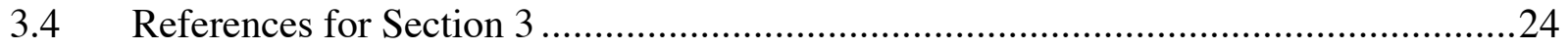

\section{SECTION 4: EFFECT OF PYROLYSIS CONDITIONS} ON CHAR COMBUSTION RATE ........................................................ 32

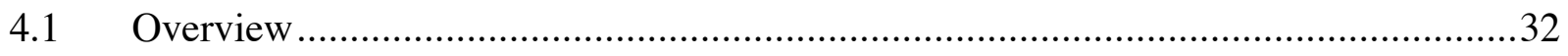

4.2. Effect of pyrolysis heating rate on char reactivity ….......................................32 


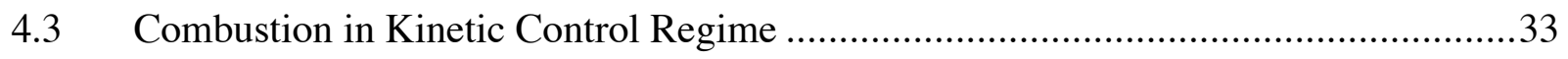

4.4 Combustion in the Regime of Diffusional Limitations ...............................................34

4.5 Combustion in External Mass Transfer Controlled Regime........................................35

4.6 The effect of heat treatment temperature and soak time..............................................37

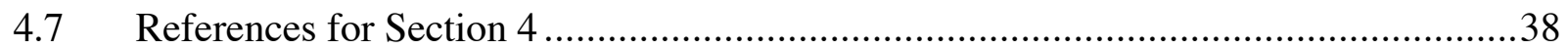

SECTION 5: EFFECT OF PARTICLE SIZE ON CHAR REACTIVITY .........................61

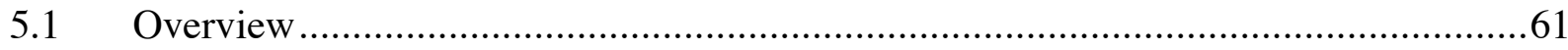

5.2. Effect of particle size on intrinsic reactivity of char ................................................61

5.3 Effect of particle size on reactivity in the regime of diffusional limitations ................62

5.4 Effect of particle size on reactivity at external mass transfer controlled regime ..........63

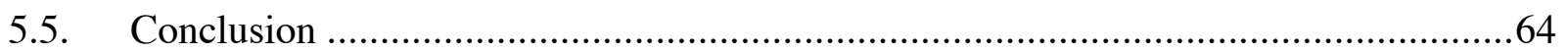

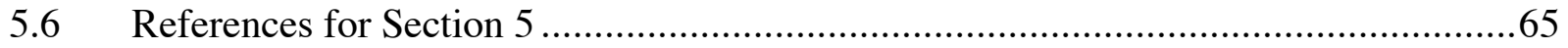

SECTION 6: DETECTION AND CHARACTERIZATION OF CHAR AND COAL PARTICLE IGNITIONS ............................................ 73

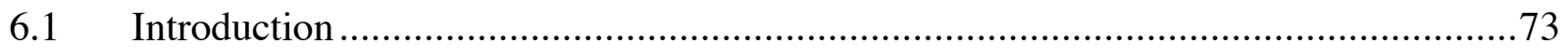

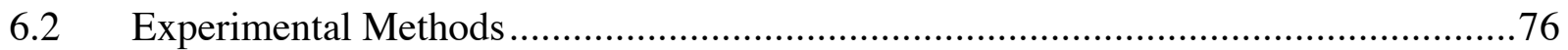

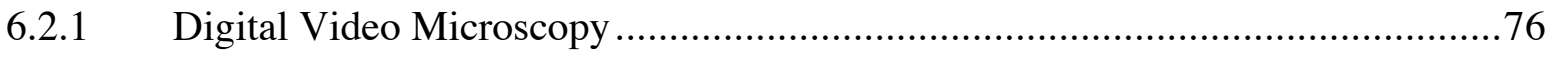

6.2.2. Combustion and Pyrolysis Experiments ………...............................................

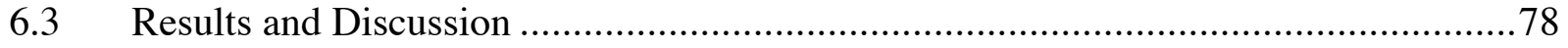

6.3.1 Homogeneous and Heterogeneous Ignitions ..................................................

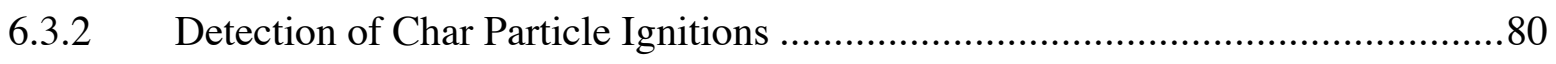

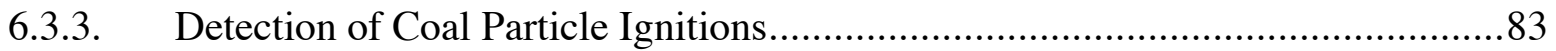

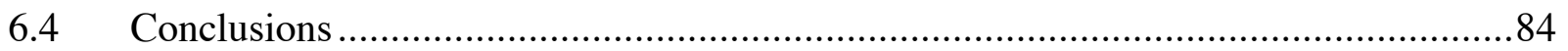

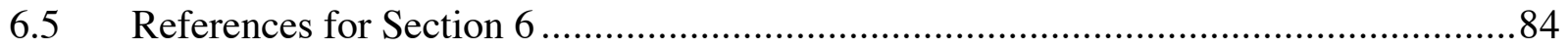

SECTION 7: MODELING THE IGNITION OF CHAR PARTICLES .............................98

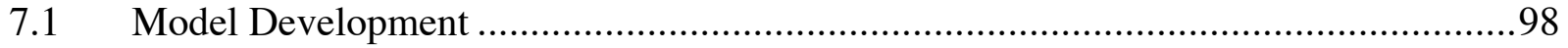

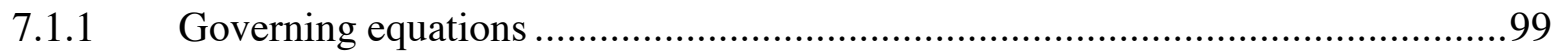

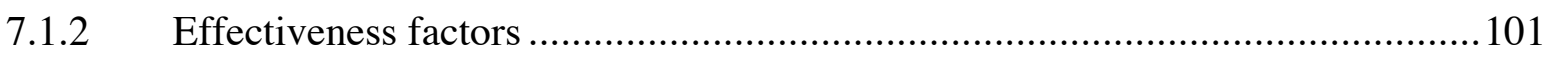

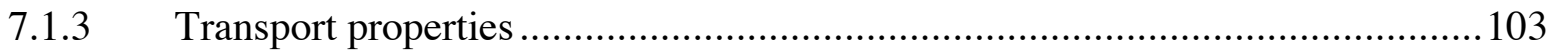

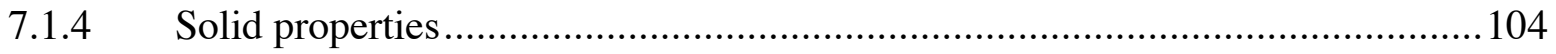




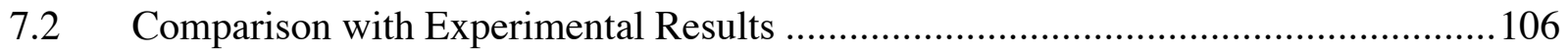

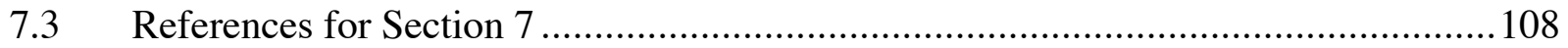

\section{SECTION 8: EFFECT OF REACTION CONDITIONS AND PORE STRUCTURAL} PARAMETERS ON CHAR PARTICLE IGNITIONS ............................ 115

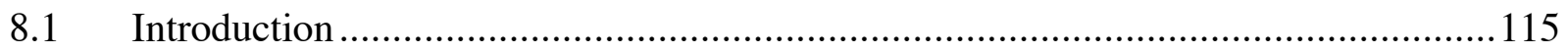

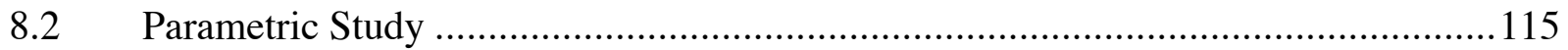

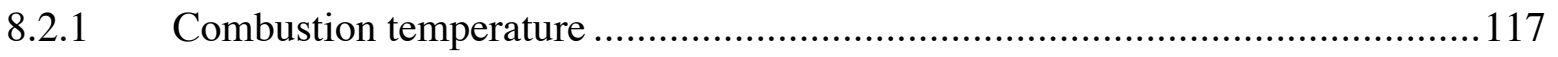

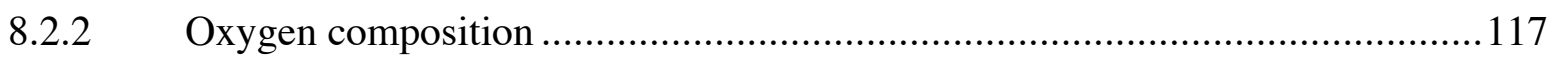

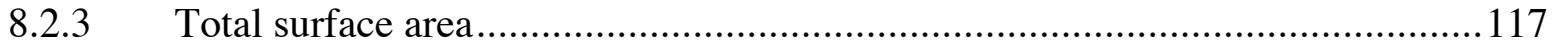

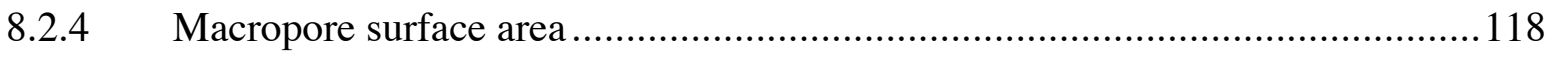

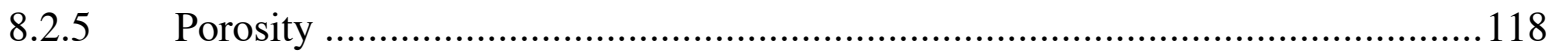

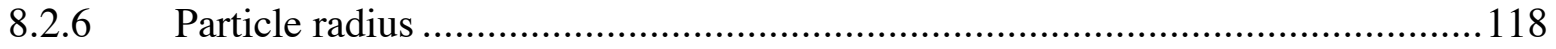

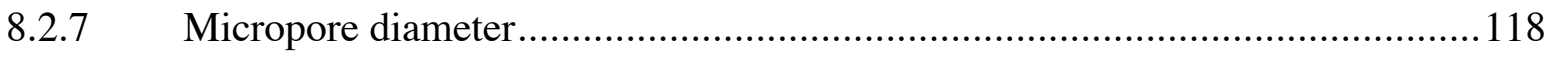

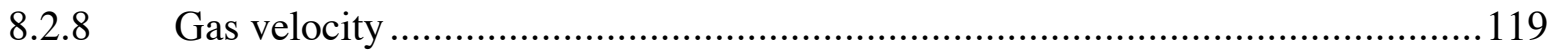

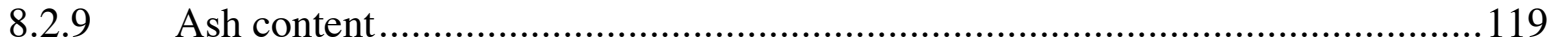

8.3 Random Variation of Char Properties …………................................................119

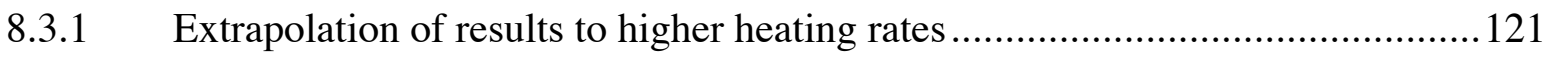

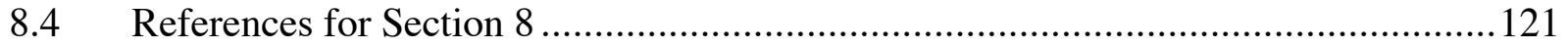




\section{SECTION 1}

\section{OBJECTIVES AND SIGNIFICANCE}

\section{$1.1 \quad$ Challenges}

About $85 \%$ of the coal produced in the United States is used to produce about $55 \%$ of its electricity. To continue using coal for electric power generation, we must make coal burn cleaner and make coal-fired plants more efficient. The 1990 Amendments to the Clean Air Act require drastic reductions in the levels of $\mathrm{SO}_{\mathrm{X}}, \mathrm{NO}_{\mathrm{X}}$ and particulate emissions. Another goal for the industry is to significantly reduce $\mathrm{CO}_{2}$ emissions by increasing the thermal efficiency of the

power plants. For all these reasons, a lot of attention has recently focused on the development of efficient and environmentally clean technologies for production of electricity. Various projects have already demonstrated the commercial feasibility of low-emission boiler systems (LEBS), as well as high-performance power systems that will improve their thermal efficiency while reducing even further the emissions of $\mathrm{SO}_{\mathrm{X}}, \mathrm{NO}_{\mathrm{X}}$ and particulates.

The current intent of the industry, however, is to move from a pollution control policy (exemplified by end-of-pipe clean-up processes for removal of $\mathrm{SO}_{\mathrm{X}}, \mathrm{NO}_{\mathrm{X}}$ and other pollutants like $\mathrm{CO}_{2}$ ) to a pollution prevention policy in which the processes are designed to prevent or minimize the generation of pollutants and hazardous wastes. As the industry shifts its emphasis from pollution clean-up and compliance with environmental regulations to pollution prevention, the requirements for process modifications that will optimize the performance of coal combustors will become even more pressing.

Optimal design and operation of advanced technology combustors will require precise knowledge of the fundamental pyrolysis and combustion mechanisms. Design engineers should know how operating conditions affect coal combustion and they should have computational tools 
to accurately predict (a) coal particle burn-off times under any process conditions and (b) carbon loads. These tools should combine a large database of properties for various coals and mathematical models that allow accurate simulations of combustion processes.

\subsection{Project Objectives}

The completed research project has made some significant contributions that will help us meet the challenges outlined in the previous section.

One of the major novelties of our experimental approach involves the application of video microscopy and digital image analysis to study important transient phenomena (like particle swelling and ignitions) occurring during coal pyrolysis and combustion. Image analysis was also used to analyze the macropore structure of chars, a dominant factor in determining char reactivity and ignition behavior at high temperatures where all the commercial processes operate. By combining advanced experimental techniques with mathematical modeling, we were able to achieve the main objectives of our project. More specifically:

1. We accurately quantified the effect of several important process conditions (like pyrolysis heating rate, particle size, heat treatment temperature and soak time) on the combustion behavior of chars. These measurements shed new light into the fundamental mechanisms of important transient processes like particle swelling and ignitions.

2. We developed and tested theoretical models that can predict the ignition behavior of char particles and their burn-off times at high temperatures where intraparticle diffusional limitations are very important.

To achieve these project objectives, the following tasks were successfully implemented.

TASK A: The transient swelling patterns of pyrolyzing coal particles were studied in a TGA reactor using video microscopy with in-situ imaging and under conditions approaching those encountered in coal utilization processes (heating rates up to $20{ }^{\circ} \mathrm{C} / \mathrm{s}$, temperatures up to 1,000 
${ }^{\circ} \mathrm{C}$ ). Our studies focused primarily on an industrially important plastic coal (Illinois \#6 from the Argonne collection) and a wide range of particle sizes $(100-850 \mu \mathrm{m})$ was used.

TASK B: Coal and char combustion were studied using several experimental protocols and under conditions where intraparticle diffusional limitations become important. Various gas flow rates and $\mathrm{O}_{2}$ concentrations were used to investigate the effect of external mass transfer limitations at high temperatures..

TASK C: A novel experimental technique (based on digital image analysis) was developed to accurately detect particle ignitions and to monitor changes in particle size during combustion. The implications of particle ignitions for the reactivity of coals and chars during combustion were carefully evaluated.

TASK D: We finally developed a mathematical model that describes the transient behavior of particles during ignition. Kinetic data and pore structural measurements obtained in earlier phases of our study were used to evaluate the ability of this model to describe the fundamental mechanisms of transient processes (like ignitions) occurring during coal and char combustion. 


\section{SECTION 2}

\section{EXPERIMENTAL EQUIPMENT AND PROCEDURES}

\subsection{TGA Reactor with in-situ Video Microscopy System (TGA/VMI)}

All of our experiments were carried out in a custom-modified thermogravimetric analyzer with in-situ video microscopy imaging capability. The reactor system was interfaced to a personal computer that performed all data acquisition and control tasks. Weight and reactor temperature data were continuously recorded during the experiments and were post-processed to measure the reactivity of coal and char samples.

The video microscopy imaging system allowed direct visualization of the structural changes that coal particles undergo during pyrolysis or combustion. Also, by tracing the light emission intensity along with reactivity measurement, important phenomena such as particle ignitions could be detected.

\subsubsection{The Reactor System}

The thermogravimetric reactor (Perkin-Elmer, TGS-2) system was interfaced to a computer that controlled the reactor temperature, gas flow and the data acquisition during the reaction (Figure 2.1). A personal computer (Apple Macintosh Quadra 900) was used to perform all control and data acquisition tasks.

For each experiment, coal samples were placed in the platinum sample pan of the reactor. The reactor had a sensitivity of $0.1 \mu \mathrm{g}$ and accuracy of $0.1 \%$; thus, it could accurately measure the weight loss during the reaction. The data acquisition and computer control tasks were 
performed using two data acquisition boards (NB-MIO-16L and NB-AO6, National Instruments).

The sample pan was placed inside a cylindrical ceramic furnace. Capable of withstanding temperatures up to $1150^{\circ} \mathrm{C}$, the furnace was well-suited for the high temperature combustion experiments and was specifically designed to provide fast heating rates. A wire heating element (FeCrAl) was wrapped around the outside of the furnace. By controlling the phase-fired heater controller that regulates the voltage through the wires heating the furnace area, the TGA system was capable of achieving hearing rates as high as $20^{\circ} \mathrm{C} / \mathrm{sec}$.

A chromel-alumel thermocouple (type $\mathrm{K}$, range $0{ }^{\circ} \mathrm{C}$ to $1000{ }^{\circ} \mathrm{C}$ ) measured the temperature inside the furnace and the control software (written in LabView, National Instruments) performed feedback control using a modified PID algorithm. The control parameters could be manually adjusted during the experiments to yield satisfactory control quality for different portions of the temperature control scheme, whether ramping or steady-state. Figures 2.2 and 2.3 show the temperature control performance for $10^{\circ} \mathrm{C} / \mathrm{sec}$ and $1{ }^{\circ} \mathrm{C} / \mathrm{sec}$ heating rates respectively; both curves show maximum deviations from the temperature set point smaller than $5^{\circ} \mathrm{C}$. The accurate temperature control ensured high repeatability.

Two mass flow controllers were used to provide the appropriate flow rates of oxygen and nitrogen during the experiment. The computer switched and adjusted the gas flow during an experiment. For example, during the pyrolysis stage, pure nitrogen flowed through reaction system and the gas was switched to an oxygen/nitrogen mixture when the combustion started.

A more detailed description of the TGA/VMI reactor, the computer interfaces, the heater control, the remotely activated mass flow controllers and the digital computer control algorithm can be found elsewhere (Matzakos 1991; Perkins 1997).

\subsubsection{Video Microscopy System}

Figure 2.4 shows the video microscopy system for the TGA/VMI reactor. Modifications were made to the furnace tube by Matzakos (1991) to allow direct visualization of the reacting particles. A flat optical window was inserted at the top of a glass side tube attached to the main furnace tube. Through the window, particle samples were imaged by a high magnification, extralong working distance microscope (JENA, Model 121) mounted outside the reactor facing downwards into the furnace. Video images of reacting particle samples were obtained with a 
color video camera (Javelin, Chromachip II) with 760x485 lines resolution attached to the microscope. A video timer (FOR-A, UTG-33) was used to superimpose on the camera signal the elapsed time for the experiment before the signal were recorded by a Super-VHS video tape recorder (Panasonic, AG-7300) with 400 lines of resolution. Initiation of the video timer and VCR recording was performed automatically by the computer control program. Thus, for each experiment the VCR was programmed to begin taping at some specific time depending on the portion of the experiment that was of interest.

By post-processing the video image sequences, we could detect the occurrence of transient phenomena like char particle ignition or fragmentation. Images from the videotapes were digitized using a 640x480 pixel frame grabber (Data Translation, Quick Capture).

\subsection{Experimental Conditions and Procedures}

\subsubsection{Sample Preparation}

We used Illinois \#6 coal from the Argonne premium coal sample collection for most of the experiments. Since this is a bituminous coal with high carbon content, we expected it to exhibit plastic behavior during the pyrolysis stage.

More than $90 \%$ of the experiments were conducted using 28-32 mesh (500-595 $\mu \mathrm{m})$ coal particles. Some experiments used 50-60 mesh (250-297 $\mu \mathrm{m})$ and 20-24 mesh (707-841 $\mu \mathrm{m})$ to study the effect of particle size on char reactivity. For each run, the reactor was loaded with about $1 \mathrm{mg}$ of coal (about 30-40 coal particles for 50-60 mesh, 5-6 particles for 28-32 mesh and 2-3 particles for 20-24 mesh). To prevent agglomeration during pyrolysis, we tried to place particles far from each other in the pan, although this configuration was hard to achieve when one had to place about 30 coal sample particles in the pan for the 50-60 mesh fraction.

\subsubsection{Data Processing}

After each experiment was completed, the computer wrote the experimental data previously stored in memory into a data file. Char sample reactivity was then determined from the weight vs. time data using the following equation: 


$$
R_{o}=\frac{d x}{d t}=-\frac{1}{m_{o}}\left(\frac{d m}{d t}\right)
$$

where:

$$
\begin{array}{ll}
x & \text { is the solid conversion, } \\
m_{o} & \text { is the initial mass of the solid in ash free basis } \\
m & \text { is the mass of unreacted carbon in any time t. }
\end{array}
$$

Figure 2.5 shows the original weight vs. time data $[\mathrm{A}]$ along with the calculated reactivity vs. conversion [B]. The two peaks corresponding to pyrolysis and combustion are the salient features in [B]. As mentioned in Chapter 1, the maximum exhibited in the combustion regime was due to the initial pore opening which increased the total internal surface area accessible to oxygen.

Since numerical differentiation is used to obtain reactivity, it is essential to choose the appropriate method to interpolate the raw weight data. During each experiment, 800-30000 weight data points are collected (depending on the burn-off time as well as the data acquisition frequency). Although the raw weight vs. time curve was monotonically decreasing, the weight data tended to oscillate along the curve due to the high sensitivity of the TGA weighing system. A cubic spline method was initially used to interpolate the data. Since this interpolating method generated a function to match all data points including the oscillating ones, the calculated reactivity curve was quite noisy, as shown in Figure 2.6 A.

A B-spline method was then employed to improve the interpolation quality. It divided the whole raw weight data set into subintervals. Within each subinterval, B-spline method interpolated weight data in the least-square sense $\left(\mathrm{L}^{2}\right.$ norm) and required continuous first derivative between subintervals. Since our program allowed for dynamic placement of the break points so that each subinterval contained more than 25 data points, data noise could not significantly influence the interpolation.

We chose C-1 quadratics as the interpolating polynomial at each subinterval. Sundback et al (1984) observed that the combustion reactivity has discontinuous $1^{\text {st }}$ derivative and contributed this feature to particle fragmentation. The earlier studies in our lab (Zygourakis, 1989; Zygourakis and Sandmann 1988) also indicated that it could also be caused by the opening of 
large internal pores during the combustion in the diffusion-limited regime. By assuming that the reactivity is a linear function of time at each interval C-1 quadratics preserve the fine details of the reactivity curve which would be smoothed out by a cubic spline. The resulting reactivity curve was demonstrated in Figure 2.6 B.

\subsubsection{Staged and Sequential Combustion Protocol}

Our flexible computer control system allowed us to design different experimental protocols. Using this system, we could specify the temperature control algorithm, gas flow, and control the video recording system to best serve our research purposes. In this study, two experimental protocols were primarily used: Staged Combustion and Sequential Combustion.

The main objective of Staged Combustion experiments was to isolate the pyrolysis and combustion process in order to distinguish the effect of pyrolysis conditions on the combustion of char particle. Figure 2.7 [A] shows the Staged Combustion protocol. The control program initiated the pyrolysis stage at $200^{\circ} \mathrm{C}$ by heating up the reactor at the specific pyrolysis heating rate until the temperature reached the heat treatment temperature (HTT). The HTT was usually $600^{\circ} \mathrm{C}$ in our study, since primary devolatilization was essentially complete around $550^{\circ} \mathrm{C}$ (Gorbaty, Larsen et al, 1982). The reactor was maintained at HTT for a specific soak time (usually 10 minutes for Staged Combustion) to ensure that most of the volatile is released. After the pyrolysis stage, the reactor was cooled down to a specified combustion temperature. Once the combustion temperature was reached, the computer switched the gas flow from pure nitrogen to a mixture of nitrogen and oxygen to start the combustion. As shown in figure 2.7 [B], two distinct reactivity peaks representing the pyrolysis and combustion stage were clearly visible. Staged combustion was primarily used to study the pyrolysis and combustion processes separately in order to elucidate the effect of pyrolysis conditions (such as heating rate, HTT and soak time) on char combustion.

In industrial applications, however, there is no clear distinction between the pyrolysis and combustion stages. Coal particles are just sent into the combustor where they pyrolyze and react with air. Therefore, pyrolysis and combustion stages occur sequentially and may overlap. To emulate the real combustion process, we also designed the sequential combustion protocol (See Figure $2.8[\mathrm{~A}])$. The main difference between staged and sequential combustion was that the 
sequential combustion introduces oxygen into the reactor right after the HTT was reached. As shown in Figure 2.8 [B], pyrolysis and combustion peaks overlapped at 550-650 seconds, which indicated that pyrolysis stage was not complete when combustion started.

The combustion temperature for staged combustion experiments was mild $\left(400-550^{\circ} \mathrm{C}\right)$ in order to study the effect of pyrolysis conditions on combustion at kinetic controlled regime. On the other hand, most of the sequential experiments are conducted at high temperatures $\left(600-1000^{\circ} \mathrm{C}\right)$ where combustion of char is in diffusional limitation regime, since the industrial coal combustion processes are in this temperature range.

\subsection{Experimental Procedure}

A typical experiment included the following steps:

- The TGA was calibrated to ensure that the weight readout without any coal sample was approximately zero.

- Coal particles were placed in the sample pan, in a configuration that kept them far away from each other to prevent agglomeration.

- After loading the coal, nitrogen flow started and continued for about 10 minutes to remove all atmospheric oxygen from the reactor.

- The temperature of the coal sample was raised to $200^{\circ} \mathrm{C}$ and kept there for about 2.5 minutes to remove the moisture.

- The experiment then proceeded according to either the staged or the sequential combustion protocol. Video taping could be started at any specific point depending on which portion of the experiment was of interest. For both experiment protocols, the sample was kept at the combustion temperature until no further weight changes could be observed, an indication that most of the carbon was burned.

- The control program was stopped, and the weight and temperature data were transferred from the computer memory into a data file. 
- The combustion temperature and oxygen concentration were raised to about $700^{\circ} \mathrm{C}$ and $50 \%$ respectively to burn off the remaining carbon (if any). The temperature was then brought back to the original combustion temperature to determine the ash content of the sample.

- The experimental data was processed with a plotting software package (KaleidaGraph , Synergy Software) to obtain the combustion reactivity and the time required to complete the combustion. ( $\mathrm{t}_{98}$, indicating time to reach $98 \%$ conversion).

Table 2.1 summarizes the range of conditions used for both the staged and sequential combustion experiments.

Table 2.1

Experimental Conditions for staged and sequential combustion

\begin{tabular}{|c|c|c|}
\hline \multicolumn{3}{|c|}{ Pyrolysis Stage } \\
\hline Heat Rate & Staged Combustion & Sequential Combustion \\
\hline $\begin{array}{c}\text { Heat Treatment } \\
\text { Temperature }\end{array}$ & $0.1,1,10^{\circ} \mathrm{C} / \mathrm{sec}$ & same \\
\hline Soak Time & $600^{\circ} \mathrm{C}$ & $\begin{array}{c}\text { Varies, depending on its } \\
\text { combustion temperature }\end{array}$ \\
\hline Flowing Gas & 10 minutes & same minute \\
\hline Gas Flow Rate & Pure $\mathrm{N}_{2}$ & same \\
\hline \multicolumn{2}{|c|}{$240 \mathrm{sccm}$} & Sequential Combustion \\
\hline $\begin{array}{c}\text { Reaction } \\
\text { Temperature }\end{array}$ & Staged Combustion & $600-1000{ }^{\circ} \mathrm{C}$ \\
\hline Flowing Gas & $\mathrm{N}_{2}$ and $\mathrm{O}_{2}$ mixture & same \\
\hline O mole fraction & $1 \%, 5 \%, 21 \%, 50 \%$ & same \\
\hline Gas Flow Rate & $240 \mathrm{sccm}$ & same \\
\hline
\end{tabular}




\section{$2.4 \quad$ References for Section 2}

Gorbaty. M. L., Larsen. J. W. and Wender. I. (1982) “Coal Science,” London, Academic Press.

Matzakos. A. (1991). "Fundamental mechanisms of coal pyrolysis and char combustion," Ph.D. Thesis, Rice University.

Perkins.D.S (1998). "Ignition of Coal and Char Particles: Effects of Pore Structure and Process Conditions," Ph.D. Thesis, Rice University

C. A. Sundback, J. M. Beer and A. F. Sarofim. (1984). "Fragmentation behavior of single coal particles in a fluidized bed" 20th International Symposium on Combustion, Ann Arbor, MI.

Zygourakis K. C.W. Sandmann, Jr. "Pore Structure Evolution During Noncatalytic Gas Solid Reactions: 3. Development and Applications of Discrete Structural Models," AIChE J., 34(12), 2030-2040 (1988).

Zygourakis K. "A New Discrete Simulation Method for Modeling Char Gasification in the Diffusion-Controlled Regime," Amer. Chem. Soc., Fuel Chem. Prepr., 34(1), 202-211 (1989). 


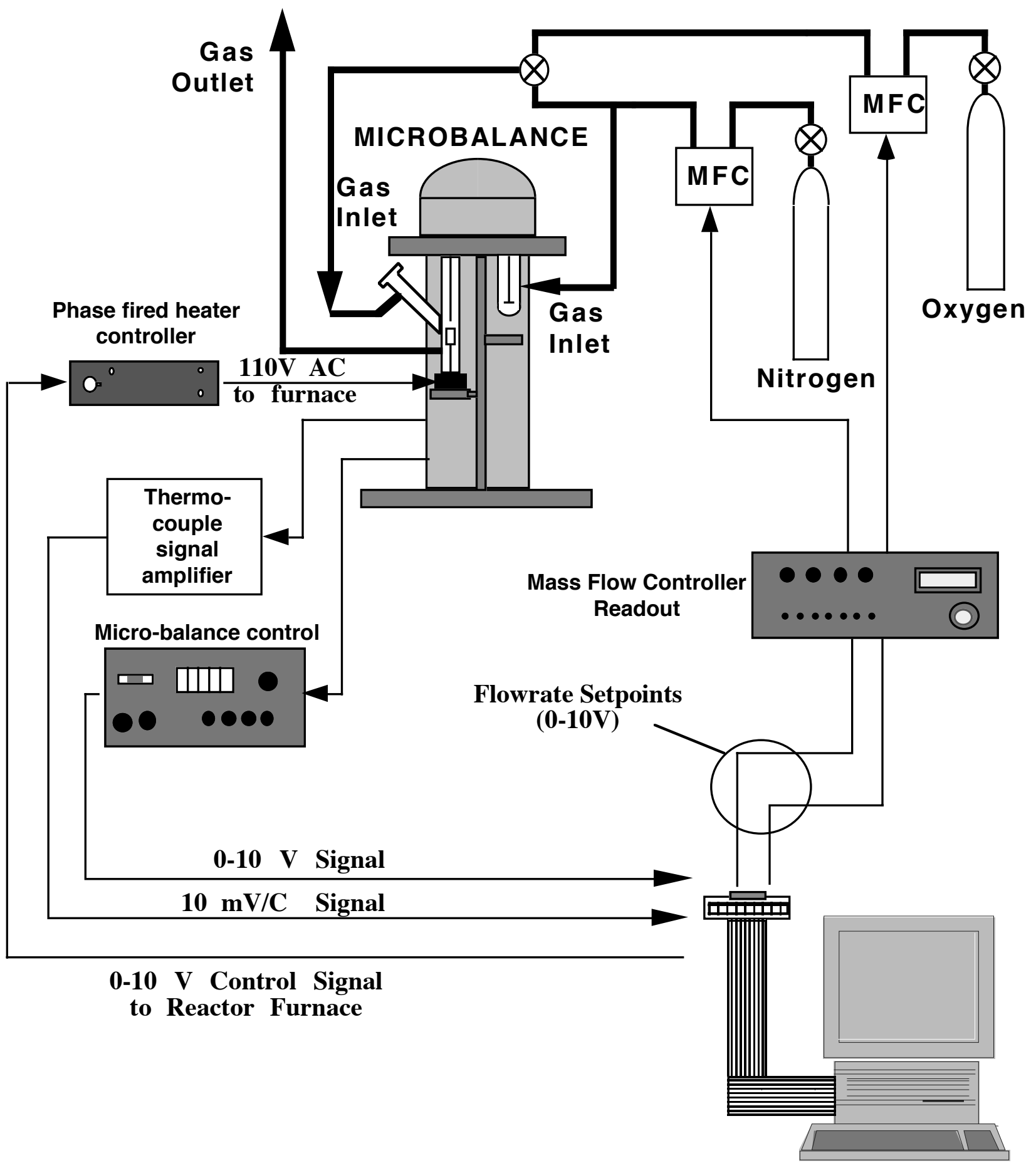

Macintosh Quadra 900

Figure 2.1 Schematic of thermogravimetric reactor with in-situ video imaging (TGA/VMI). 

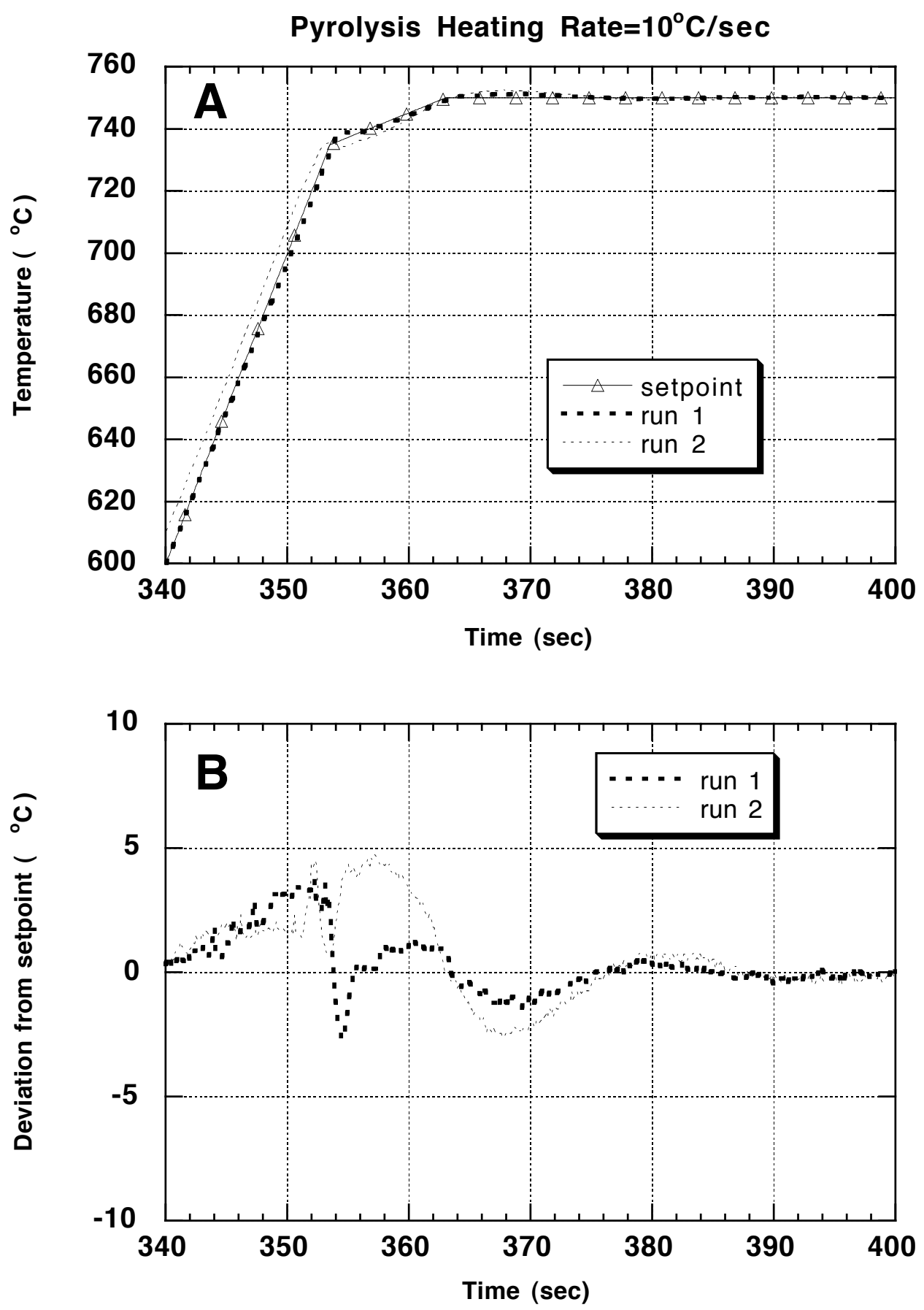

Figure 2.2 Temperature control performance for pyrolysis heating rates equal to $10^{\circ} \mathrm{C} / \mathrm{sec}$. $[\mathrm{A}]$ : Temperature ramp. [B] Deviation from set point. 

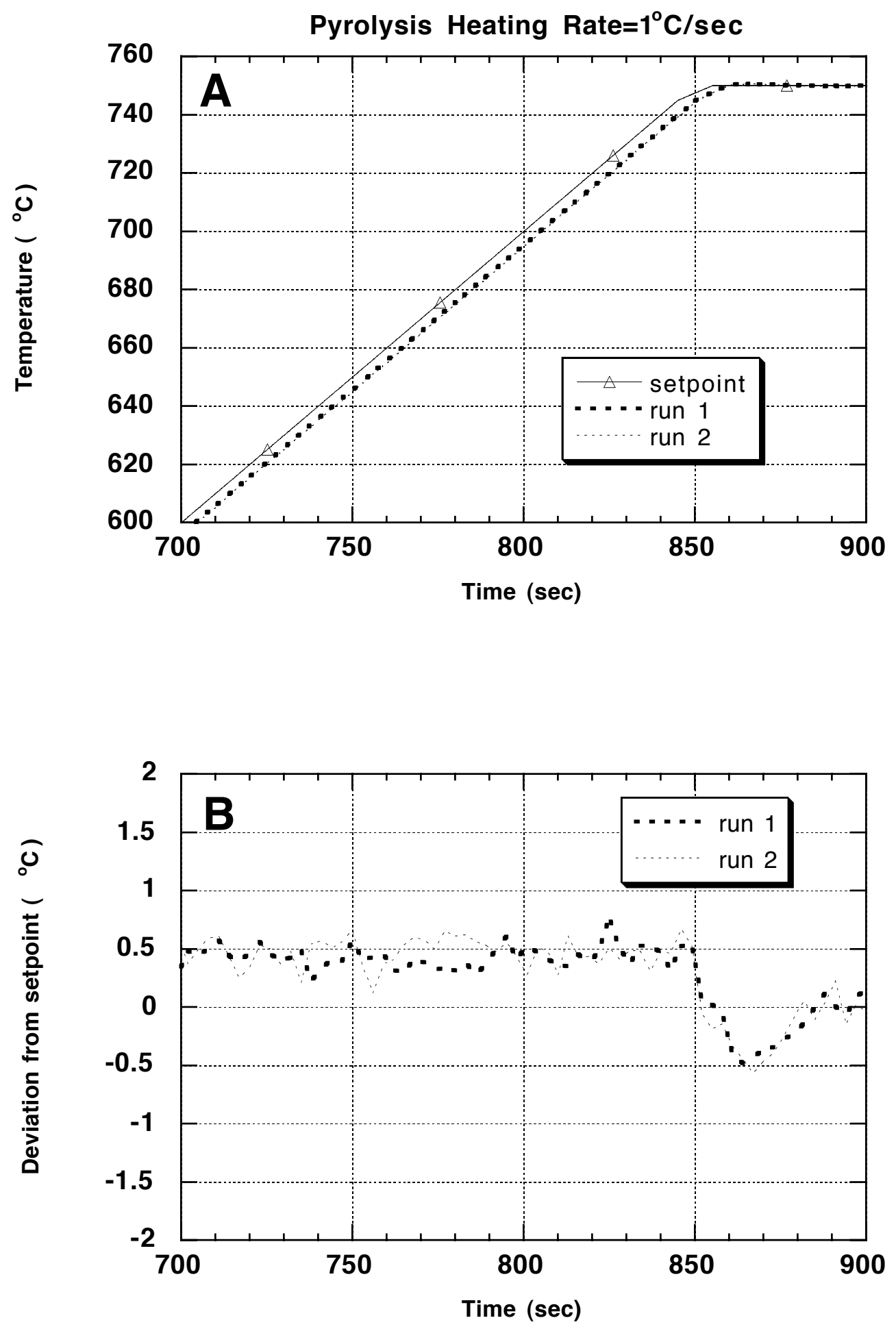

Figure 2.3 Temperature control performance for pyrolysis heating rates equal to $10^{\circ} \mathrm{C} / \mathrm{sec}$. [A]: Temperature ramp. [B]: Deviation from set point. 

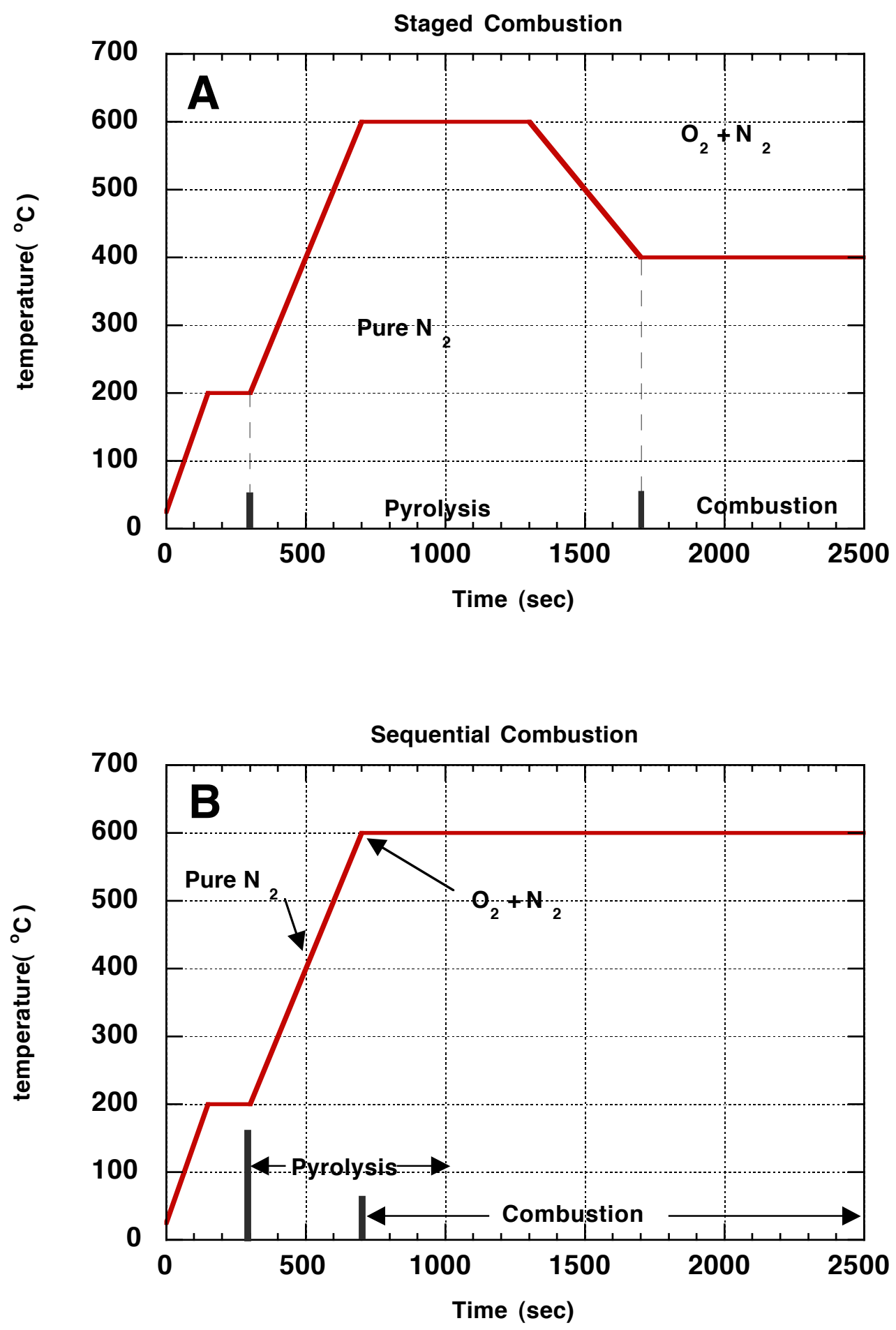

Figure 2.4: Experimental procedure for Staged [A] and Sequential Combustion [B]. 

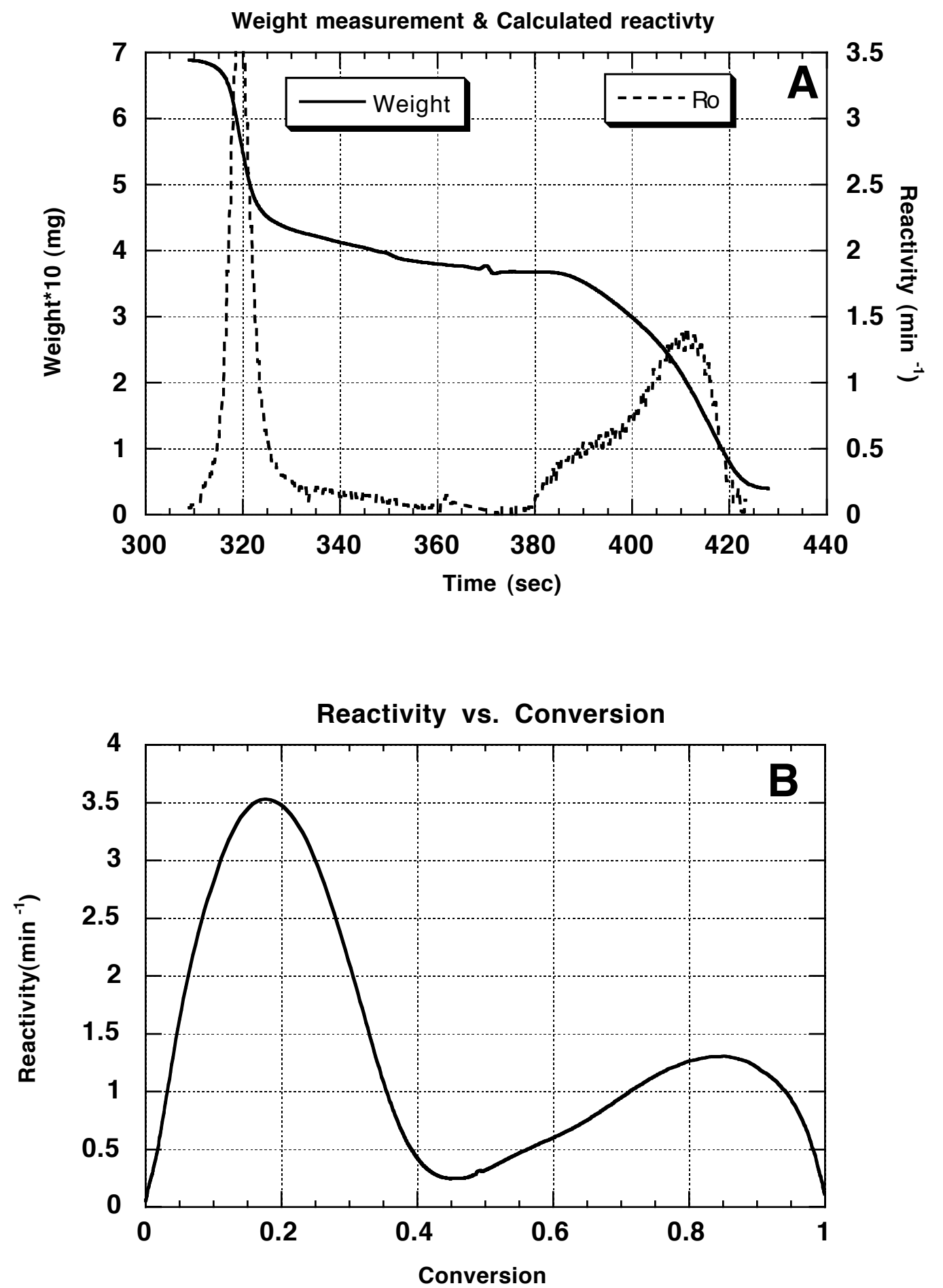

Figure 2.5 TGA measured weight vs. time $[\mathrm{A}]$ and calculated reactivity vs. time $[\mathrm{A}\}$ and conversion [B].

Pyrolysis Heating Rate $=10^{\circ} \mathrm{C} / \mathrm{sec}$, Combustion Temperature $=1000^{\circ} \mathrm{C}, \mathrm{O}_{2}=21 \%$. 

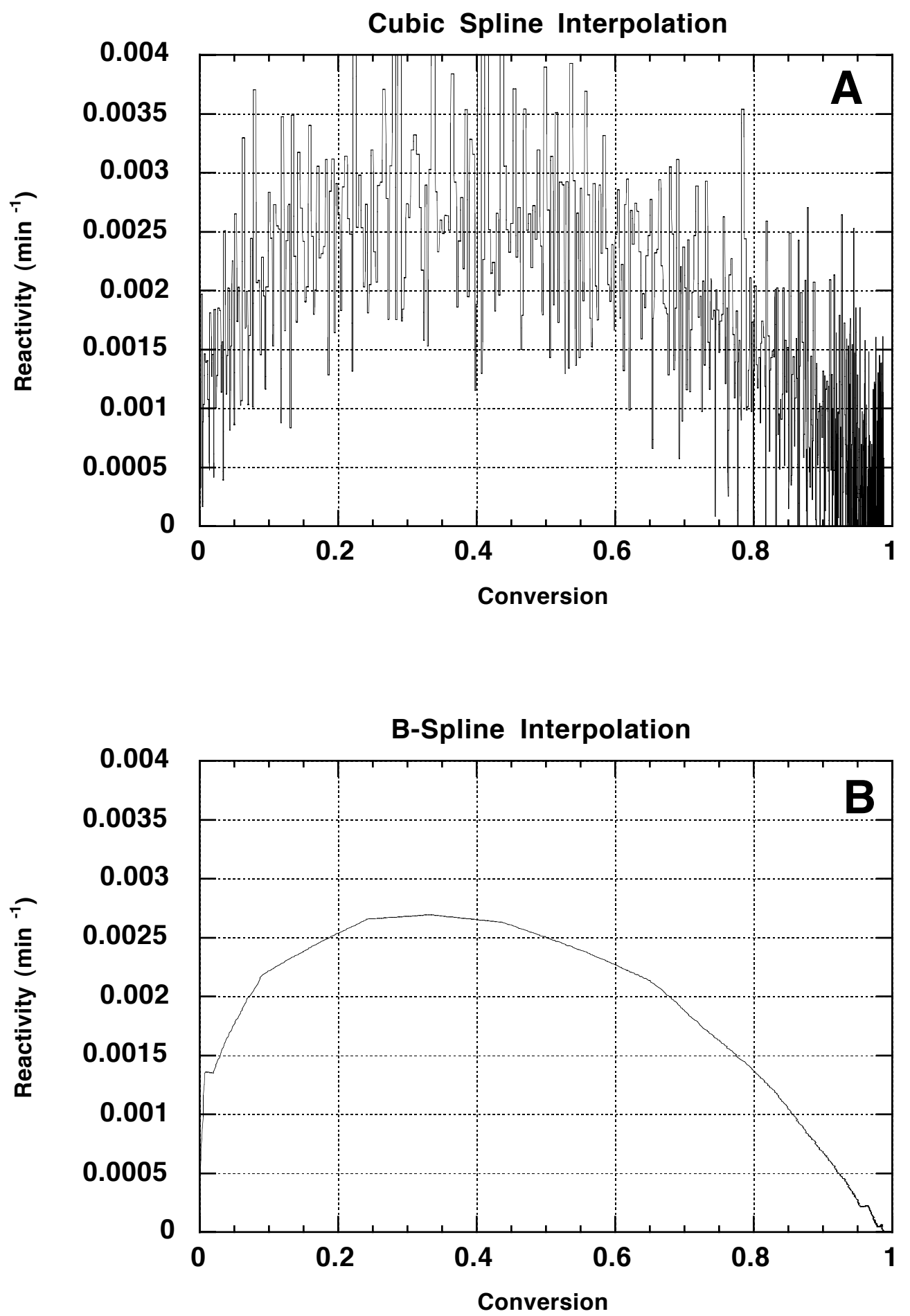

Figure 2.6 Comparison of cubic spline [A] and B-spline data interpolation. Pyrolysis Heating Rate $=0.1^{\circ} \mathrm{C} / \mathrm{sec}$, Combustion Temperature $=420^{\circ} \mathrm{C}, \mathrm{O}_{2}=5 \%$. 

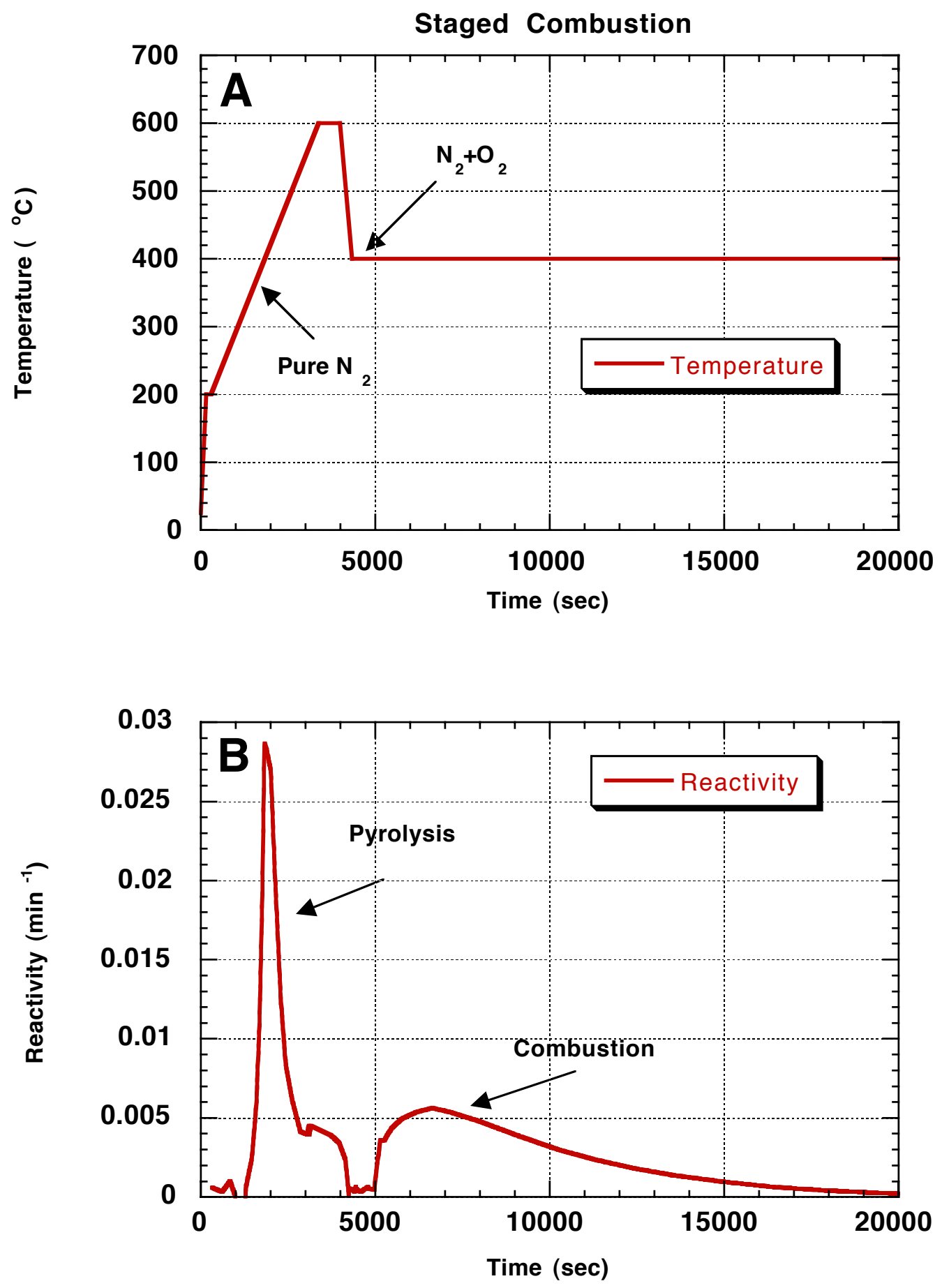

Figure 2.7 Two separate reactivity peaks for pyrolysis and combustion are obvious in staged combustion.

[A]: temperature control program; [B]: corresponding reactivity pattern.

Pyrolysis Heating rate $=0.1^{\circ} \mathrm{C} / \mathrm{sec}, \mathrm{HTT}=400^{\circ} \mathrm{C}$. 

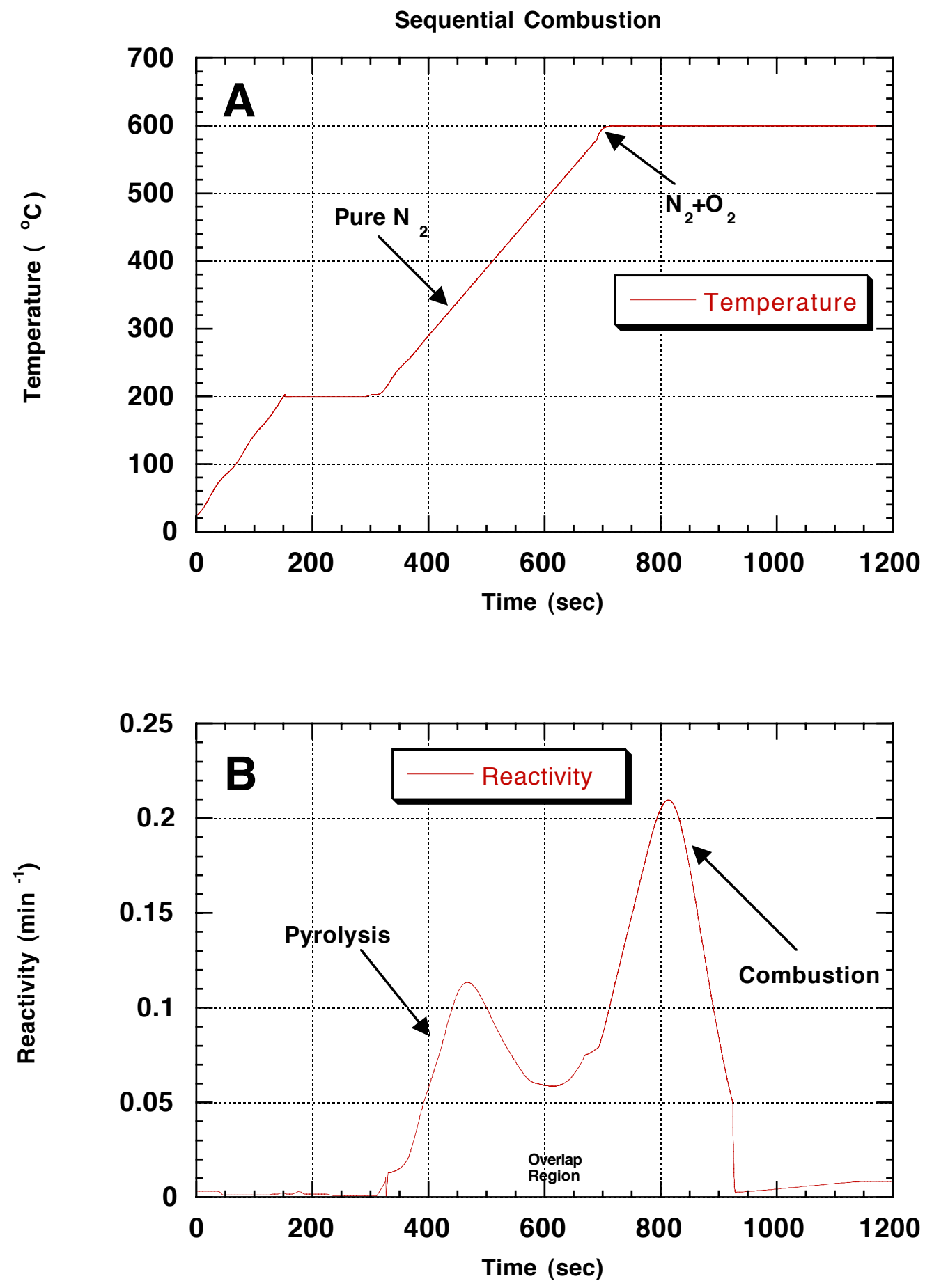

Figure 2.8: $\quad$ Sequential combustion yields overlapping pyrolysis and combustion reactivity peaks. [A]: Reactor temperature setpoint; $[\mathrm{B}]$ : reactivity pattern.

Heating rate $=1{ }^{\circ} \mathrm{C} / \mathrm{sec}, \mathrm{HTT}=600^{\circ} \mathrm{C}$. 


\section{SECTION 3}

\section{PYROLYSIS AND THE EFFECT OF HEATING RATE ON CHAR MACROPORE STRUCTURE}

\subsection{Many coals soften and become plastic during pyrolysis}

The study of plastic behavior was conducted with Illinois \#6 coal, a bituminous coal with high ash content. Using the TGA/VMI reactor, we were able to follow continuously throughout the pyrolysis stage the evolution of size and shape of each coal particle along with the total weight of the coal sample.

During the plastic phase, bubbles form inside the particle due to the release of volatile gases, causing an internal pressure build-up. Initially, the particle expands because the gas volatiles are released faster than they can escape to the outside. The bubbles increase in size until they break through the surface of the particle releasing the volatile gases to the particle exterior. After that, the particle contracts until new bubbles start forming in the particle interior and internal pressure starts to increase again.

Figure 3.1 presents digitized images showing typical changes in the size and shape of Illinois \#6 coal particles during pyrolysis. The heating rate for this experiment was 20 ${ }^{\circ} \mathrm{C} / \mathrm{sec}$. When the reactor temperature exceeded a certain value (about $380^{\circ} \mathrm{C}$ ), the coal particles started to swell. A quantitative analysis of the videotaped pyrolysis histories led to the following conclusions.

- Pyrolysis heating rates affected the plastic behavior of coal particles. For low heating rates (such as $0.1^{\circ} \mathrm{C} / \mathrm{sec}$ ), the particles swelled until they achieved their maximum size and maintained it. On the other hand, for fast heating rates $\left(10\right.$ or $\left.20^{\circ} \mathrm{C} / \mathrm{sec}\right)$, particles 
rapidly expanded to their maximum size and vigorous "bubbling" took place as the particles slowly shrank to achieve their final size.

- Coal-derived char particle had about the same size as their original coal particle under slow pyrolysis heating rate, while higher heating rates produced char particle substantially larger than the original size.

\subsection{Pyrolysis conditions affect the devolatilization rates}

During the pyrolysis stage, thermal rupture of various molecular bonds yielded volatile gases in the form of low molecular weight gases as well as other chemically complex liquid and tars. Since the pyrolysis conditions such as heating rate, heat treatment temperature, soak time will affect the rate as well as the total amount of the thermal energy input, we expected that these conditions will ultimately affect the devolatilization behavior of the coal particle.

The TGA reactor allowed continuous monitoring of the weight loss of the pyrolyzing coal samples. Analysis of the weight loss data could help us shed light on the effect of various pyrolysis conditions on the devolatilization of coal.

Figure 3.2 illustrated the effect of soak time on the total weight loss during devolatilization of Illinois \#6 coal. Data were obtained from our staged combustion experiments for which we could adjust the soak time by changing the temperature control algorithm accordingly. When the soak time was longer, volatile (mostly in the form of gas), should have more time to diffuse to the particle exterior; therefore, longer soak time should yield larger weight loss. The experimental results were consistent with the theory. For all the pyrolysis heating rates tested, longer soak times always yielded higher weight loss.

Figure 3.3 demonstrated the effect of heating treatment temperature and pyrolysis heating rate on the devolatilization. Data were obtained from sequential experiments. As mentioned in Chapter 1, primary devolatilization occurred in the temperature range of $350-550^{\circ} \mathrm{C}$, while secondary devolatilization took place between $600-800^{\circ} \mathrm{C}$. Coal pyrolyzed at $450^{\circ} \mathrm{C}$ yields fewer volatiles than coal pyrolyzed at $600^{\circ} \mathrm{C}$, probably because 
the primary devolatilization was not complete. Therefore, we expected an overlap of pyrolysis and subsequent combustion process. On the other hand, coal pyrolyzed at $750^{\circ} \mathrm{C}$ released more volatile matter than coal treated at $600^{\circ} \mathrm{C}$, due to the induction of secondary devolatilization which yielded mainly $\mathrm{H}_{2}$ and $\mathrm{CH}_{4}$.

The effect of pyrolysis heating rate was quite interesting. For HTT equal to $450{ }^{\circ} \mathrm{C}$ and $600^{\circ} \mathrm{C}$, the amount of released volatiles increased slightly with increasing heating rates. This observation agreed with the theoretical predictions (Fletcher, Kerstein et al. 1989) of the chemical percolation devolatilization (CPD) model and the experimental observations of many other investigators (Matzakos 1991; Ismail 1993; Gibbins-Matham and Kandiyoti 1988;). For HTT equal to $750^{\circ} \mathrm{C}$, however, the result was just opposite: coals pyrolyzed at smaller heating rates yielded slightly more volatiles. The possible explanation was that when the heating rate was small, it took longer time to reach HTT than higher heating rate did. For example, it took 5500 seconds for temperature to reach $750^{\circ} \mathrm{C}$ from $200^{\circ} \mathrm{C}$ when heating rate is $0.1^{\circ} \mathrm{C} /$ sec compared with only 55 seconds needed for $10^{\circ} \mathrm{C} / \mathrm{sec}$. Thus, volatiles will have longer time to diffuse out of the coal particle at lower heating rates. In other word, the "effective soak time" is longer for lower heating rates. Also notice that coal pyrolyzed at $750^{\circ} \mathrm{C}$ with heating rate of $0.1^{\circ} \mathrm{C} / \mathrm{sec}$ had weight loss higher than 50\%, while the Argonne coal sample brochure (Vorres, 1990) reports $40 \%$ volatile matter content for this coal.

From the TGA experimental data we also determined the temperature range where maximum devolatilization occurs for different heating rates. Previous investigators in our lab observed a shift of the maximum rate to higher temperatures as pyrolysis heating rate increased (Matzakos 1991; Ismail 1993). However, our experiments suggested that the reactivity peaks occurred at almost the same temperature range, both for sequential and staged combustion experiments as shown in Figures 3.4 and 3.5. The maximum rate seemed to shift slightly to higher conversion levels, however; when we plotted devolatilization rate against conversion (Figure 3.6). Thanks to the accurate temperature and flow rate control, pyrolysis rate results showed little variation among different runs. 


\subsection{Pyrolysis heating rates affect the macropore structure of produced chars}

The pyrolysis conditions, especially the pyrolysis heating rate, had strong influence on the macropore structure of coal-derived char particle. Figure 3.7 presents the binary images of polished cross sections of char particles prepared from different heating rates (Boissiere, 1993), clearly showing the effect of pyrolysis heating rates. At low heating rate, the internal pressure buildup was moderate since the volatile production rates are so slow that gas escape before bubbles can grow to large size. As a result, char produced under low heating rate exhibited a few scattered large cavities with thick walls and several smaller cavities (Figure $3.7[$ A]).

At faster heating rates, however, the volatile production rate increased substantially leading to considerably higher pressures in the particle interior and, thus, to larger bubble sizes and more particle swelling. At heating rates equal to $1^{\circ} \mathrm{C} / \mathrm{sec}$ and $10^{\circ} \mathrm{C} / \mathrm{sec}$ (Figure $3.7[B]$ and $[C])$, formation of thin walled cavities were observed and the char particle started to show cellular internal structure.

In order to quantify the effect of pyrolysis heating rate on macropore structure of char, previous investigators applied digital image processing to analyze the structure properties of char samples (Boissiere, 1993; Zygourakis, 1993). For 28-32 mesh Illinois chars, Boissiere (1993)'s structural data for heating rates between 0.1 to $10^{\circ} \mathrm{C} / \mathrm{sec}$ is presented in Table 3.1.

Table 3.1

Macropore structure data for 28-32 mesh Illinois \#6 chars. (Boissiere 1993)

\begin{tabular}{|l|l|l|l|}
\hline $\begin{array}{l}\text { Heating Rate } \\
\left({ }^{\circ} \mathrm{C} / \mathrm{sec}\right)\end{array}$ & $\begin{array}{l}\text { Particle Radius } \\
(\mathrm{mm})\end{array}$ & Macroporosities & $\begin{array}{l}\text { Macropore SA } \\
\left(\mathrm{cm}^{2} / \mathrm{cm}^{3}\right)\end{array}$ \\
\hline 0.1 & 0.317 & $0.592 \pm 0.030$ & $865 \pm 73$ \\
\hline 1 & 0.325 & $0.595 \pm 0.025$ & $1244 \pm 98$ \\
\hline 10 & 0.407 & $0.648 \pm 0.025$ & $1040 \pm 85$ \\
\hline
\end{tabular}


The data of Table 3.1 suggest that increasing pyrolysis heating rates led to larger char particles, higher macroporosity and higher macropore surface area. The fact that char produced at $1^{\circ} \mathrm{C} / \mathrm{sec}$ had larger macropore surface area than $10^{\circ} \mathrm{C} / \mathrm{sec}$ was unexpected. Subsequent combustion experiments, however; confirmed the validity of this result.

The foregoing experimental results elucidated the effect of pyrolysis conditions (especially the pyrolysis heating rate) on the macropore structure of char particles. Higher heating rates produce char particles with more open macropore structure. In the next chapter, we will discuss how the macropore structure affects the overall reactivity during the char combustion process.

\subsection{References for Section 3}

Boissiere. F. (1993). "Influence of pyrolysis conditions on the macropore structure of char particles" M.S. Thesis, Rice University.

Fletcher.T.H., Kerstein.A.R., Pugmire.R.J. and Grant.D.M.(1989). "A chemical percolation model for devolatilization: temperature and heating rate effects." Amer.Chem.Soc., Div.Fuel Chem.Preprints.34(4):1272.

Gibbins_Matham.J. and Kandiyoti.R. (1989). "Coal Pyrolysis Yields from Fast and Slow Heating in a Wire-Mesh Apparatus with a Gas Sweep". Energy\& Fuels 2(4):505.

Ismail. A. (1993). "The effect of process conditions on coal pyrolysis and char reactivity". Ph.D. Thesis, Rice University.

Matzakos. A. (1991). "Fundamental mechanisms of coal pyrolysis and char combustion," Ph.D. Thesis, Rice University.

Perkins.D.S (1998). "Ignition of Coal and Char Particles: Effects of Pore Structure and Process Conditions," Ph.D. Thesis, Rice University

Vorres, K.S. (1990). "The Argonne premium coal sample program". Energy \& Fuels 4:420-426

Zygourakis. K. (1993). "Effect of pyrolysis conditions on the macropore structure of coal-derived chars" Energy \& Fuels 7:33. 


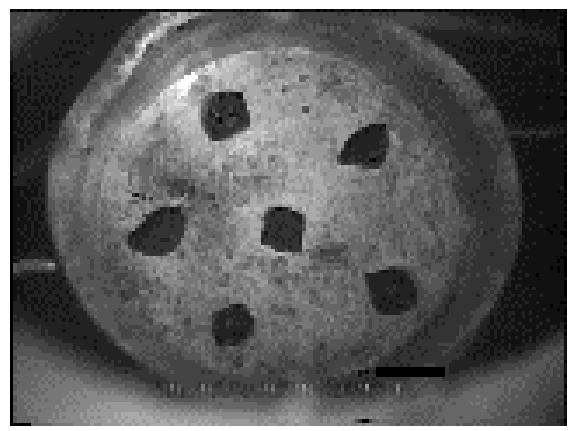

(1) $\mathrm{T}=380^{\circ} \mathrm{C}$

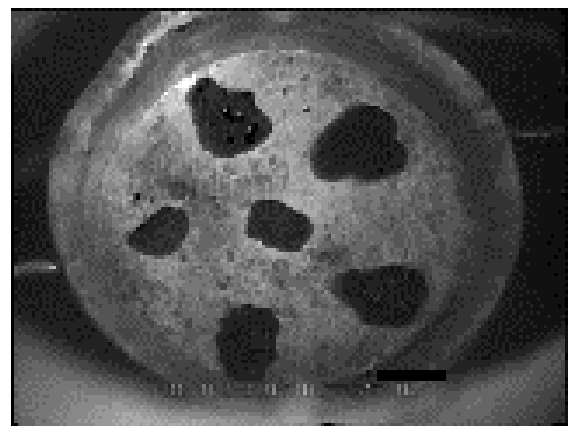

(2) $\mathrm{T}=420^{\circ} \mathrm{C}$

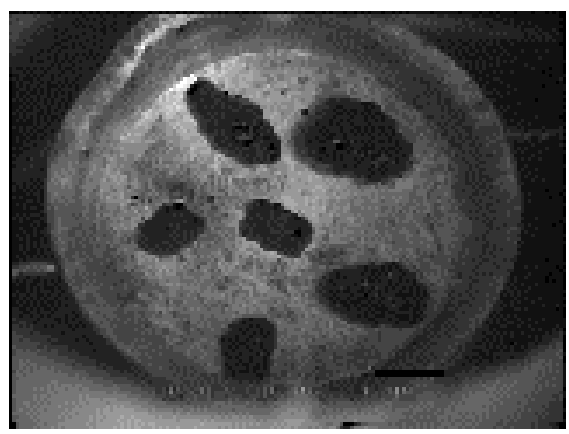

(3) $\mathrm{T}=470{ }^{\circ} \mathrm{C}$

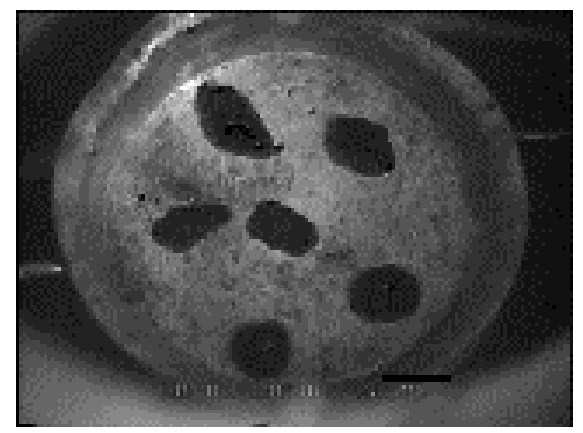

(4) $\mathrm{T}=420^{\circ} \mathrm{C}$

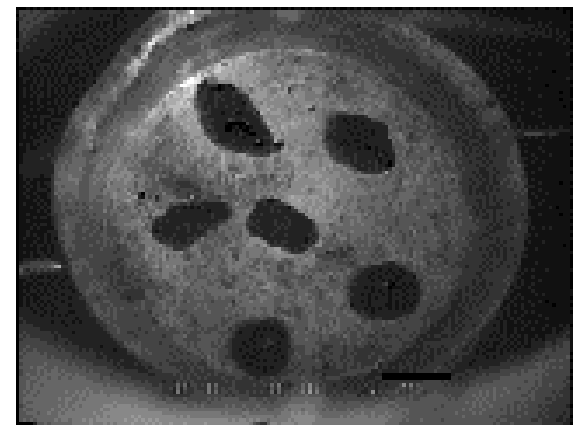

(5) $\mathrm{T}=490^{\circ} \mathrm{C}$

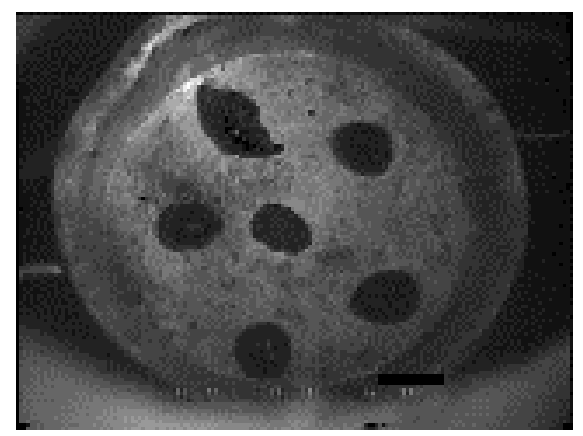

(6) $\mathrm{T}=600^{\circ} \mathrm{C}$

Figure 3.1: $\quad$ Sequence of images illustrating plastic behavior of Illinois \#6 coal (28-32 mesh) during pyrolysis stage. The scale bar is $1 \mathrm{~mm}$. Pyrolysis Heating Rate $=20^{\circ} \mathrm{C} / \mathrm{sec}$. 


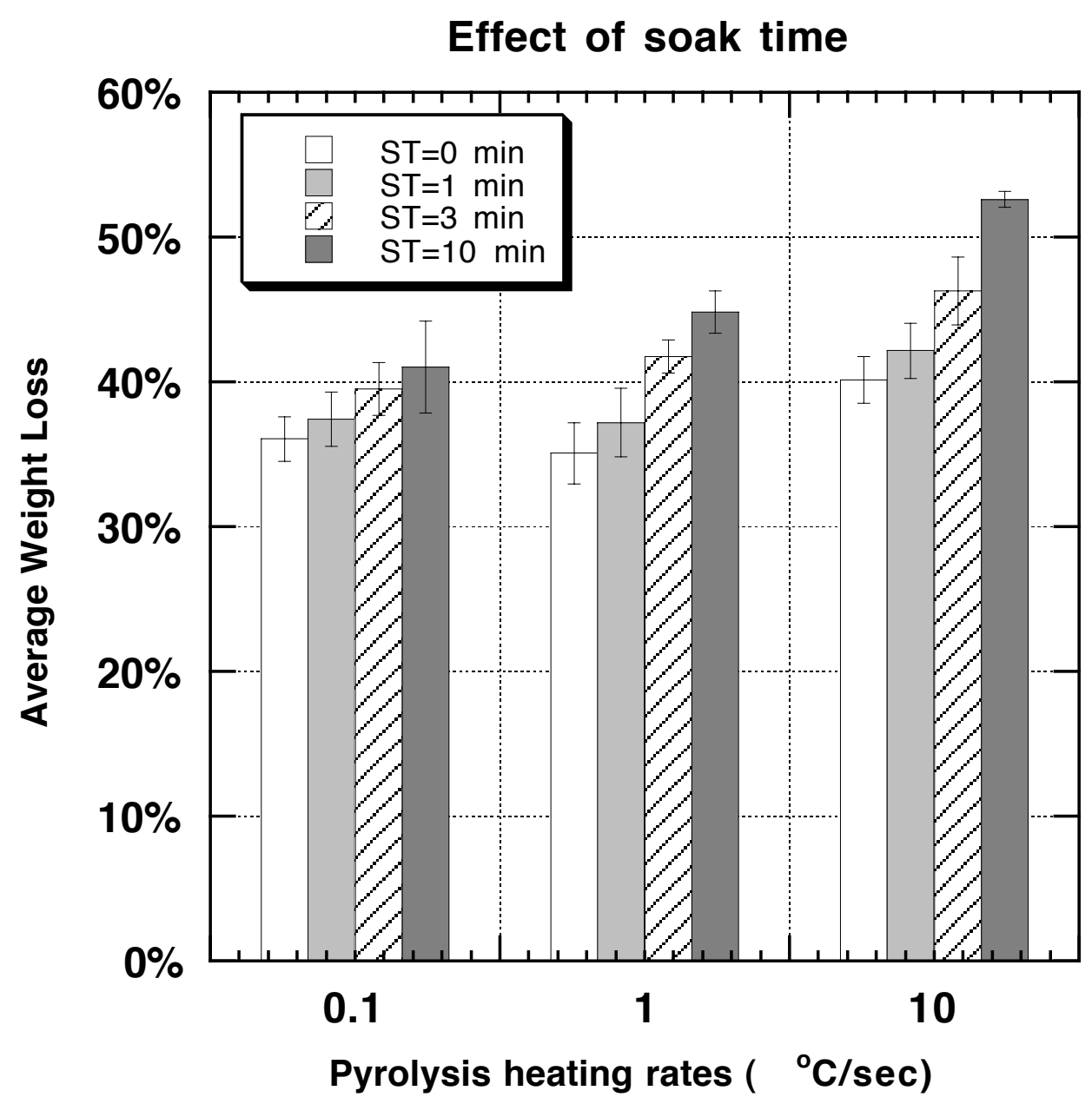

Figure 3.2: Effect of soak time and pyrolysis heating rate on the total amount of volatiles released during pyrolysis stage.

Heat Treatment Temperature $($ HTT $)=600^{\circ} \mathrm{C}$

Parent Coal: Illinois \#6, 28-32 mesh. 


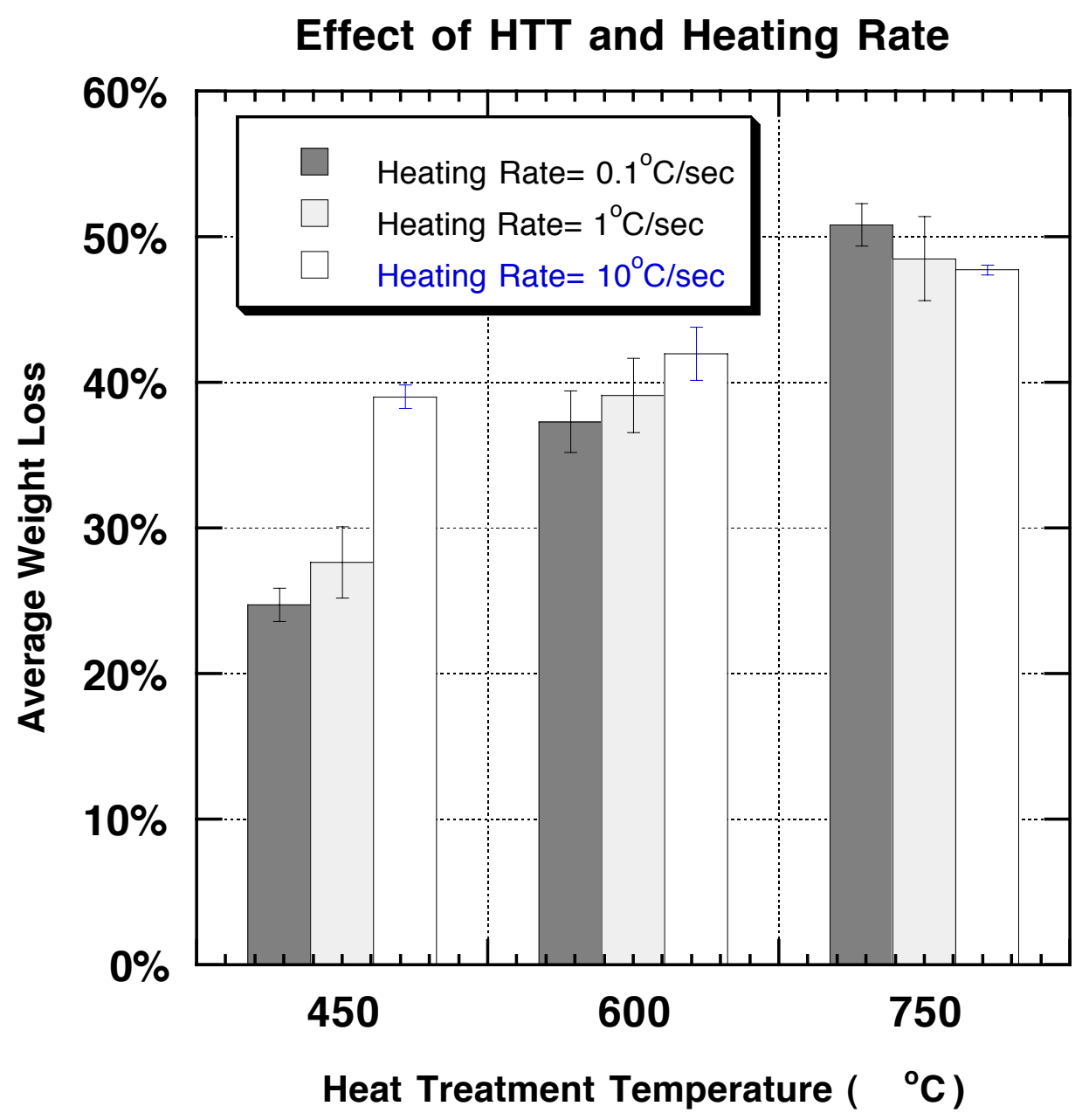

Figure 3.3: $\quad$ Effect of Heat Treatment Temperature (HTT) and pyrolysis heating rate on total amount of volatiles released during pyrolysis stage.

Soak Time = 0 min - Parent Coal: Illinois \#6, 28-32 mesh. 

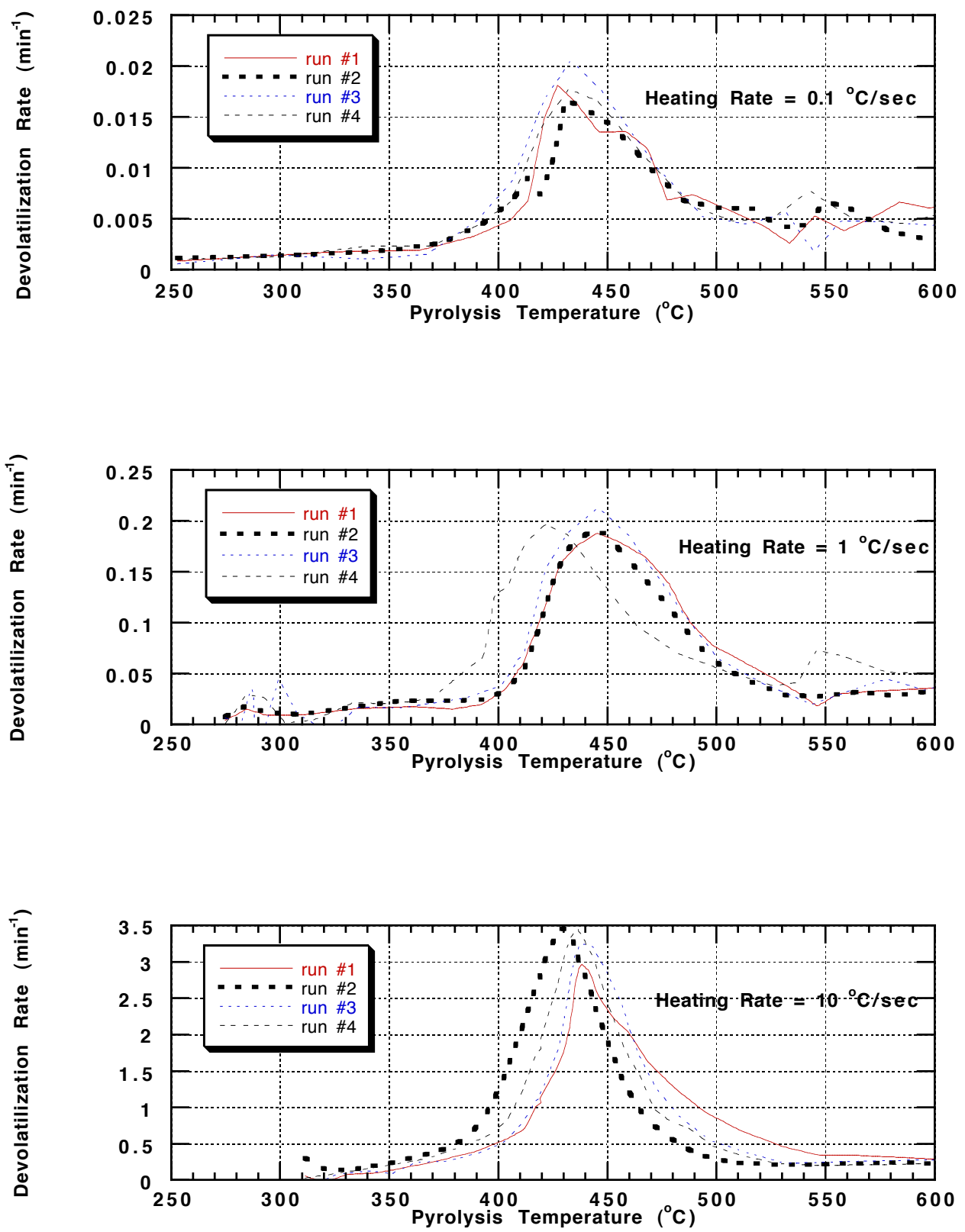

Figure 3.4: Sequential combustion experiments: Effect of pyrolysis heating rate on devolatilization rate of Illinois \#6 coal particles.

$\mathrm{HTT}=600^{\circ} \mathrm{C}$, Soak Time $=0 \mathrm{~min}$. 

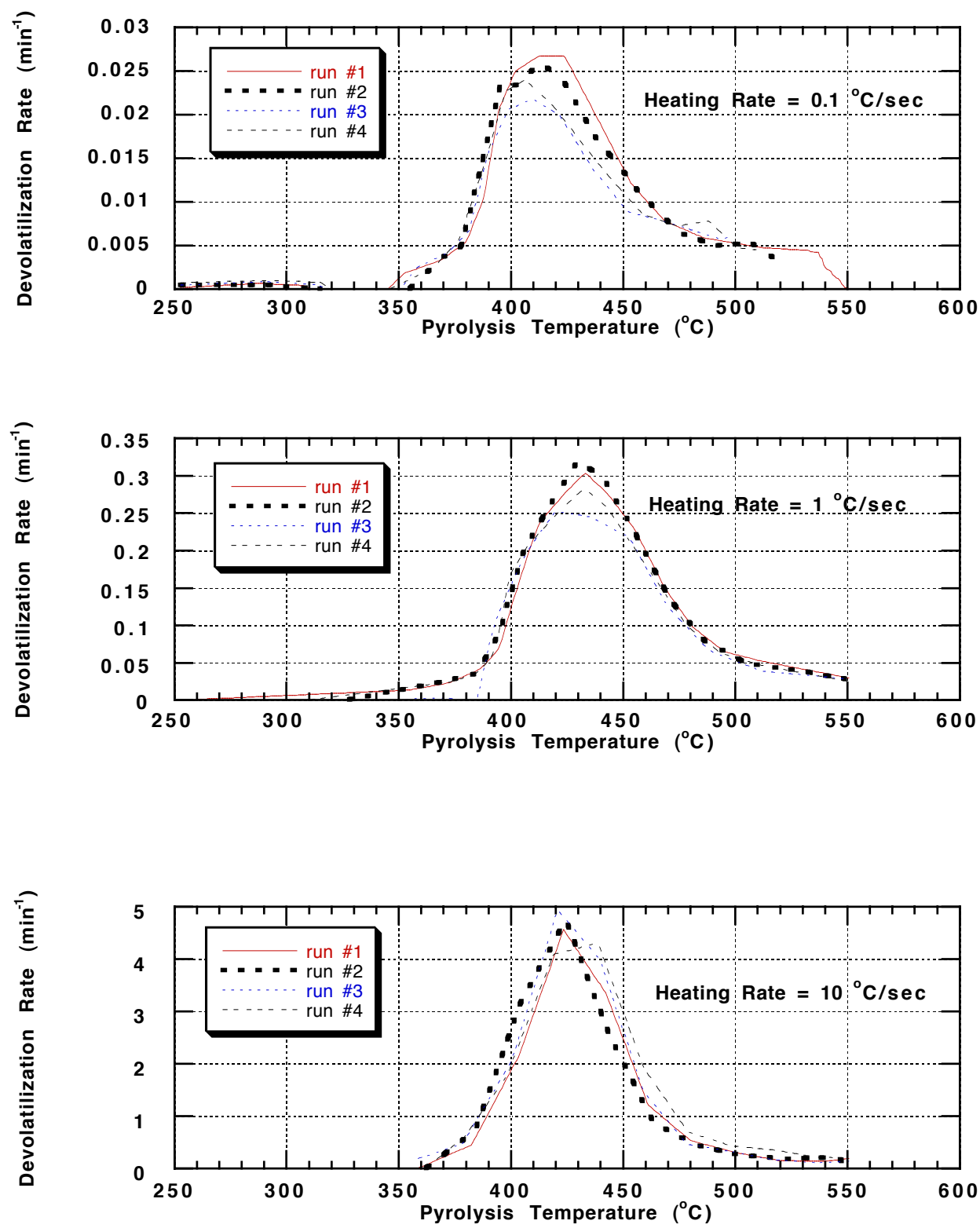

Figure 3.5. Staged combustion experiments: Effect of pyrolysis heating rate on devolatilization rate of Illinois \#6 coal particles.

$\mathrm{HTT}=600^{\circ} \mathrm{C}$, Soak Time $=10 \mathrm{~min}$. 

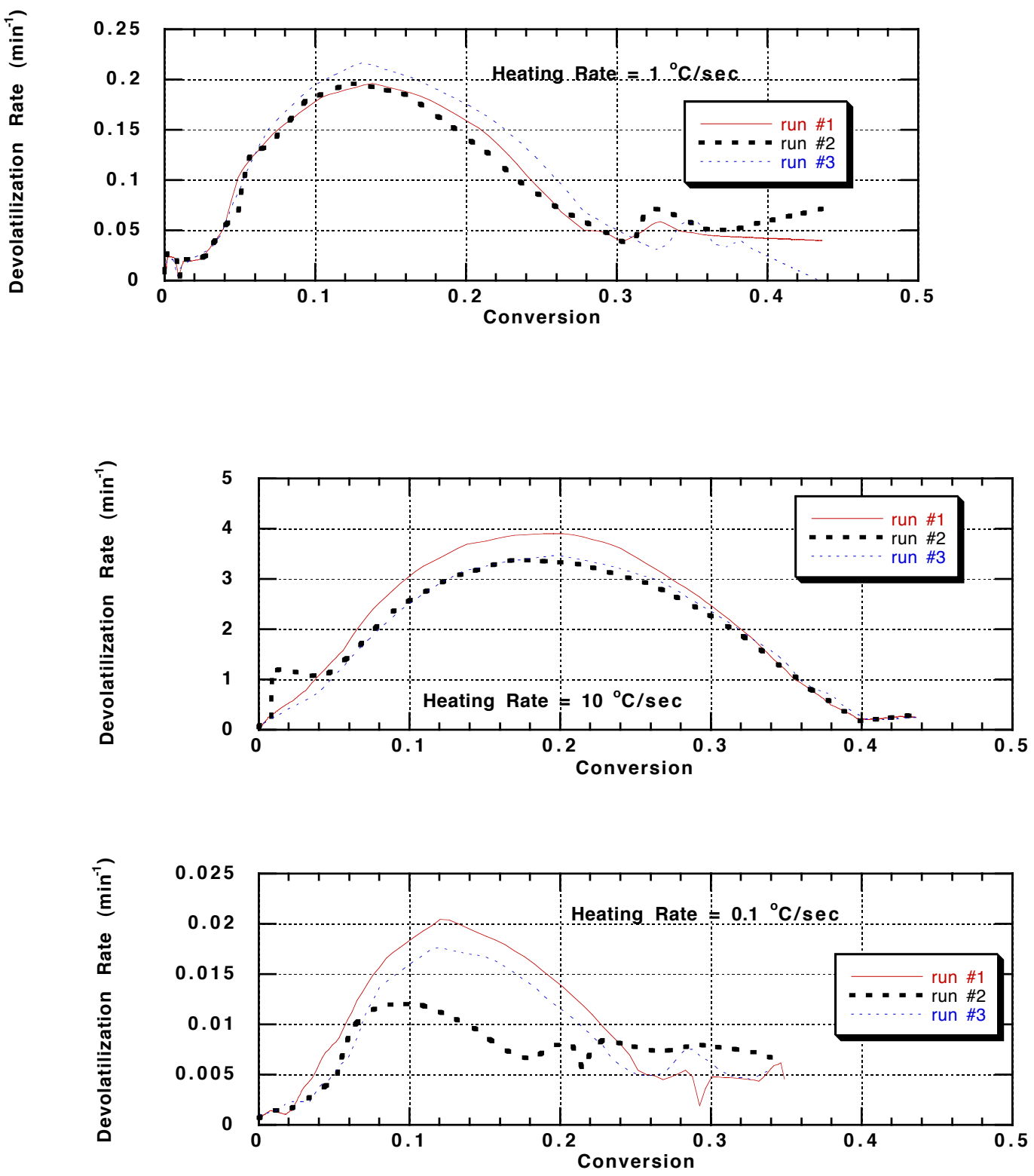

Figure 3.6: Sequential combustion experiments: Effect of pyrolysis heating rate on devolatilization rate of Illinois \#6 coal particles. $\mathrm{HTT}=600^{\circ} \mathrm{C}$, Soak Time $=0 \mathrm{~min}$. 


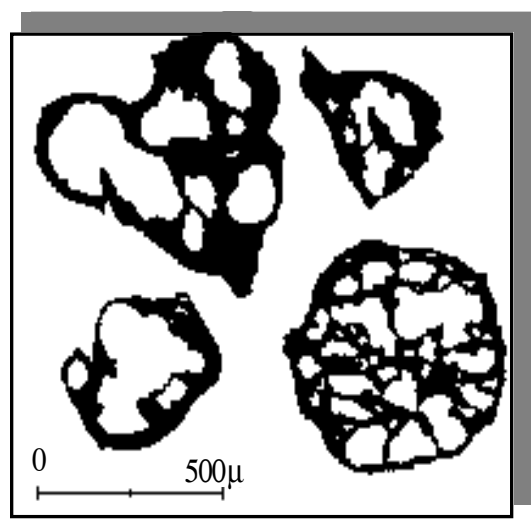

a. Heating Rate $=0.1^{\circ} \mathrm{C} / \mathrm{sec}$

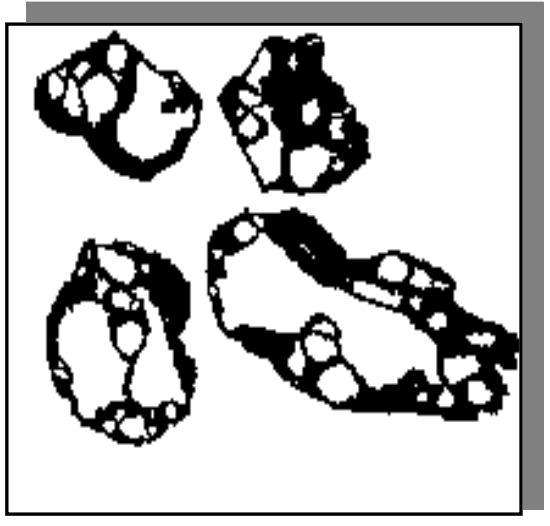

b. Heating Rate $=1^{\circ} \mathrm{C} / \mathrm{sec}$

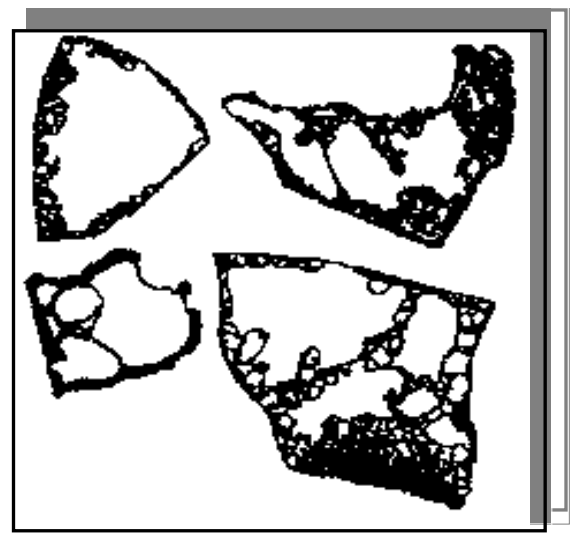

\section{c. Heat Rate $=10^{\circ} \mathrm{C} / \mathrm{sec}$}

Figure 3.7: Cross-sectional images of char produced from different pyrolysis heating rates.

Parent Coal: Illinois \#6, 28-32 mesh. 


\section{SECTION 4}

\section{EFFECT OF PYROLYSIS CONDITIONS ON CHAR COMBUSTION RATE}

\section{$4.1 \quad$ Overview}

Earlier experimental results from our lab revealed that higher heating rates produce chars with larger particle size, higher macroporosity and macropore surface area and larger macropore size. In this section, extensive combustion results are presented to elucidate the influence of macropore structure on the combustion rate and ultimately, the burn-off time required to complete the combustion. This information may be very useful in selecting operating conditions that will enhance the char reactivity and in optimizing the design of industrial combustors, since shorter burn-off time leads to smaller combustor size.

\subsection{Effect of pyrolysis heating rate on char reactivity}

Char combustion experiments were conducted at temperatures ranging from $375^{\circ} \mathrm{C}$ to $1000^{\circ} \mathrm{C}$ in order to illustrate the effect of pyrolysis heating rate and macropore structure on the reactivity of produced chars. Pyrolysis heating rates from 0.1 to $10{ }^{\circ} \mathrm{C} / \mathrm{sec}$ were used for these experiments. For low combustion temperatures, we utilized the stage combustion protocol to study the effect of heating rate on the intrinsic reactivity of char. We also used the sequential combustion protocol in order to approximate combustion at industrial conditions. The oxygen concentration used for these experiments ranged from $1 \%$ to $21 \%$. For each set of parameters, at least three runs were carried out to test the reproducibility of the results. Besides measuring 
reactivity as a function of overall conversion, we also estimated the average reactivity by considering reactivity data from $0-99 \%$ conversion at $1 \%$ intervals.

For each experiment, we also computed $\mathrm{t}_{98}$ defined as the time required to reach $98 \%$ conversion. Although $\mathrm{t}_{100}$ or $\mathrm{t}_{99}$ (the time required to reach $99 \%$ or complete conversion respectively) may appear to be a more natural choice, it was experimentally very difficult to reach $100 \%$ conversion. The true ash residue weight, a parameter needed to calculate the true carbon content, was hard to measure precisely due to the sensitivity of TGA to temperature and atmospheric conditions.

\subsection{Combustion in Kinetic Control Regime}

Figures 4.1 to 4.4 show the experimental results for char combustion at $400^{\circ} \mathrm{C}$ and $420^{\circ} \mathrm{C}$ with $2 \%$ and $5 \%$ oxygen concentration. Chars prepared at different pyrolysis heating rates exhibited similar reactivity vs. conversion patterns. As expected, the average reactivities and burn-off time $\mathrm{t}_{98}$ were also quite similar.

Earlier results (see Section 3) demonstrated that chars prepared at different pyrolysis heating rates have different macropore structures. However, Figures 4.1 to 4.4 show that the reactivity patterns of chars with different macropore structures are very similar, suggesting that macropores do not play a significant role in determining reaction kinetics at low combustion temperatures.

At low combustion temperatures, combustion takes place in the kinetic controlled regime. Chemical kinetics is the rate-limiting factor since combustion rates are relatively slow compared to oxygen's diffusion rate. The small micropores (which account for most of the internal surface area) are fully accessible to oxygen as indicated in the cartoons of Figure 4.5 [A] and [B]. Consequently, the micropore surface area determines the total reaction rate.

Since the micropore surface area is the determining factor for the overall reaction rate and the reactivity patterns for all chars are similar, these results provide strong evidence that the pyrolysis heating rates did not affect the micropore surface area of char particles. Neither did the heating rate appear to influence the chemical nature and concentration of reactive sites. 


\subsection{Combustion in the Regime of Diffusional Limitations}

At higher temperatures, the combustion rates accelerate and become significantly larger than the oxygen transport rates. In this regime, the interconnected large macropores become the arteries transporting oxygen to the particle interior. Oxygen, however, reacts before it has a chance to penetrate the smaller pores and diffusional limitations appear in the micropores emanating from the larger pores. As shown in the cartoons of Figure 4.5B, only the portion of micropores near their mouth opening to the macropores will be accessible to oxygen, and the pore surface area utilized for reaction would be proportional to the macropore surface area. Hence, char particles produced at faster pyrolysis heating rate should exhibit higher combustion rates since they have larger macropore surface areas.

Our experimental results provided strong evidence in support of this hypothesis. At higher combustion temperatures, chars prepared at different heating rates exhibited different reaction rates. Figures 4.6 and 4.7 present the results of char combusted at $450^{\circ} \mathrm{C}$ with $21 \% \mathrm{O}_{2}$. Although previous studies in our laboratory (Matzakos 1991; Ismail 1994) usually considered that combustion at $450^{\circ} \mathrm{C}$ took place in the kinetic control regime, the results presented here clearly show that a transition into the diffusion-limited regime has already begun at this temperature.

At higher combustion temperatures, reactivity differences among the three chars were even more pronounced. Figures 4.8 to 4.11 demonstrate that at 500 and $550{ }^{\circ} \mathrm{C}$, reactions clearly take place in the diffusion-limited regime as chars prepared at different heating rates exhibit different reactivity. Also note that for all the parameter sets tested, chars prepared at $1{ }^{\circ} \mathrm{C} / \mathrm{sec}$ always exhibited higher reaction rates than those prepared at $10{ }^{\circ} \mathrm{C} / \mathrm{sec}$. This confirms the validity of the structural measurements obtained earlier in our lab (Boissiere 1993) that showed that chars produced at $1{ }^{\circ} \mathrm{C} / \mathrm{sec}$ possess the largest macropore surface areas.

When chars were combusted at $550^{\circ} \mathrm{C}$ with $21 \%$ oxygen, some particles ignited (Figures 4.12 and 4.13). Although light emissions associated with these ignitions were not significant and were hardly detectable by visual observation, combustion for char prepared from $10{ }^{\circ} \mathrm{C} / \mathrm{sec}$ exhibited distinctive spikes which suggested that 2-3 char particles ignited and greatly enhanced the instantaneous reactivity. However, chars prepared at $1^{\circ} \mathrm{C} / \mathrm{sec}$ still had the largest reactivity even though no ignition could be visually detected. This can be explained if we assume that a series of faint, "overlapping" ignitions occurred in this case as suggested in Section 6. 
Earlier studies in our lab used much higher oxygen concentration (33\%-50\%) to demonstrate the effect of pyrolysis heating rate on char ignition (Matzakos 1991; Matzakos and Zygourakis 1993). They also concluded that char particles with more open macropore structure are more prone to ignite than their counterparts produced at lower heating rates because the former chars exhibited faster heat generation and slower heat dissipation rates (Matzakos 1991; Matzakos and Zygourakis 1993). In the present study, on the other hand, the maximum oxygen concentration used was $21 \%$ in order to approximate the operation industrial burners that primarily use air as the feed gas. Ignitions could still be observed in some cases, but their intensity and frequency were much lower than those observed when chars were combusted at 33-50\% oxygen concentration.

From the experimental results, we may conclude that pyrolysis heating rates are instrumental in determining the char combustion rates. Higher heating rate produce chars with larger macropore surface areas that lead to higher observable reaction rates in the diffusion-limited regime and require less time for complete combustion. Also, high pyrolysis heating rates favor char ignitions, a phenomenon that can greatly enhance the overall reactivity.

\subsection{Combustion in External Mass Transfer Controlled Regime}

We also conducted combustion experiments at temperatures that ranged from 700 to $1000{ }^{\circ} \mathrm{C}$ and approached industrial combustion temperatures (see Figures 4.14 to 4.17). These highly reproducible results (see Figure 4.18) revealed several interesting aspects:

- Reactivity differences among chars produced at different pyrolysis heating rates were not as pronounced as those observed at lower temperatures $\left(500-550{ }^{\circ} \mathrm{C}\right)$. Especially for combustion temperatures higher than $850^{\circ} \mathrm{C}$, chars prepared under different heating rates exhibited very similar reactivities.

- An increase in combustion temperature from 700 to $1000{ }^{\circ} \mathrm{C}$ did not significantly increase the observed reaction rate. As seen in Figure 4.17, the average char reactivities did not depend strongly on the combustion temperature. 
- For combustion at $850^{\circ} \mathrm{C}$ and $1000^{\circ} \mathrm{C}$, there was a pronounced shift of the reactivity maximum toward higher conversions (60-70\%). On the other hand, reactivity patterns for combustion at lower temperatures usually exhibited a peak at around 30-40\% conversion.

These results strongly indicate that combustion at temperatures ranging from 700 to $1000{ }^{\circ} \mathrm{C}$ takes place in the regime of external mass transfer control. Due to the extremely fast reaction at these temperatures, diffusion limitations occur not only in smaller micropores but in the larger macropores as well. Under such conditions, oxygen is consumed completely before if can diffuse deeply into the particle interior. Thus, most of the internal surface area is inaccessible to oxygen and reactions only take place in a small shell close to the particle external surface.

In the regime of external mass transfer control, we can express the reaction rate in the following form:

$$
R_{o b s}=k_{g} A\left(C_{b}-C_{A}\right)
$$

The left-hand side term represents the observed reaction rate per unit mass, while the right-hand side stands for the external mass transfer rate, with $k_{g}$ being the external mass transfer coefficient, $\mathrm{A}$ is the total external surface area per unit mass, and $C_{\mathrm{b}}$ and $C_{A}$ are the bulk and particle surface concentration of oxygen respectively.

Equation (4.1) also implies that for a constant oxygen concentration, $k_{g}$ is solely responsible for the reaction rate of any char particle with specific radius. Since $k_{\mathrm{g}}$ increases only slightly with ambient temperature, the total reaction rate should increase slightly with temperature as well, as shown in Figure 4.17.

A "pore opening: mechanism is a possible explanation for the shift of reactivity peaks toward higher conversions observed at high combustion temperatures. Due to the strong diffusion limitations in both the micropores and micropores, reaction is confined to a thin layer near the external particle surface. As the carbon solid is consumed, the external surface recedes and previously inaccessible internal pores open to the particle exterior and become available for reaction with oxygen. This opening of internal pores increases the total internal surface area available for reaction and, thus, enhances the overall reaction rate. 
Figure 4.19 demonstrates this mechanism. Images $\mathrm{E}$ and $\mathrm{F}$ of this sequence clearly shows "holes" on the particle surface indicating the opening of previously closed pores as the carbon is consumed by reaction. The progressive opening of more internal pores increases the internal surface area and shifts the reactivity peak towards higher conversion level as shown in the plots for combustion at $850^{\circ} \mathrm{C}$ and $1000{ }^{\circ} \mathrm{C}$ (Figures 4.15 and 4.16 ).

Although we expect ignitions for these high temperature combustions, surprisingly no significant ignition is detected; however, we can't rule out the possibility of faint ignition.

\subsection{The effect of heat treatment temperature and soak time}

The effect of heat treatment temperature (HTT) and soak time (ST) (two important pyrolysis conditions) on char reactivity was also studied.

To assess the effect of heat treatment temperature on the intrinsic reactivity of char, experiments were conducted with different HTT and the results were presented in Figure 4.20. For the same soak time and pyrolysis heating rate, chars prepared with HTT equal to $600^{\circ} \mathrm{C}$ had higher reactivity than those prepared with an HTT of $700^{\circ} \mathrm{C}$. Since these combustion experiments took place in the kinetic controlled regime, we can conclude that the difference of observed reaction rates is due to differences in the intrinsic reactivity of char.

Earlier studies of HTT effects (Serio, Solomon et al. 1989) implied that higher HTT causes an increase in the molecular order of char due to the annealing of the organic and mineral components and microporosity of the chars. In other words, the high treatment temperature causes a sintering of active carbon and results in a decrease of the intrinsic reactivity.

The effect of soak time was studied by conducting experiments in both the kinetic and diffusion limitation controlled regime. Figure 4.20 also shows that at HTT=600C, shorter soak times produce chars that are more reactive at lower temperatures than chars produced after longer soak times. Thus, longer soak times decrease the intrinsic reactivity of chars. Figures 4.21 and 4.22 show the results of high temperature combustion. It was obvious that soak time had a strong effect on the reactivity in this regime. Chars produced with no soak time were about $70 \%$ more active than those treated with 10 minutes soak time. As expected, $t_{98}$ was much shorter for chars produced with no soak time. 


\subsection{References for Section 4}

Boissiere, F. (1993). "Influence of pyrolysis conditions on the macropore structure of char particles", M.S. Thesis, Rice University.

Ismail, A. (1994). "The effect of process conditions on coal pyrolysis and char reactivity," Ph.D. Thesis, Rice University.

Matzakos, A. (1991). "Fundamental mechanisms of coal pyrolysis and char combustion," Ph.D. Thesis, Rice University.

Matzakos, A. N. and K. Zygourakis (1993). "Computerized thermogravimetric reactor with video microscopy imaging system for coal pyrolysis and combustion studies." Rev. Sci. Instrum. 64(6): 1541-1548.

Serio, M. A., P. R. Solomon, et al. (1989). "The effect of minerals and pyrolysis conditions on char gasification rates." Amer. Chem. Soc., Div. Fuel Chem. Prepr. 34(1): 9-21. 


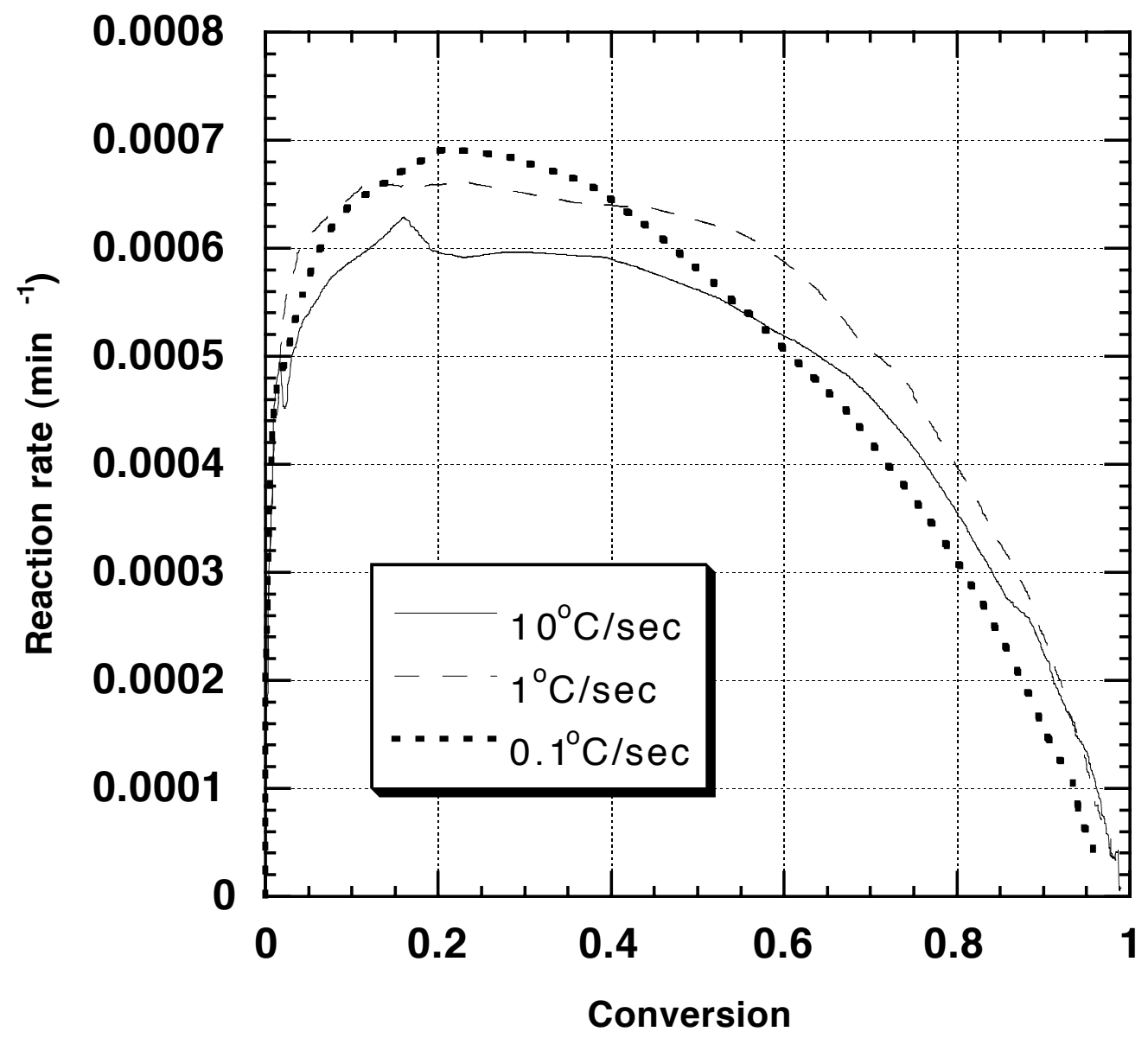

Figure 4.1: Reactivity plots for 28-32 mesh Illinois \#6 char particles prepared at different pyrolysis heating rates.

Combustion Temperature $=400^{\circ} \mathrm{C}$ - Oxygen concentration $=2 \%$

$\mathrm{HTT}=600{ }^{\circ} \mathrm{C}$ - Soak Time $=10$ minutes - Staged Combustion . 

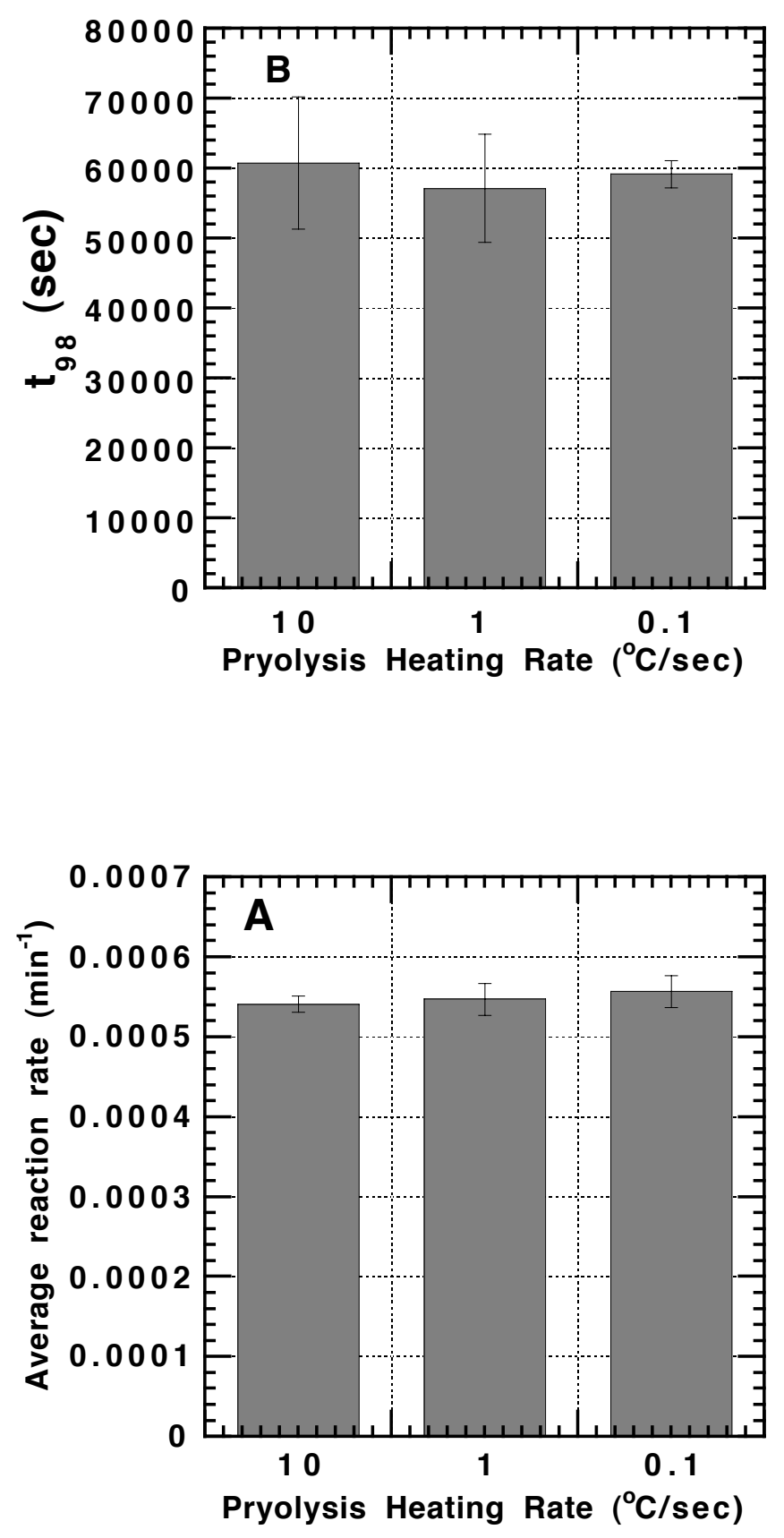

Figure 4.2: $\quad$ Burn-off times $\mathrm{t}_{98}$ (top) and average reactivities (bottom) [A] for Illinois \#6 for chars prepared under different pyrolysis heating rates.

Combustion temperature $=400^{\circ} \mathrm{C}-$ Oxygen concentration $=2 \%$

$\mathrm{HTT}=600^{\circ} \mathrm{C}$, Soak Time $=10$ minutes, Staged Combustion 


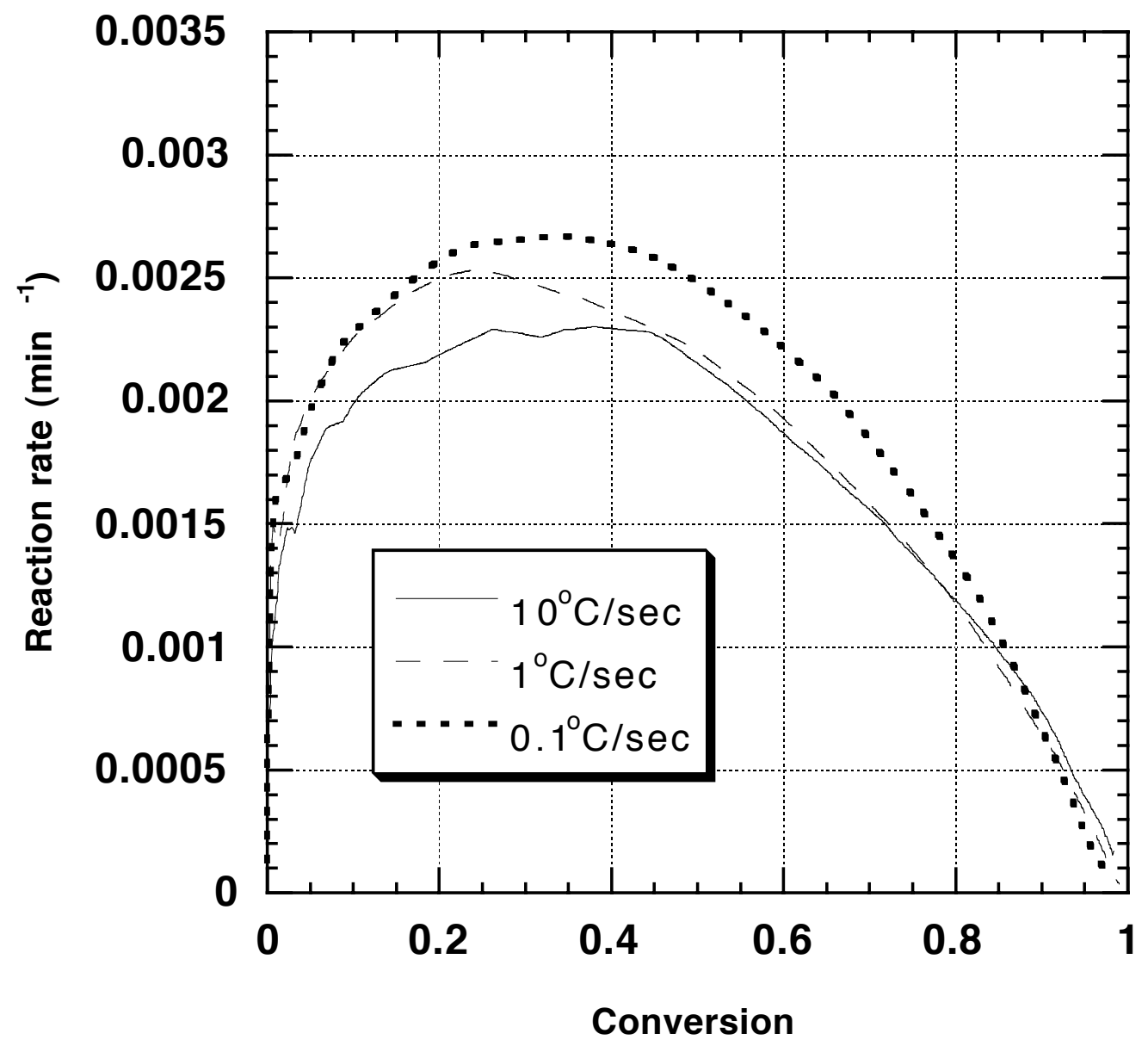

Figure 4.3: Reactivity plots for 28-32 mesh Illinois \#6 char particles prepared at different pyrolysis heating rates.

Combustion Temperature $=420^{\circ} \mathrm{C}-$ Oxygen concentration $=5 \%$ $\mathrm{HTT}=600^{\circ} \mathrm{C}$ - Soak Time $=10$ minutes - Staged Combustion . 

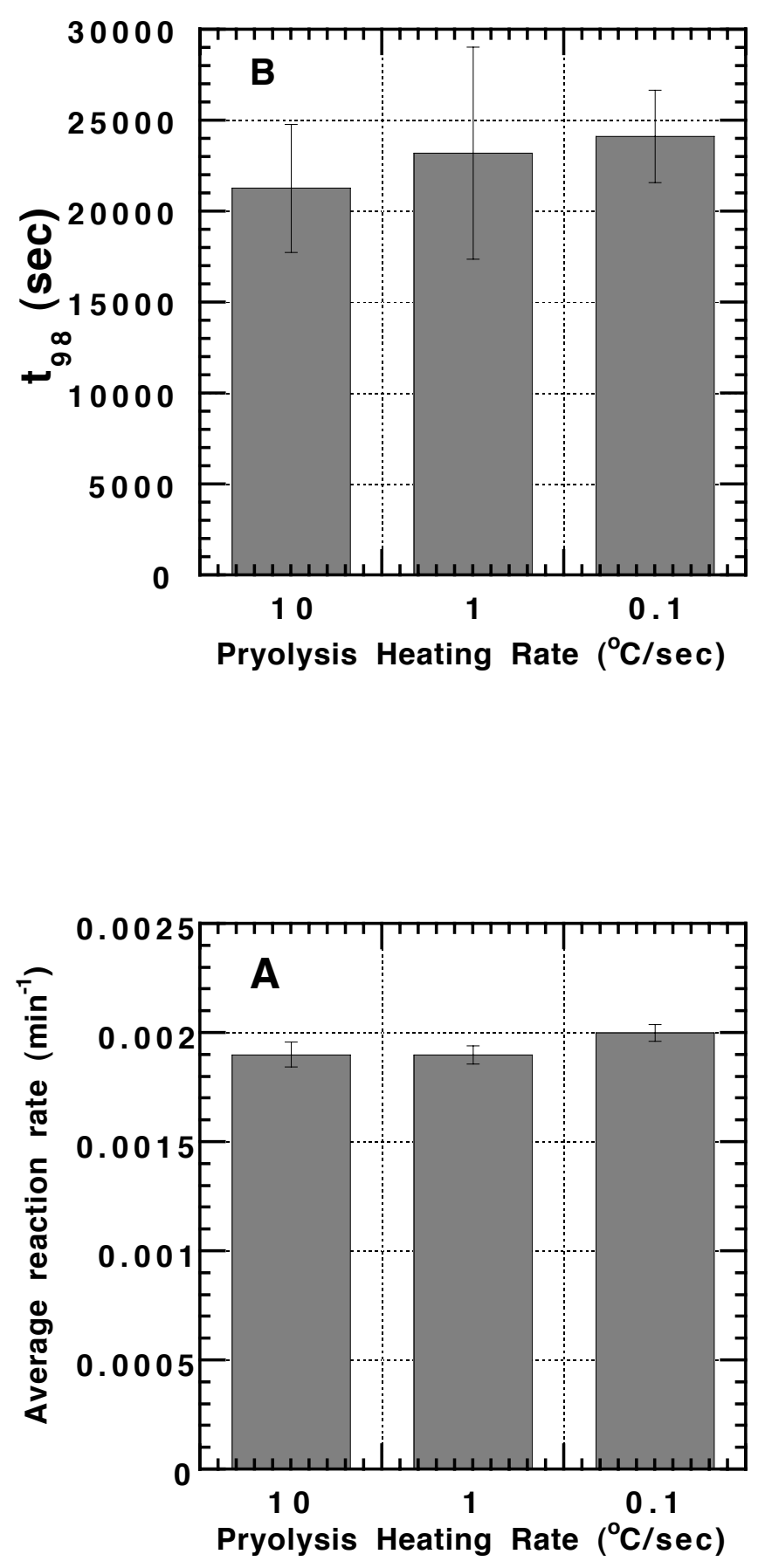

Figure 4.4: Average reactivities [top] and burn-off times $\mathrm{t}_{98}$ [bottom] for Illinois \#6 Char prepared under different pyrolysis heating rates.

Combustion temperature $=420^{\circ} \mathrm{C}-$ Oxygen concentration $=5 \%$ $\mathrm{HTT}=600^{\circ} \mathrm{C}$ - Soak Time $=10$ minutes - Staged Combustion . 


\section{Kinetic control regime}
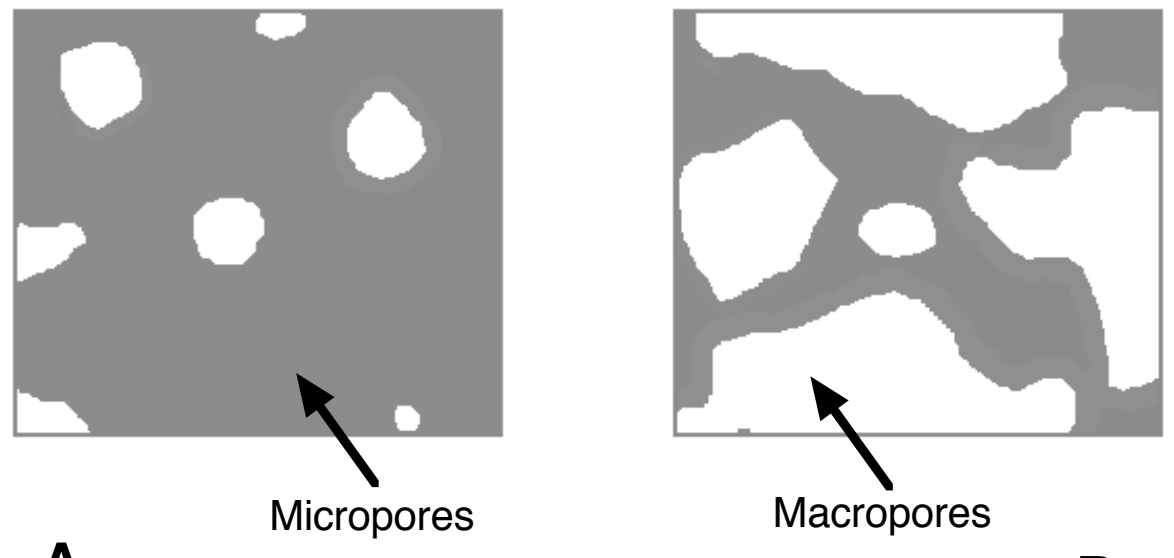

A

Micropores

Macropores

Diffusion limited regime
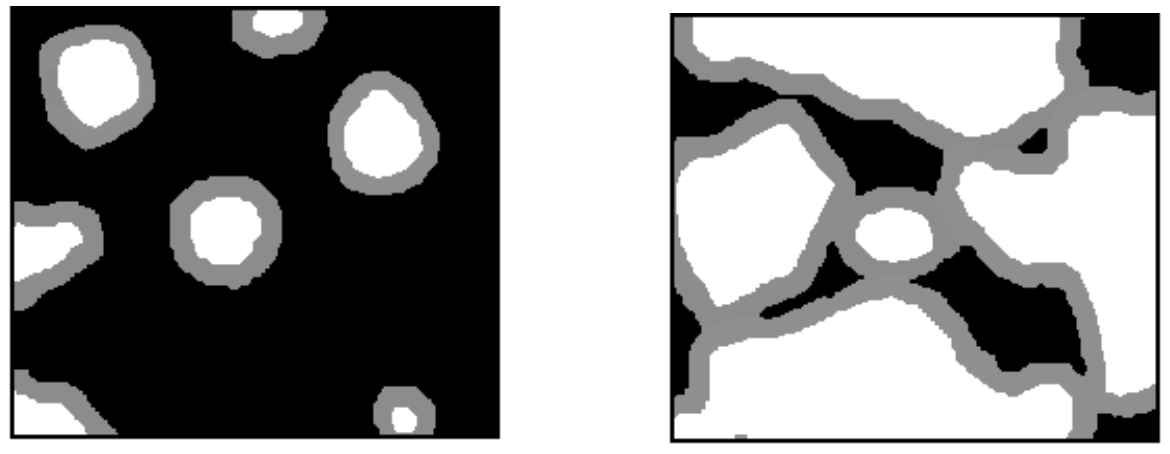

C

D

Open pore space

Internal pore surface accessible to oxygen

Internal pore surface inaccessible to oxygen

Figure 4.5: Illustration of the utilization of the internal surface area of two structurally different chars when combusted in the kinetic control and diffusion limited regime. 


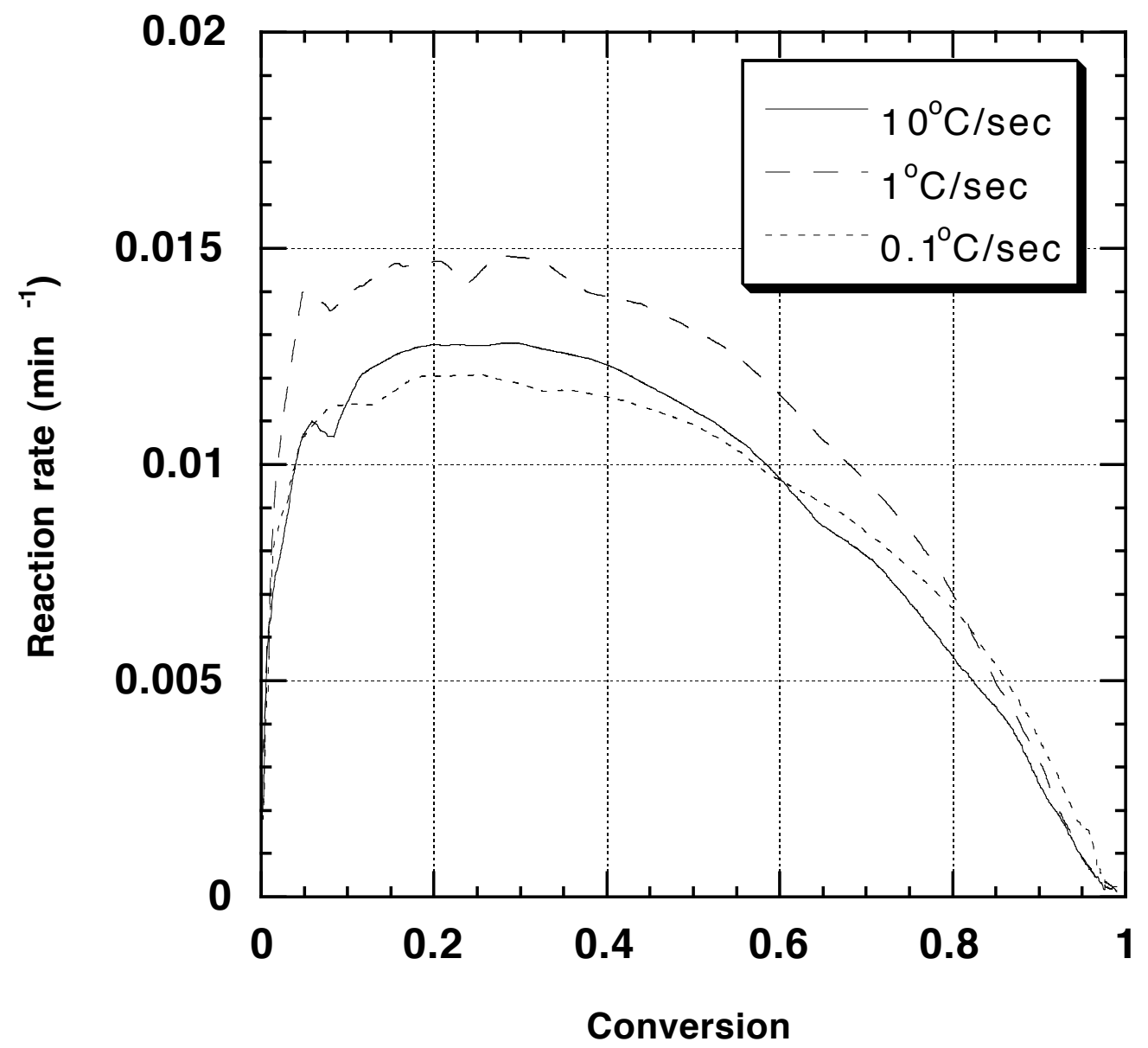

Figure 4.6: Reactivity plots for 28-32 mesh Illinois \#6 char particles prepared at different pyrolysis heating rates.

Combustion Temperature $=450^{\circ} \mathrm{C}-$ Oxygen concentration $=21 \%$ $\mathrm{HTT}=600^{\circ} \mathrm{C}$ - Soak Time $=10$ minutes - Staged Combustion . 

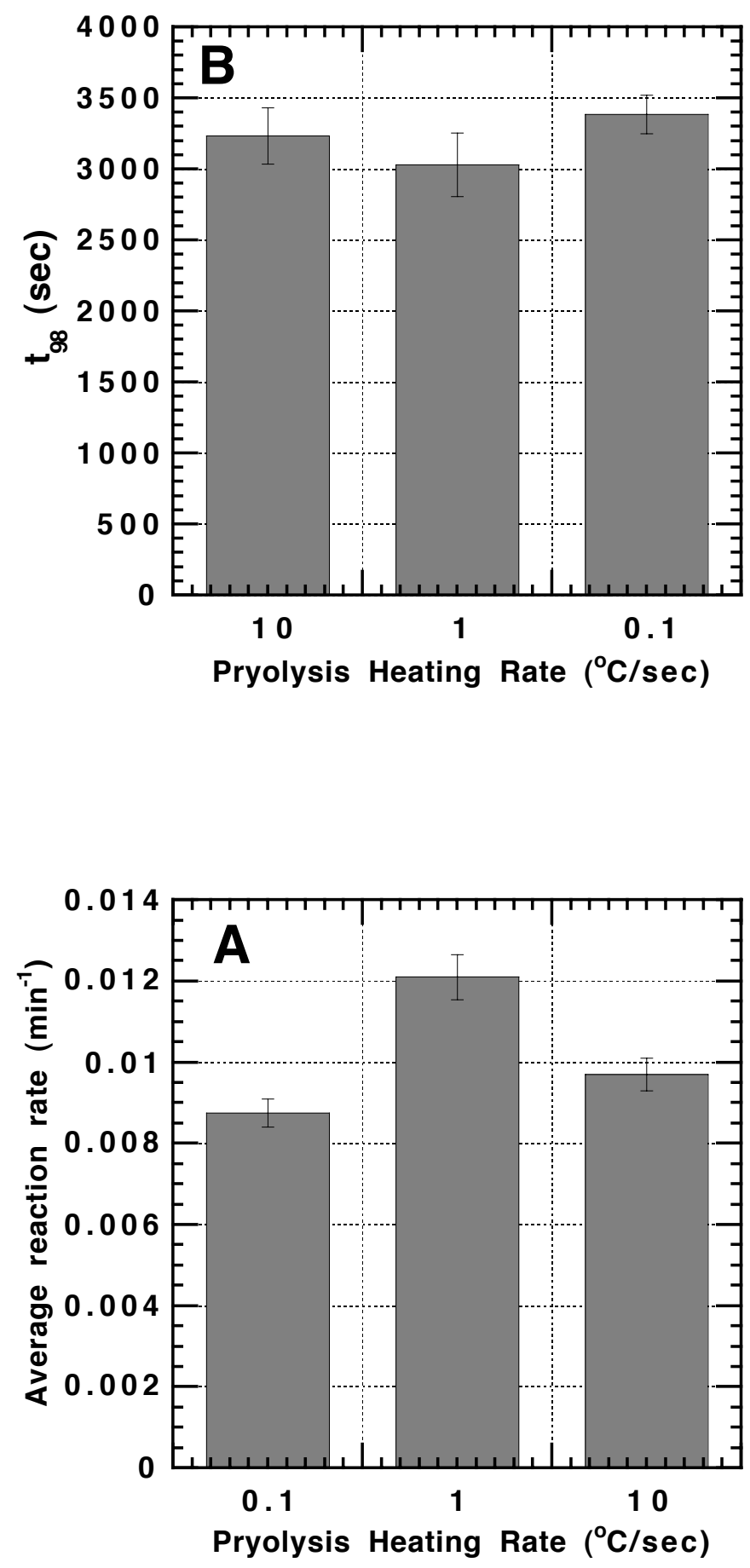

Figure 4.7: Burn-off times $t_{98}$ (top) and average reactivities (bottom) for Illinois \#6 Char prepared under different pyrolysis heating rates.

Combustion temperature $=450^{\circ} \mathrm{C}-$ Oxygen concentration $=21 \%$ $\mathrm{HTT}=600^{\circ} \mathrm{C}$, Soak Time $=10$ minutes, Staged Combustion. 


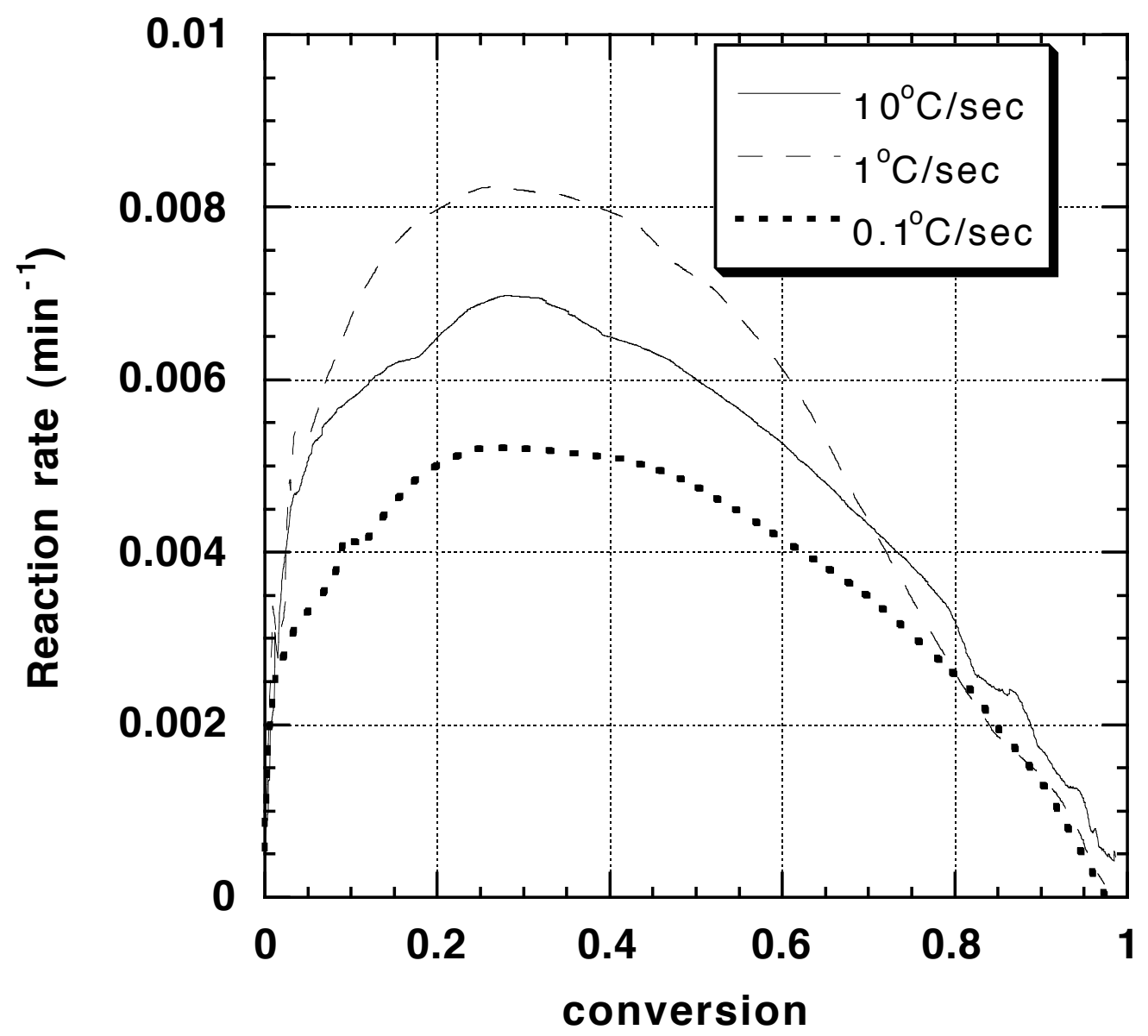

Figure 4.8: Reactivity plots for 28-32 mesh Illinois \#6 char particles prepared at different pyrolysis heating rates.

Combustion Temperature $=500^{\circ} \mathrm{C}-$ Oxygen concentration $=5 \%$

$\mathrm{HTT}=500^{\circ} \mathrm{C}$ - Soak Time $=0 \mathrm{~min}-$ Sequential Combustion. 

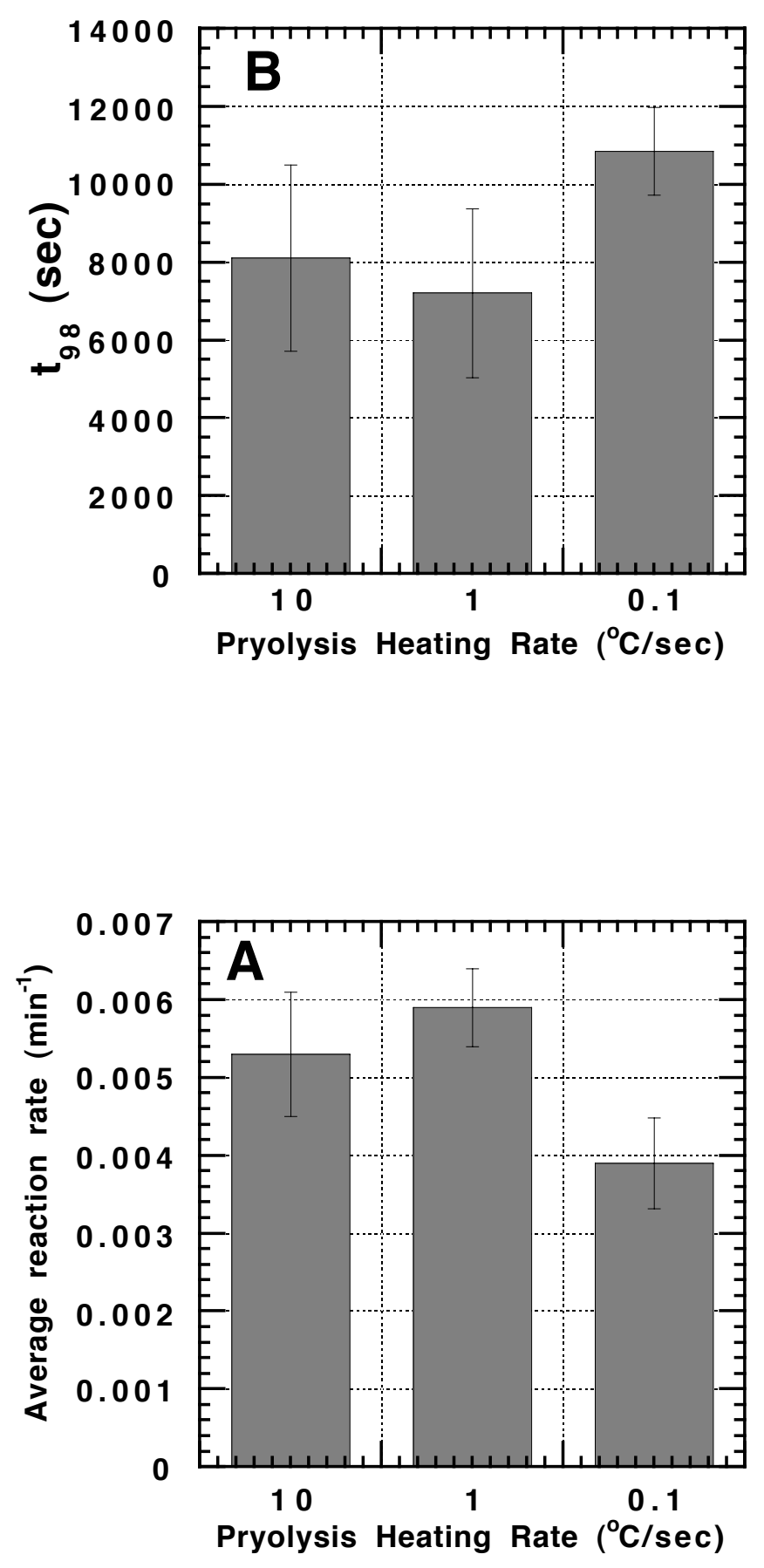

Figure 4.9: Average Reactivity [A] and $\mathrm{t}_{98}[\mathrm{~B}]$ comparison for Illinois \#6 chars prepared under different pyrolysis heating rates.

Combustion temperature $=500^{\circ} \mathrm{C}-$ Oxygen concentration $=5 \%$ $\mathrm{HTT}=500^{\circ} \mathrm{C}$ - Soak Time $=0 \mathrm{~min}-$ Sequential Combustion. 


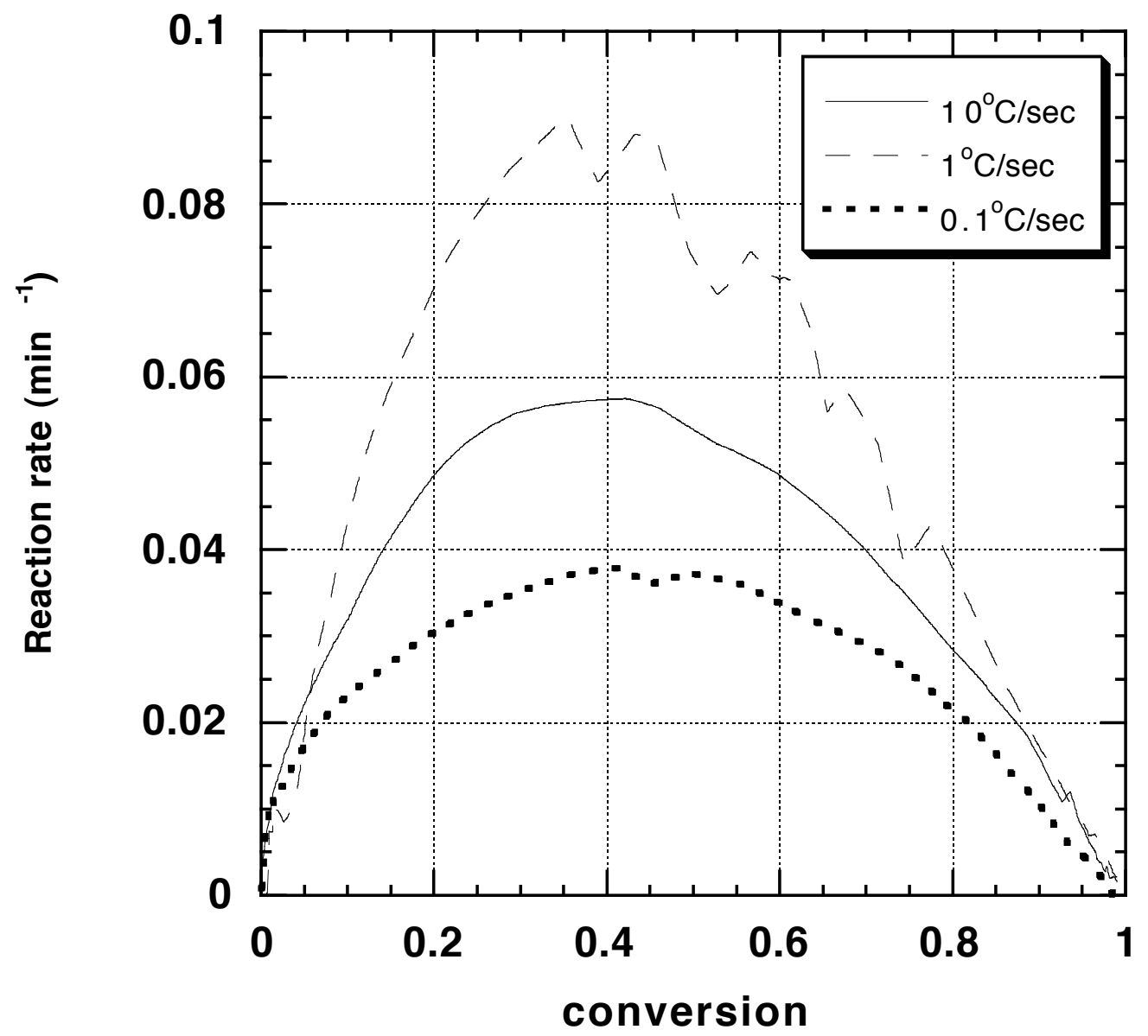

\section{$\mathrm{T}=550^{\circ} \mathrm{C}, 5 \% \mathrm{O}_{2}$}

Figure 4.10: Reactivity plots for 28-32 mesh Illinois \#6 char particles prepared at different pyrolysis heating rates.

Combustion Temperature $=550^{\circ} \mathrm{C}-$ Oxygen concentration $=5 \%$.

$\mathrm{HTT}=550^{\circ} \mathrm{C}$, Soak Time $=0 \mathrm{~min}-$ Sequential Combustion . 

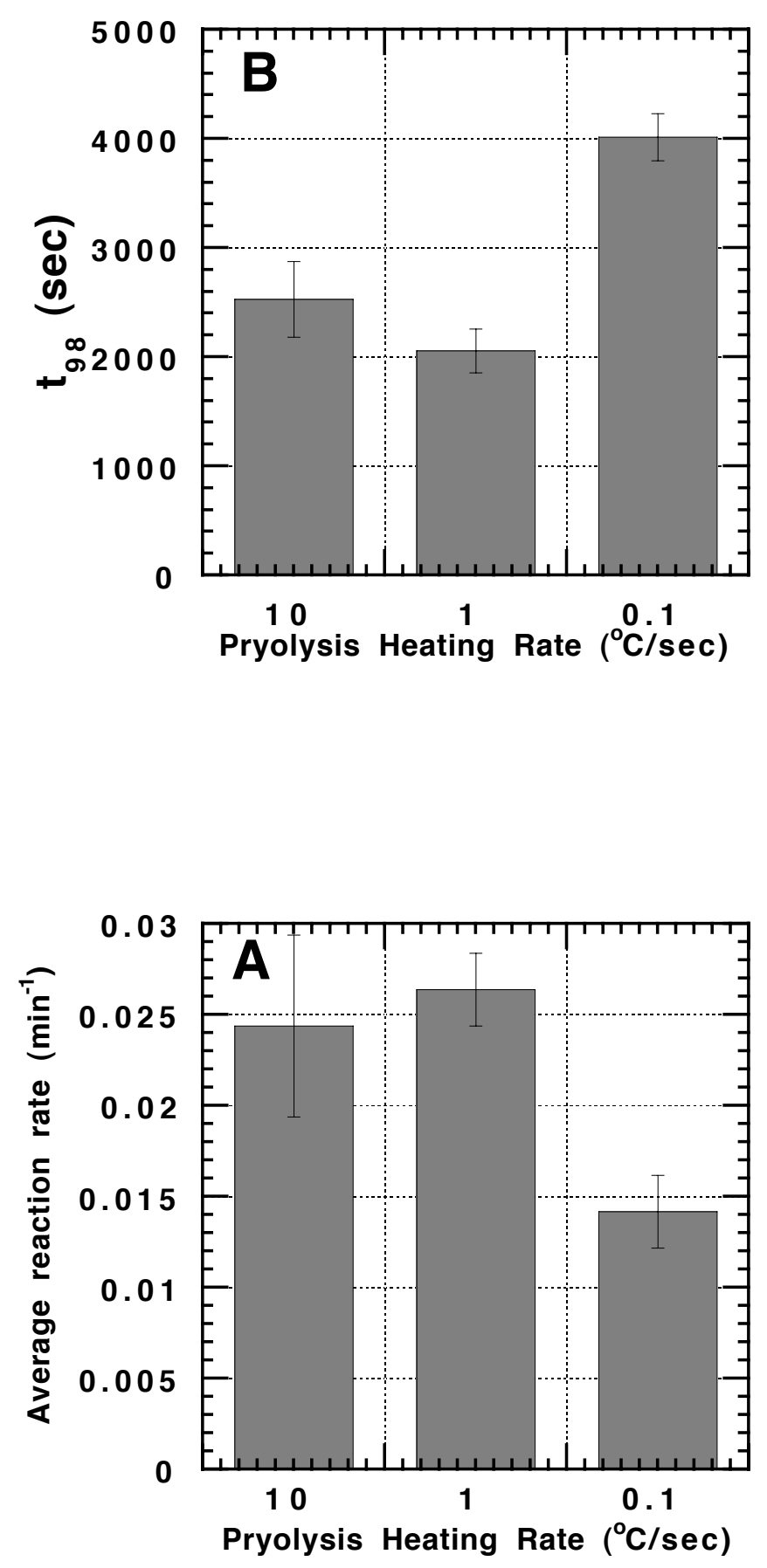

Figure 4.11: Burn-off times $\mathrm{t}_{98}$ and average reactivities for Illinois \#6 chars prepared under different pyrolysis heating rates.

Combustion temperature $=550^{\circ} \mathrm{C}-$ Oxygen concentration $=5 \%$ $\mathrm{HTT}=550^{\circ} \mathrm{C}$, Soak Time $=0$ minutes, Sequential Combustion 


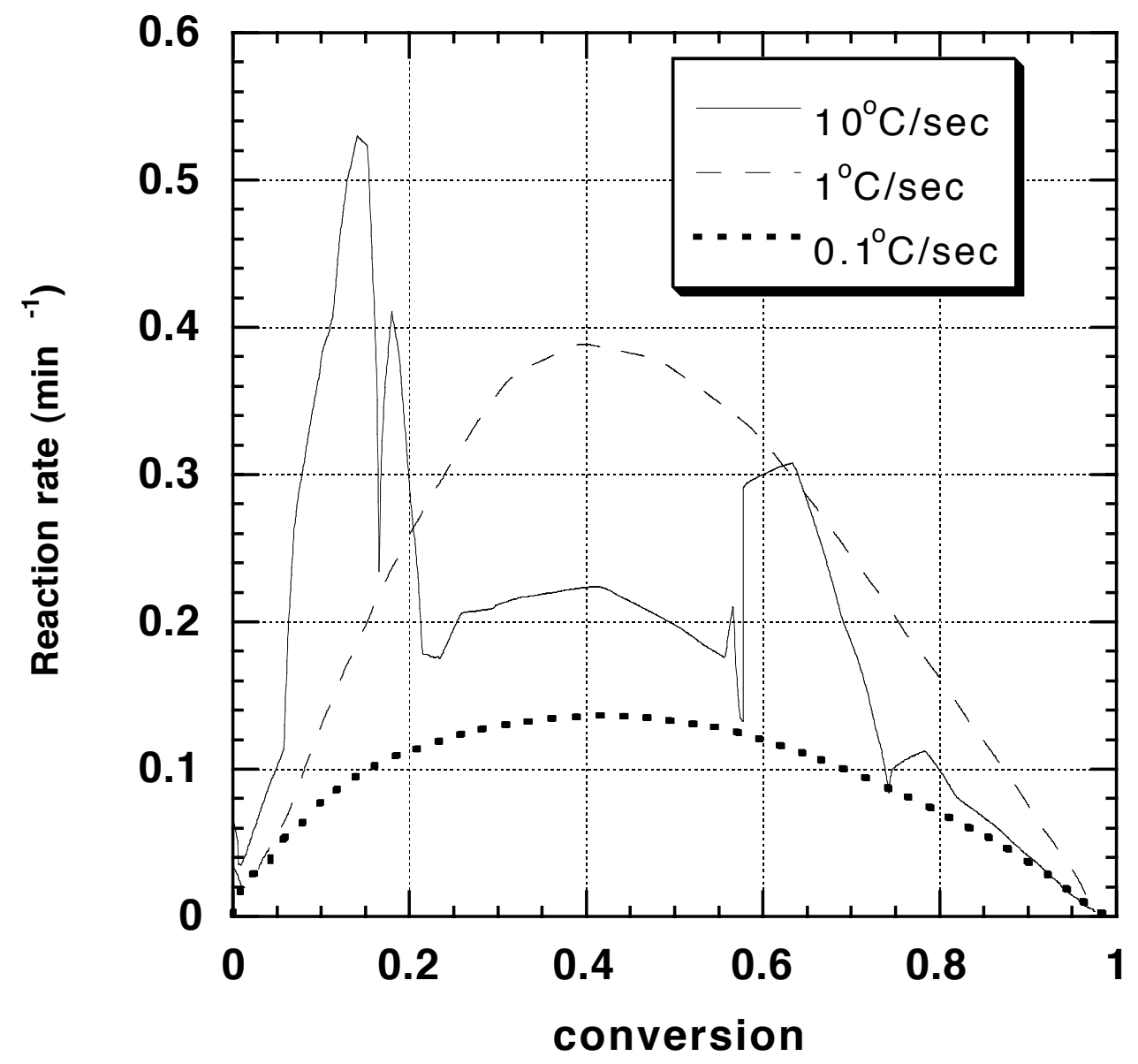

Figure 4.12: Reactivity plots for 28-32 mesh Illinois \#6 char particles prepared at different pyrolysis heating rates.

Combustion Temperature $=550^{\circ} \mathrm{C}-$ Oxygen concentration $=21 \%$ $\mathrm{HTT}=550^{\circ} \mathrm{C}-$ Soak Time $=0$ min - Sequential Combustion . 

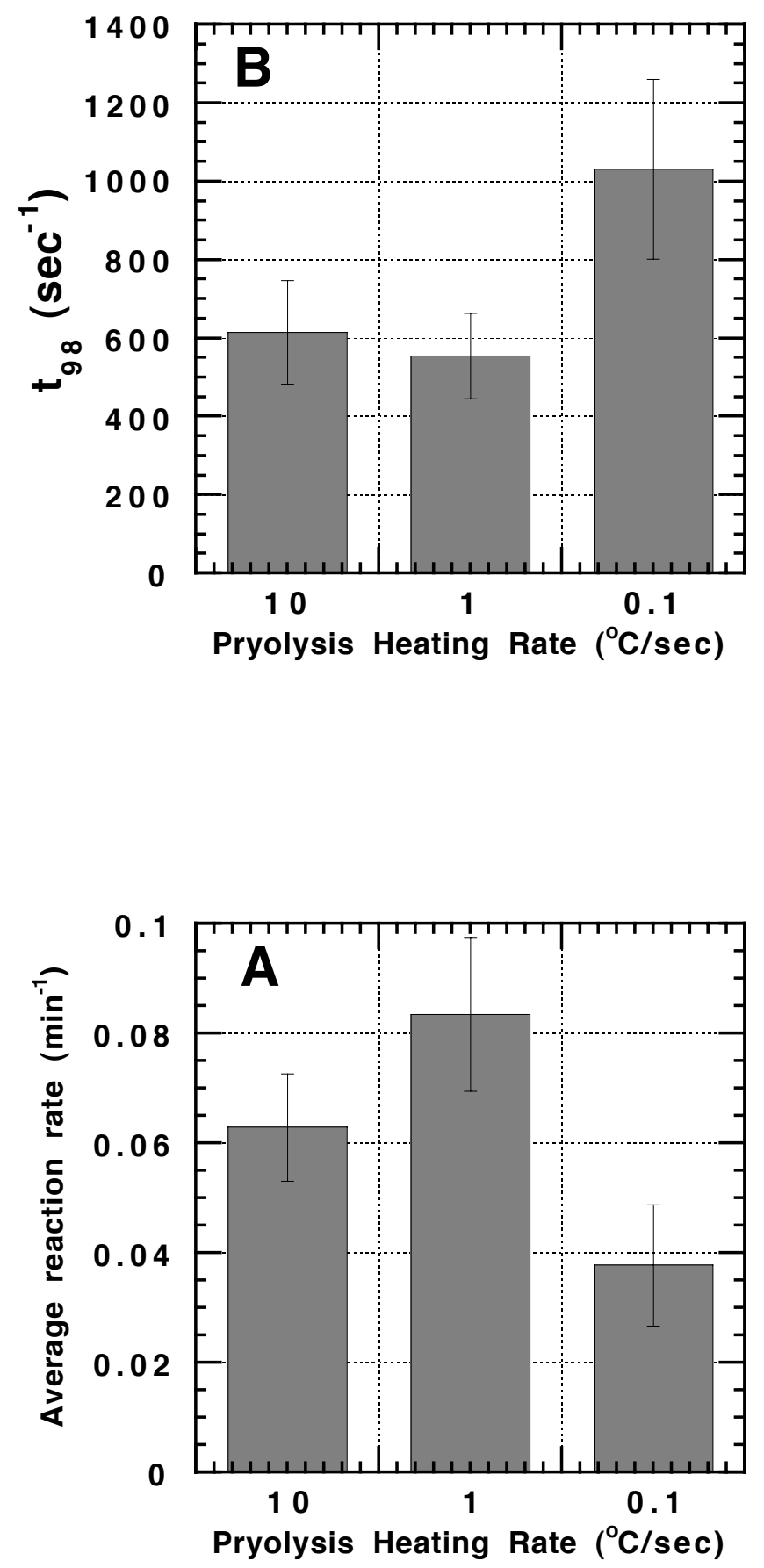

Figure 4.13: Burn-off times 98 and average reactivities for Illinois \#6 chars prepared under different pyrolysis heating rates.

Combustion temperature $=550^{\circ} \mathrm{C}-$ Oxygen concentration $-21 \%$ $\mathrm{HTT}=550^{\circ} \mathrm{C}-$ Soak Time $=0 \mathrm{~min}-$ Sequential Combustion. 


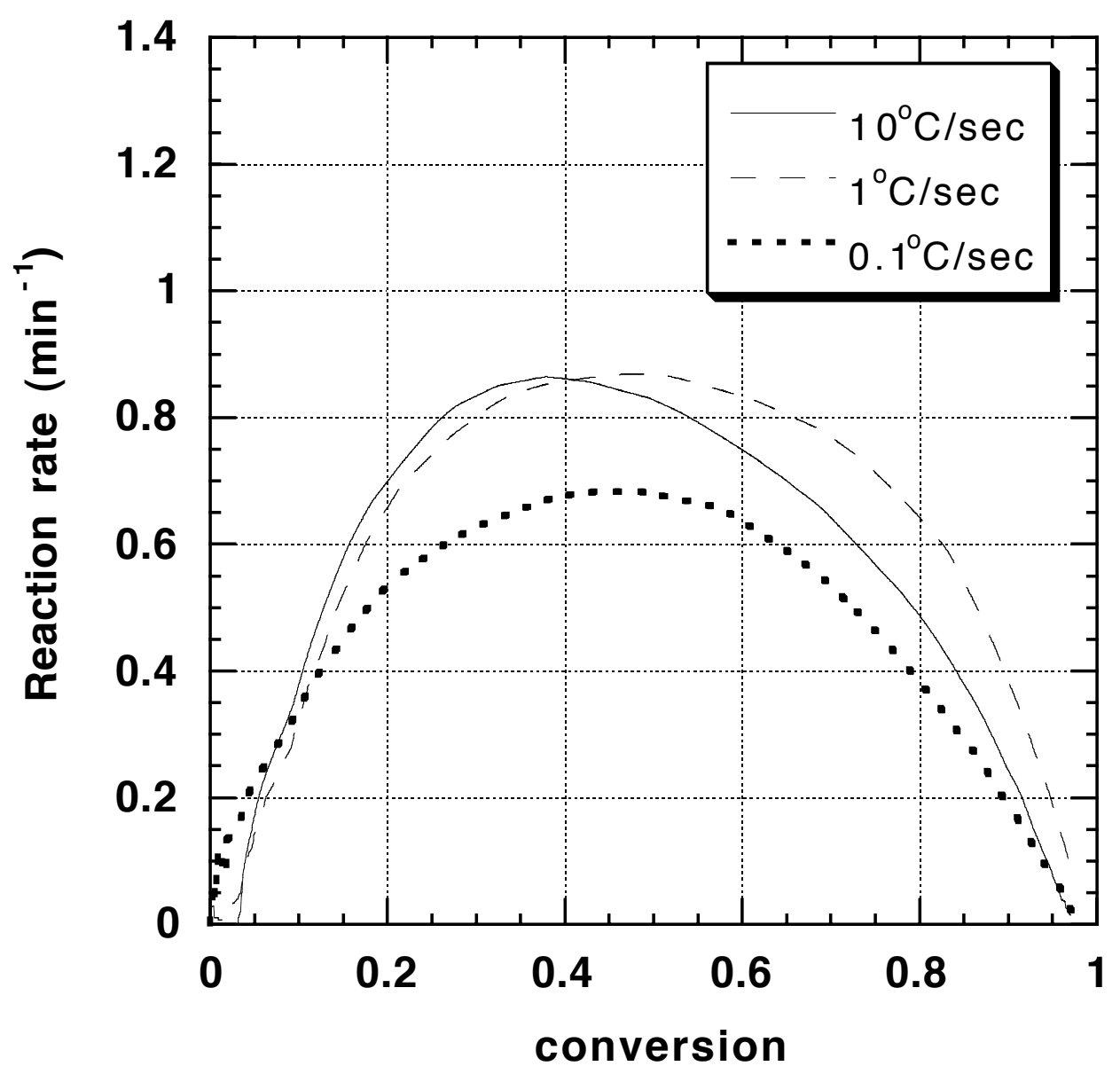

$\mathrm{T}=7^{\circ} 0^{\circ} \mathrm{C}, 21 \% \mathrm{O}_{2}$

Figure 4.14: Reactivity plots for 28-32 mesh Illinois \#6 char particles prepared at different pyrolysis heating rates.

Combustion Temperature $=700^{\circ} \mathrm{C}-$ Oxygen concentration $=21 \%$ $\mathrm{HTT}=700^{\circ} \mathrm{C}$ - Soak Time $=0$ min - Sequential Combustion . 


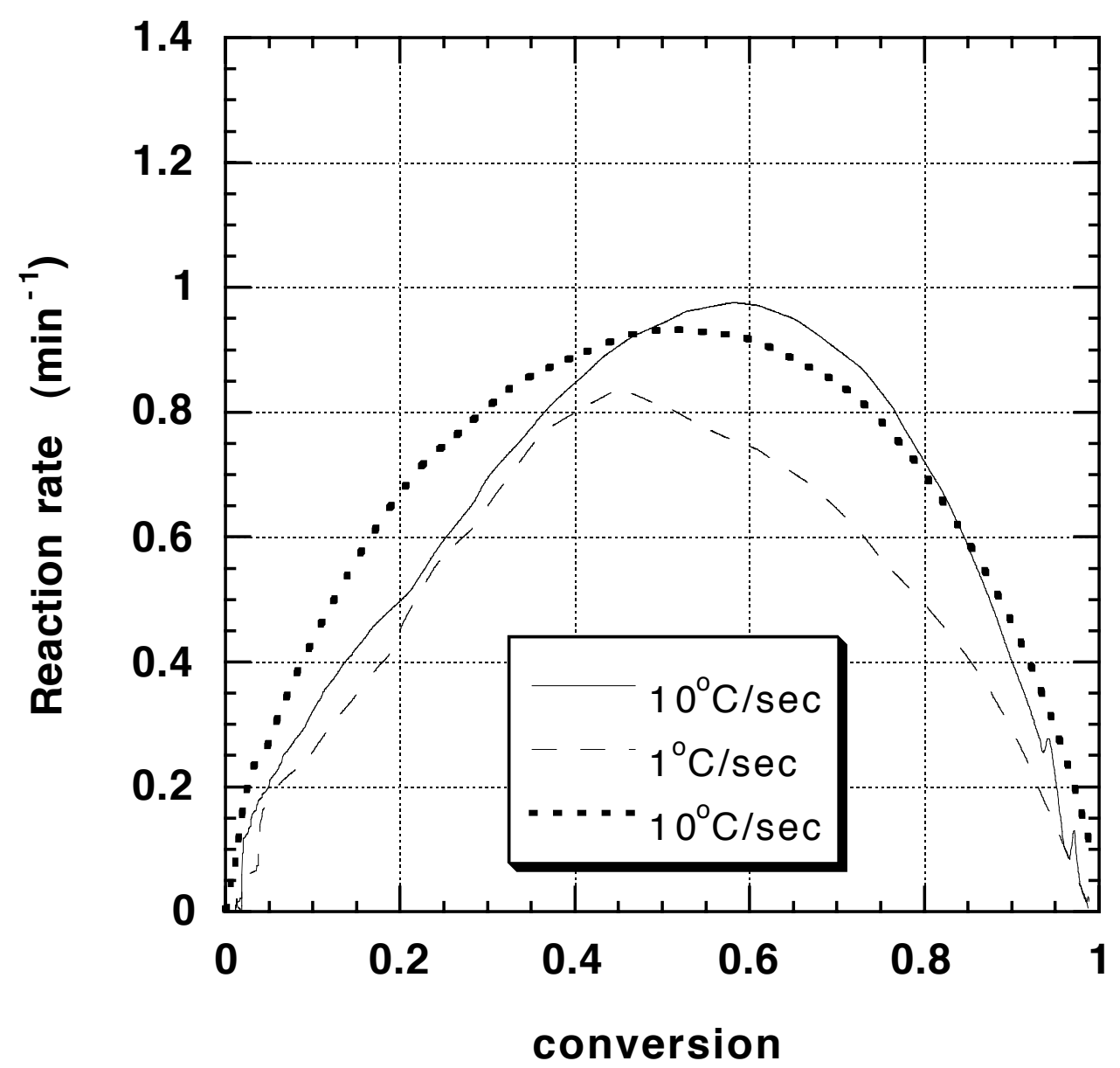

Figure 4.15: Reactivity plots for 28-32 mesh Illinois \#6 char particles prepared at different pyrolysis heating rates.

Combustion Temperature $=850^{\circ} \mathrm{C}-$ Oxygen concentration $=21 \%$ $\mathrm{HTT}=850^{\circ} \mathrm{C}$ - Soak Time $=0$ min - Sequential Combustion . 


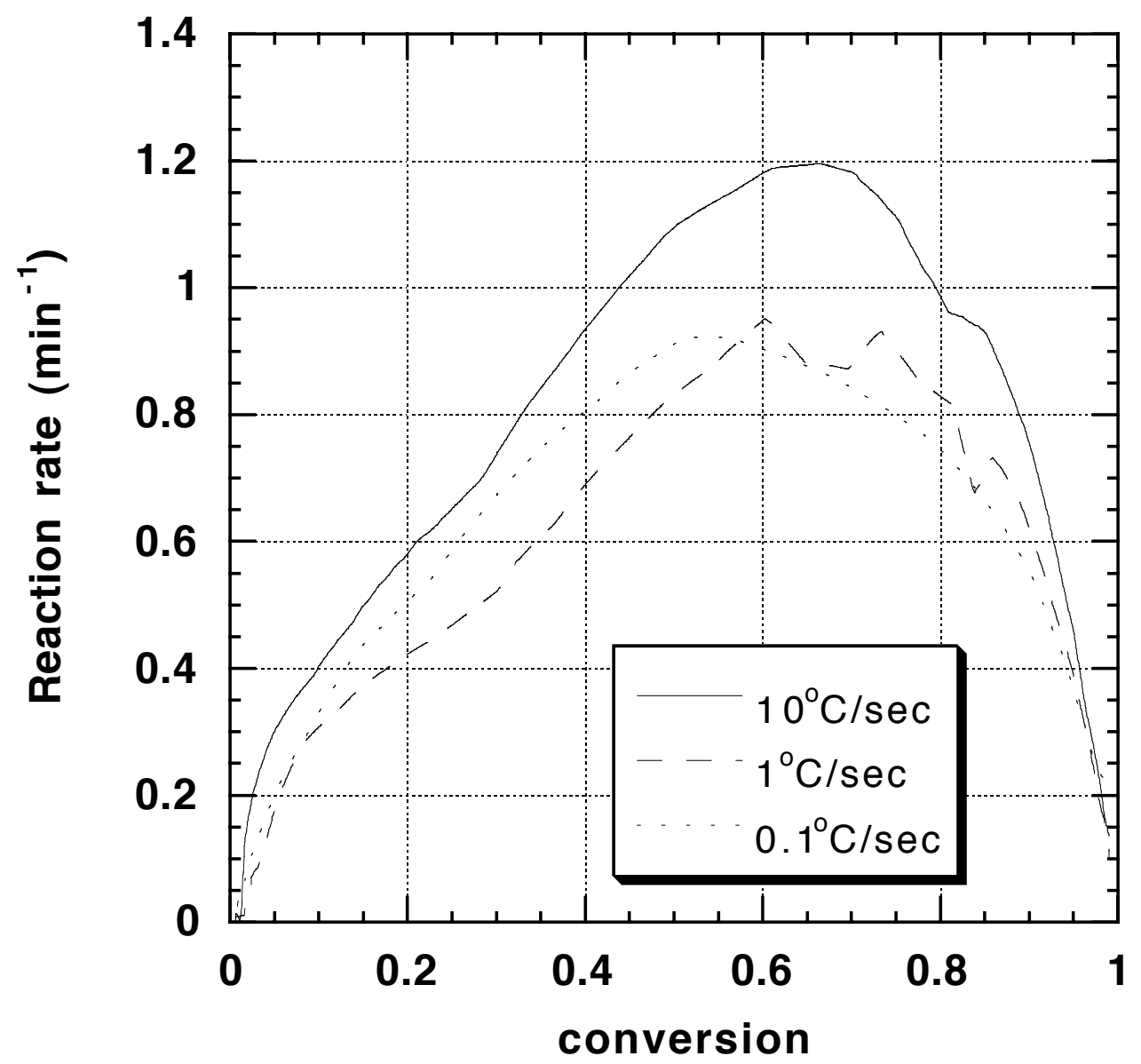

Figure 4.16: Reactivity plots for 28-32 mesh Illinois \#6 char particles prepared at different pyrolysis heating rates.

Combustion Temperature $=1000^{\circ} \mathrm{C}-$ Oxygen concentration $=21 \%$ $\mathrm{HTT}=1000^{\circ} \mathrm{C}$ - Soak Time $=0$ min - Sequential Combustion . 


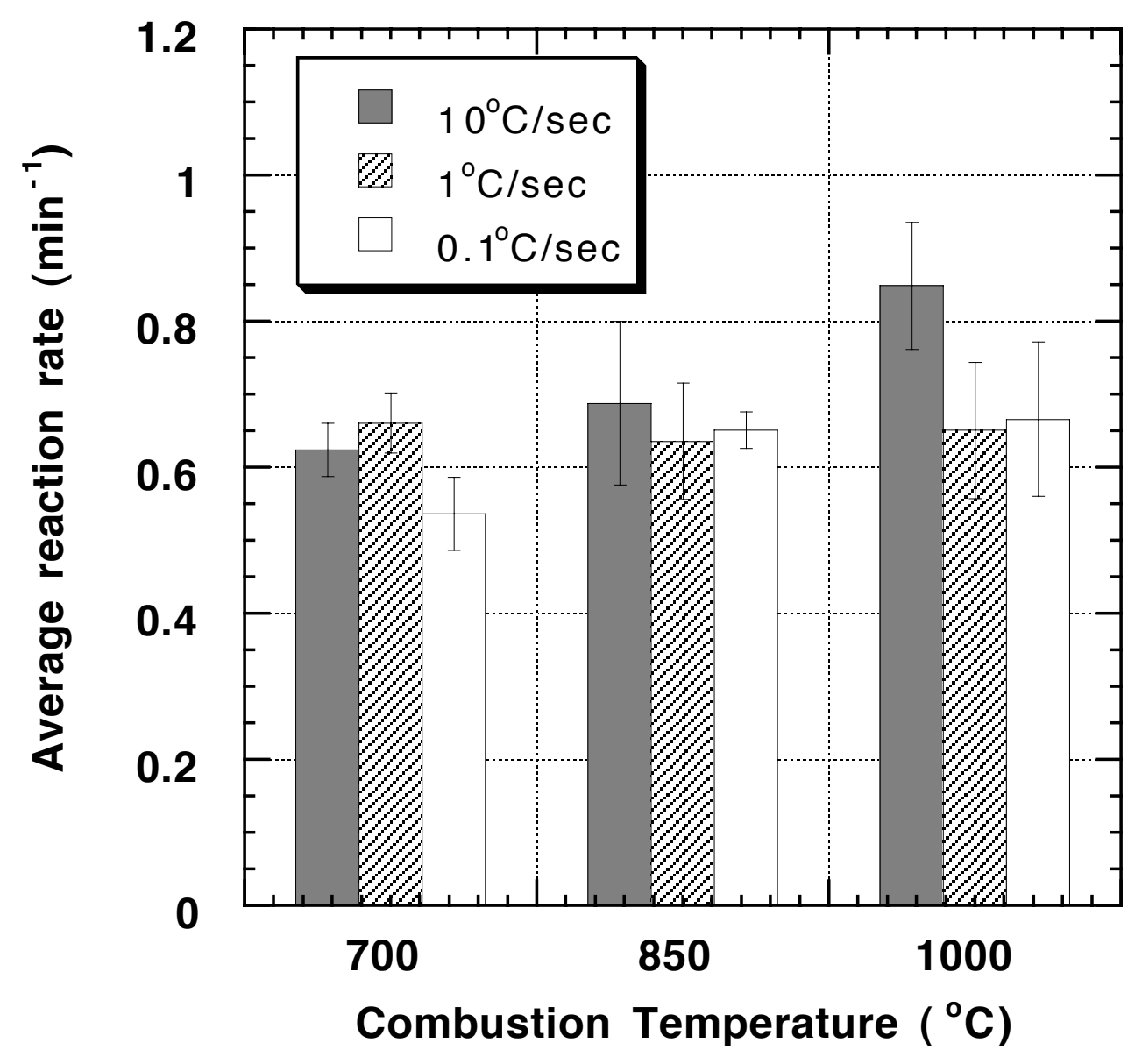

Figure 4.17: Comparison of average reactivities of Illinois \#6 chars produced at different pyrolysis heating rates.

Combustion Temperatures $=700,850$ and $1000^{\circ} \mathrm{C}-$ Oxygen concentration $=21 \%$ Soak time $=0$ min - Sequential Combustion. 


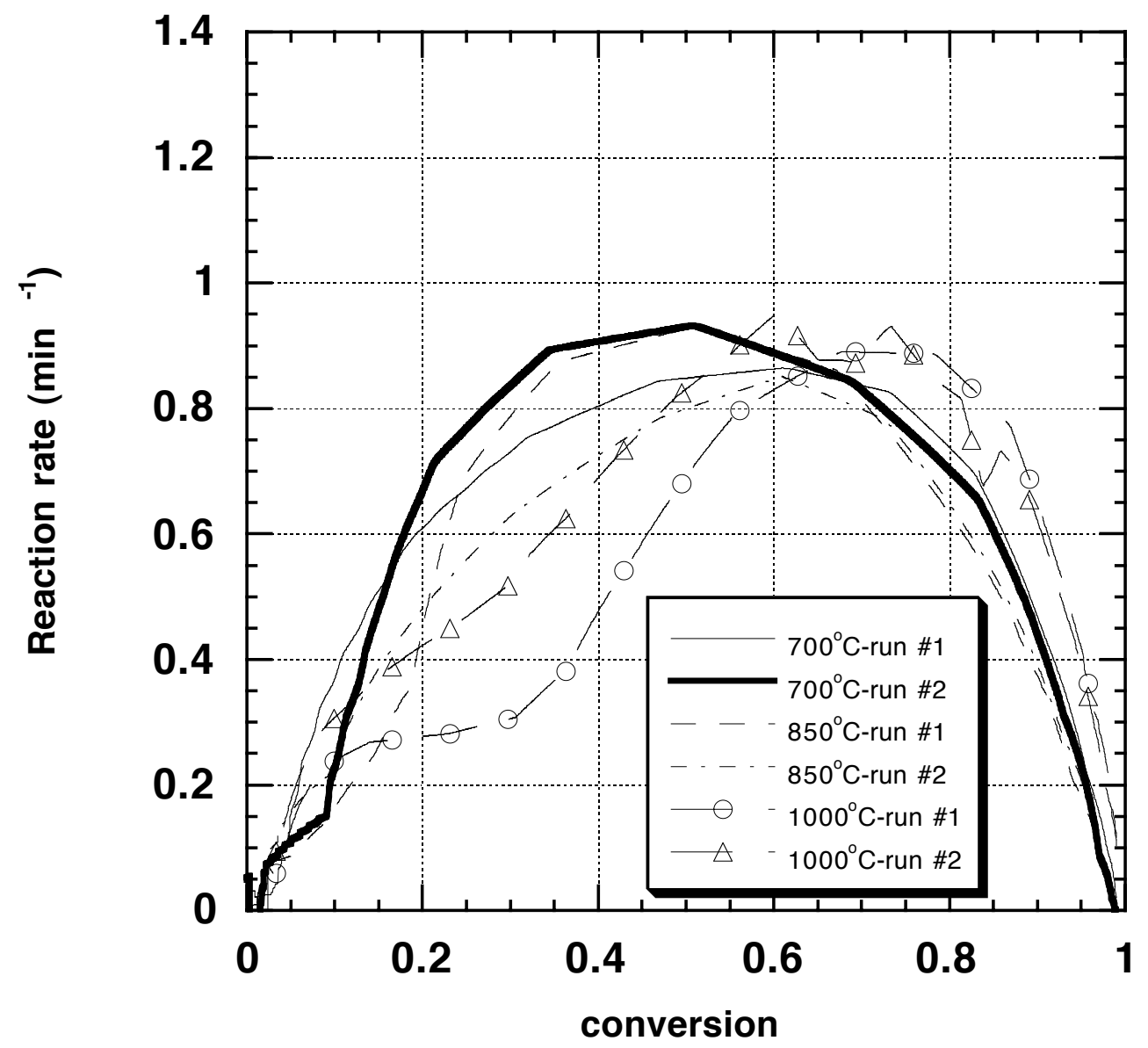

Figure 4.18 Reactivity plots for 28-32 mesh Illinois \#6 char particles for several individual runs. 

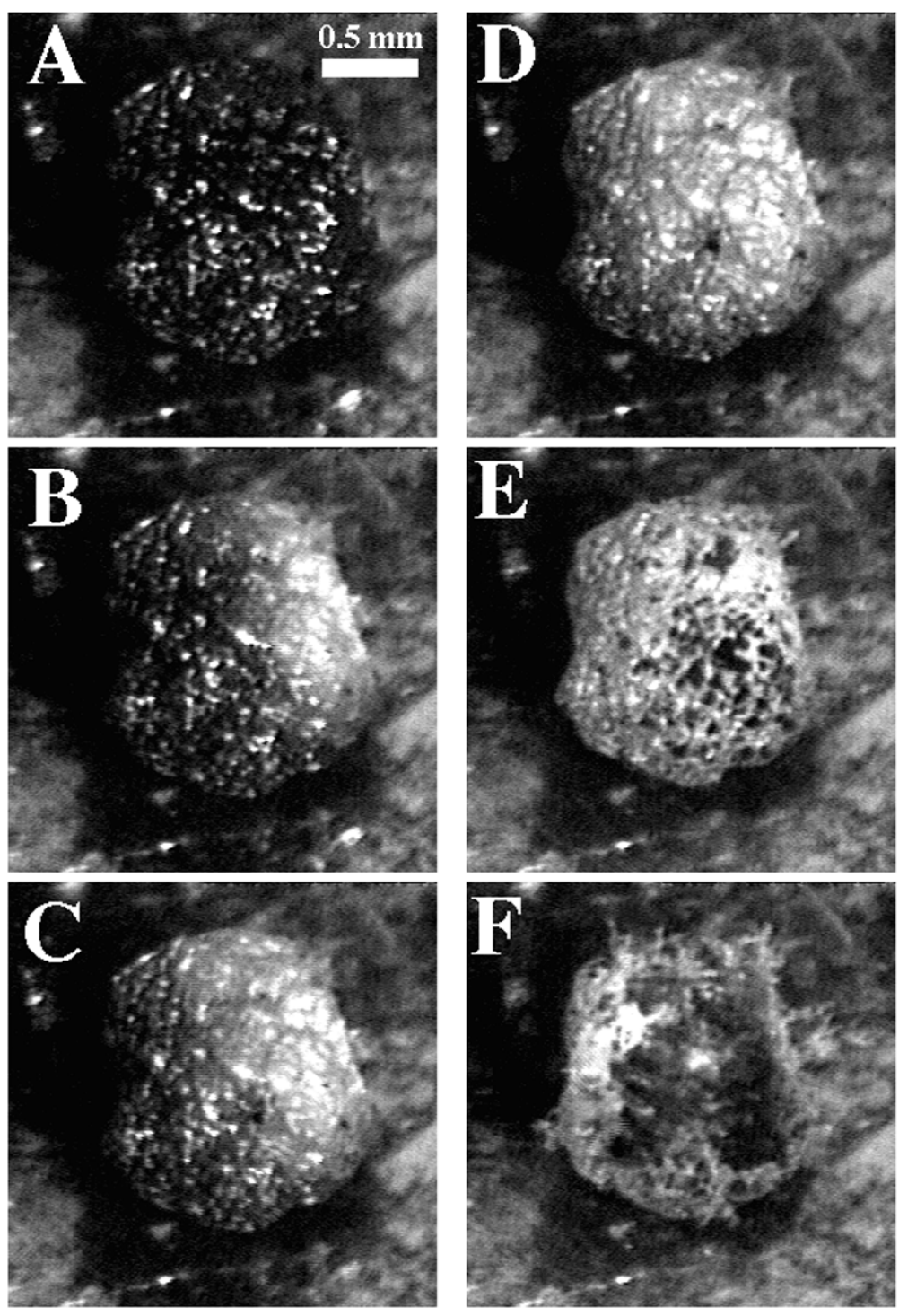

Figure 4.19: Sequence of digital images illustrating pore opening at high combustion temperatures.

Coal: Pocahontas \#3 20-24 mesh - Pyrolysis heating rate $=20^{\circ} \mathrm{C} / \mathrm{sec}$ Combustion temperature $=850^{\circ} \mathrm{C}-$ Oxygen concentration $=33 \%$ 


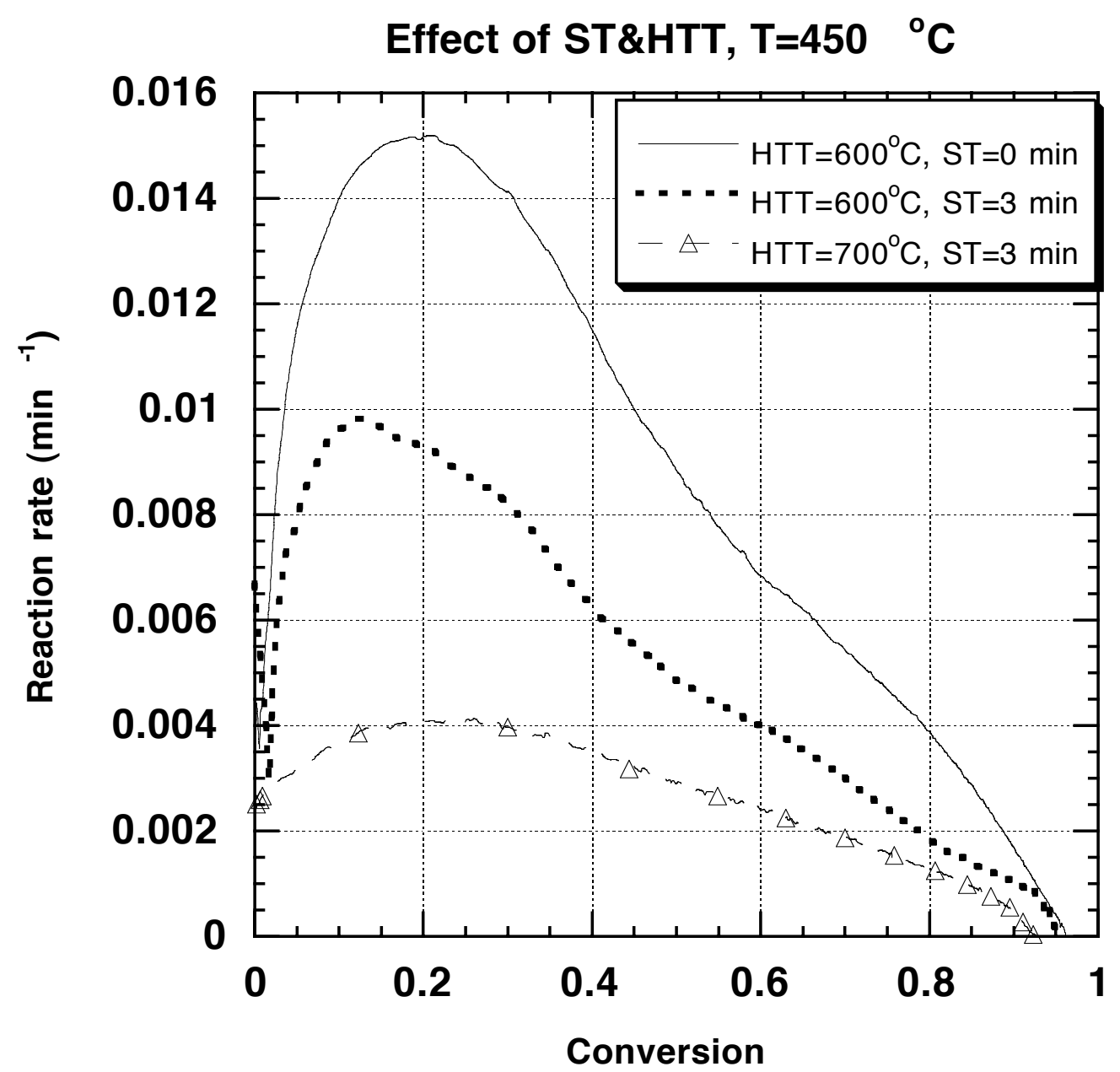

Figure 4.20: Effect of Soak Time and HTT on 28-32 Illinois \#6 char reactivity. Combustion Temperature $=450^{\circ} \mathrm{C}-$ Oxygen concentration $=21 \%$ Heating Rate $=0.1^{\circ} \mathrm{C} / \mathrm{sec}$ - Staged Combustion. 


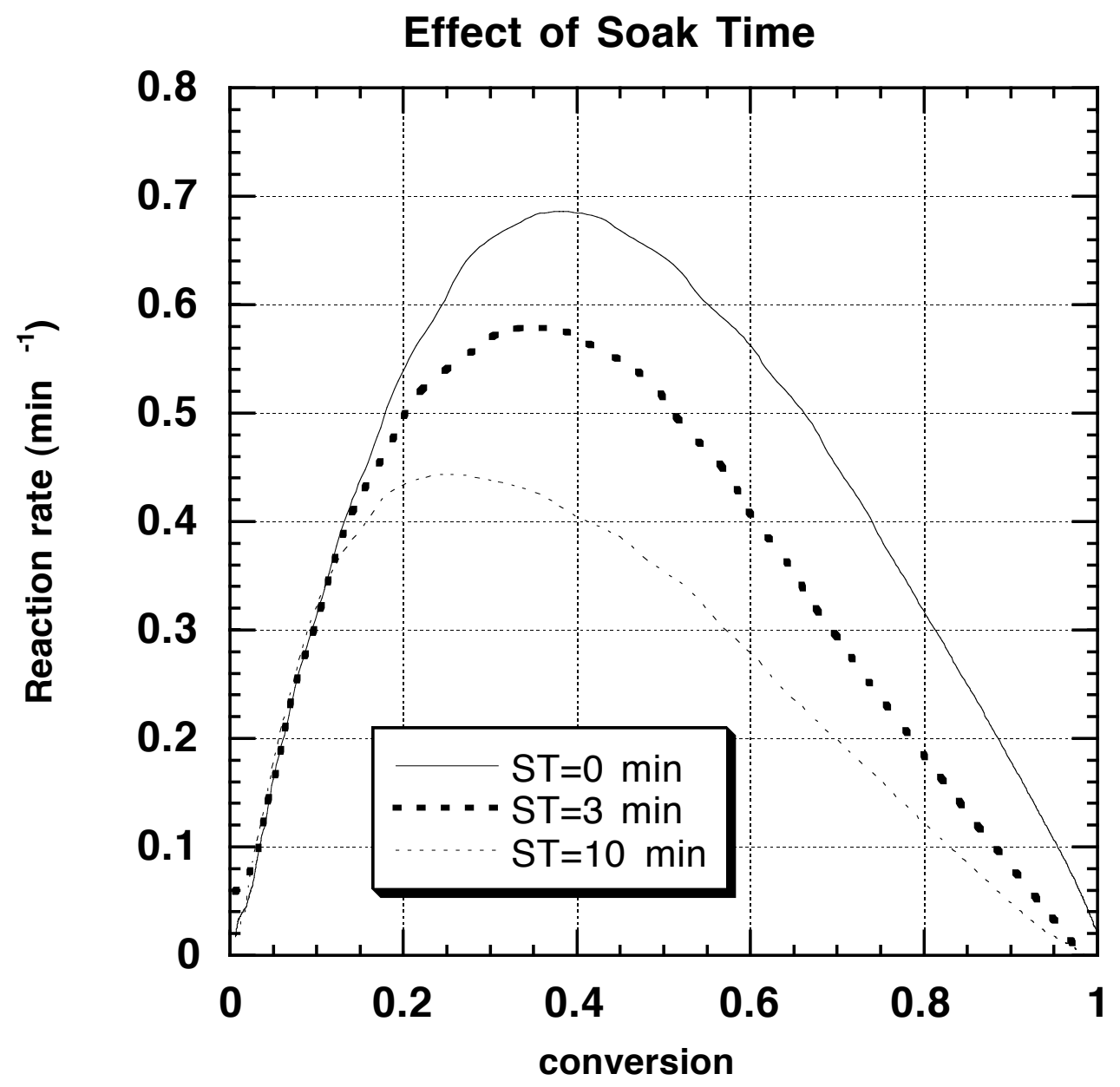

Figure 4.21: Effect of soak time on Illinois \#6 char reactivity.

Combustion Temperature $=700^{\circ} \mathrm{C}-$ Oxygen concentration $=21 \%$ $\mathrm{HTT}=700^{\circ} \mathrm{C}-$ Pyrolysis heating rate $=1{ }^{\circ} \mathrm{C} / \mathrm{sec}-$ Sequential Combustion 

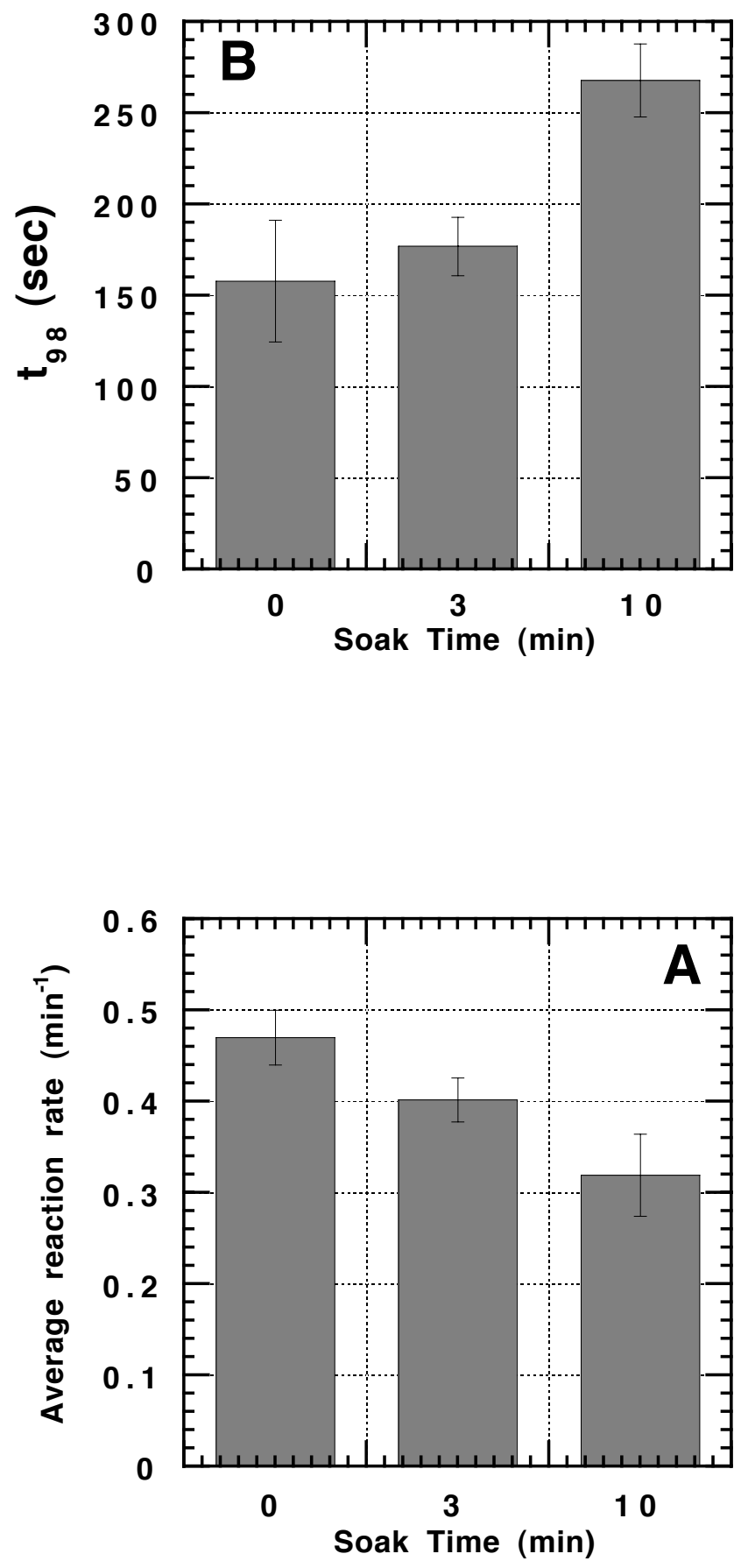

Figure 4.22: Effect of soak time on burn-off times and average reactivities of 28-32 mesh Illinois \#6 chars.

Combustion Temperature $=700^{\circ} \mathrm{C}-$ Pyrolysis heating rate $=0.1^{\circ} \mathrm{C} / \mathrm{sec}$. 


\section{SECTION 5}

\section{EFFECT OF PARTICLE SIZE ON CHAR REACTIVITY}

\section{$5.1 \quad$ Overview}

The effect of coal particle size on the macropore structure of devolatilized chars has been extensively studied in our lab (Zygourakis, 1993). These earlier studies reported significant differences in the macropore structure of chars produced from coal particles of different sizes. Smaller char particles often developed cenosphere structures with only a few large spherical cavities per particle. On the other hand, the macropores of large char particles had more tortuous boundaries. The majority of these particles exhibited the characteristic cellular pore structure with small pores embedded in the walls separating the larger cavities. The measured macropore structure parameters were also different. Chars produced from larger coal size fractions had had larger average macropore size and smaller values of macropore surface area per unit volume (Zygourakis, 1993).

Our objective here is to study the effect of particle size on char reactivity. Two size fractions were used in our experiments: 20-25 mesh (707-841 $\mu \mathrm{m})$ and 50-60 mesh (250$300 \mu \mathrm{m})$. Experiments were conducted at temperatures ranging from $420^{\circ} \mathrm{C}$ to $1000^{\circ} \mathrm{C}$.

\subsection{Effect of particle size on intrinsic reactivity of char}

When combusted at low temperatures, chars prepared from 20-25 and 50-60 mesh coal particles had very similar reactivities (Figure 5.1). Also, Figure 5.2 shows that there is no significant difference of the average burn-off times for these two sizes. 
Since the other pyrolysis and combustion conditions were identical, these experimental results lead to the conclusion that initial particle size doesn't have any effect on intrinsic reactivity of chars. Also, these results present additional evidence that combustion at or below $420^{\circ} \mathrm{C}$ took place in the kinetic controlled regime.

\subsection{Effect of particle size on reactivity in the regime of diffusional limitations}

As mentioned in section 5.1, chars produced from large coal particles have smaller macropore surface areas than chars obtained from small coal particles. Furthermore, it is well known that the Thiele modulus is proportional to the particle size. Thus, we expect that in the diffusional limitation regime, larger particle chars will exhibit lower reactivity since a smaller fraction of the pore surface area of these particles will be accessible to oxygen.

Results presented in Figures 5.3 and 5.4 support this hypothesis. At $550^{\circ} \mathrm{C}$ and $21 \%$ oxygen concentration, 20-25 mesh chars exhibit lower reactivity and longer burn-off times than 50-60 mesh chars. Good repeatability was observed as illustrated in Figure 5.5 .

To explain the reactivity results at high combustion temperatures, the heat generation and heat removal rates must be considered. If $r$ is the char particle radius, the total heat generation rate is then proportional to $r^{3}$, while heat removal rate is proportional to $r^{2}$. Thus, the ratio of heat removal and generation is proportional to $\mathrm{r}^{-1}$. In other words, it is more difficult for larger particles to dissipate the heat generated by the exothermic combustion reaction. As a result, the internal temperatures of larger particles will rise to values that can be much higher than the ambient temperature. Such temperature excursions eventually lead to thermal ignition of the particles and greatly enhance the overall reactivity. Sotirchos and Amundson (1984a-d) were among the first to predict that larger particles will ignite more easily than smaller ones. This prediction has been confirmed theoretically by Ismail (1993) and experimentally by Matzakos (1991) and Perkins (1998). 
To further test this theory, we conducted combustion experiments at $650^{\circ} \mathrm{C}$ with $50 \%$ oxygen concentration. Video recording showed that under such conditions, 2 out of 320 25 mesh char particles ignited with luminous flames. No such ignitions were observed, however, during combustion of 50-60 mesh chars._The reactivity pattern shown in Figure 5.6 clearly reflects this difference in combustion behavior with larger particles having higher reactivities.

This information is very important for industrial practice. It suggests that for high combustion temperature and high oxygen concentration, it is not always beneficial to use smaller particle size. Larger particles may ignite more easily leading to tremendous enhancement of the overall char reactivity. This observation may lead to reduction of the operating cost associated with the grinding and sifting processes.

\subsection{Effect of particle size on reactivity at external mass transfer controlled regime}

As reported in Section 4, combustion at high temperatures takes place in the external mass transfer control regime, where the reaction primarily occurs in macropores near the particle surface. Under such conditions, the reaction rate is controlled by the oxygen transfer rate. Since external mass transfer rate is proportional to the external surface area of the particle $A=4 \pi r^{2}$, more oxygen can enter the larger char particles because of their larger radius. As a result, the absolute reactivity $\mathrm{R}_{\text {absolute }}$, which is defined as amount of carbon being consumed per unit time, is higher for larger char particles.

However, we can not compare $\mathrm{R}_{\text {absolute }}$ of different sized chars since their initial carbon contents are different. To understand the effect of the particle size on char reactivity, we need to compare the reaction rate per initial mass of the particle $R_{o}\left(R_{\text {absolute }} / m_{o}\right.$, as mentioned in equation 2.1 of Chapter 2) because it is independent of particle size or initial carbon content. Similarly, we can also compare $\mathrm{R}_{\mathrm{v}}\left(\mathrm{R}_{\mathrm{absolute}}\right.$ / initial particle volume $)$ because $R_{o}$ and $R_{v}$ are differed only by a constant particle density. 
Since $R_{\text {absolute }} \propto r^{2}$ while $V_{\text {particle }} \propto r^{3}$, the $R_{o}$ or $R_{v}$ of char particles combusted in the regime of external mass transfer should be proportional to $\mathrm{r}^{-1}$. Since the average sizes of the 20-25 and 50-60 mesh particle fractions differ by more than 2.5 times, we would expect larger char particles to have much lower reactivities than the smaller ones.

Figure 5.7 presents results from combustion at $\mathrm{T}=1000{ }^{\circ} \mathrm{C}$ with $21 \%$ oxygen. Although the 50-60 mesh particles have higher reactivity, the magnitude of the difference was far less than we expected. Experiments at $700{ }^{\circ} \mathrm{C}$ and $850^{\circ} \mathrm{C}$ also revealed similar patterns. The likely explanation for this behavior is that the large particles cannot dissipate the heat of combustions as effectively as the smaller particles. Thus, heat accumulation leads to high internal temperatures and ignitions that enhance the reactivity of burning chars.

The above theory is difficult to verify experimentally because it is not easy to measure particle internal temperatures. However, it was supported by the results from model calculations reported in later sections. Simulations showed that for large particles combusted at high temperatures, their internal temperatures can be as much as 300-400 ${ }^{\circ} \mathrm{C}$ higher than the ambient temperature. The results also suggested that under such conditions, these particles can be considered isothermal, as no significant intraparticle thermal gradient was present.

\subsection{Conclusion}

The effect of coal particle size on the overall reactivity of chars is very complicated, especially in the regime of diffusional limitation. At high combustion temperatures, large particle sizes could lead to small effectiveness factors due to the lower accessibility of their internal pore surface area to oxygen. On the other hand, large particles may ignite due to the fact that they cannot dissipate the generated heat as effectively as smaller particles.

Most of the industrial coal utilization processes take place at relatively high temperatures where diffusion limitation are inevitable. Our study indicates that for any specific combustion or utilization conditions, there may exist an optimal particle size 
from the economic viewpoint. The use of larger particle can reduce grinding and sifting cost; but unless these particles ignite, they will have lower reactivity and longer burn-off times.

\subsection{References for Section 5}

Ismail. A. (1993). “The effect of process conditions on coal pyrolysis and char reactivity”. Ph.D. Thesis, Rice University.

Matzakos. A. (1991). "Fundamental mechanisms of coal pyrolysis and char combustion," Ph.D. Thesis, Rice University.

Perkins.D.S (1998). "Ignition of Coal and Char Particles: Effects of Pore Structure and Process Conditions," Ph.D. Thesis, Rice University.

Sotirchos. S. V. and Amundson. N. R. (1984a). "Diffusion and reaction in a char particle and in the surrounding gas phase: A continuous model" Ind. Eng. Chem. Fundam. 23 : 191.

Sotirchos. S. V. and Amundson. N. R. (1984b). "Diffusion and reaction in a char particle and in the surrounding gas phase: Two limiting models" Ind. Eng. Chem. Fundam. 23 : 180.

Sotirchos. S. V. and Amundson. N. R. (1984c). "Dynamic behavior of a porous char particle burning in an oxygen-containing environment: Part I: Constant particle radius" AIChE J. 30 (4): 537.

Sotirchos. S. V and Amundson. N. R. (1984d). "Dynamic behavior of a porous char particle burning in an oxygen-containing environment: Part II: Transient analysis of a shrinking particle" AIChE J. 30(4) : 549.

Zygourakis. K. (1993). "Effect of pyrolysis conditions on the macropore structure of coal-derived chars", Energy \& Fuels 7:33. 


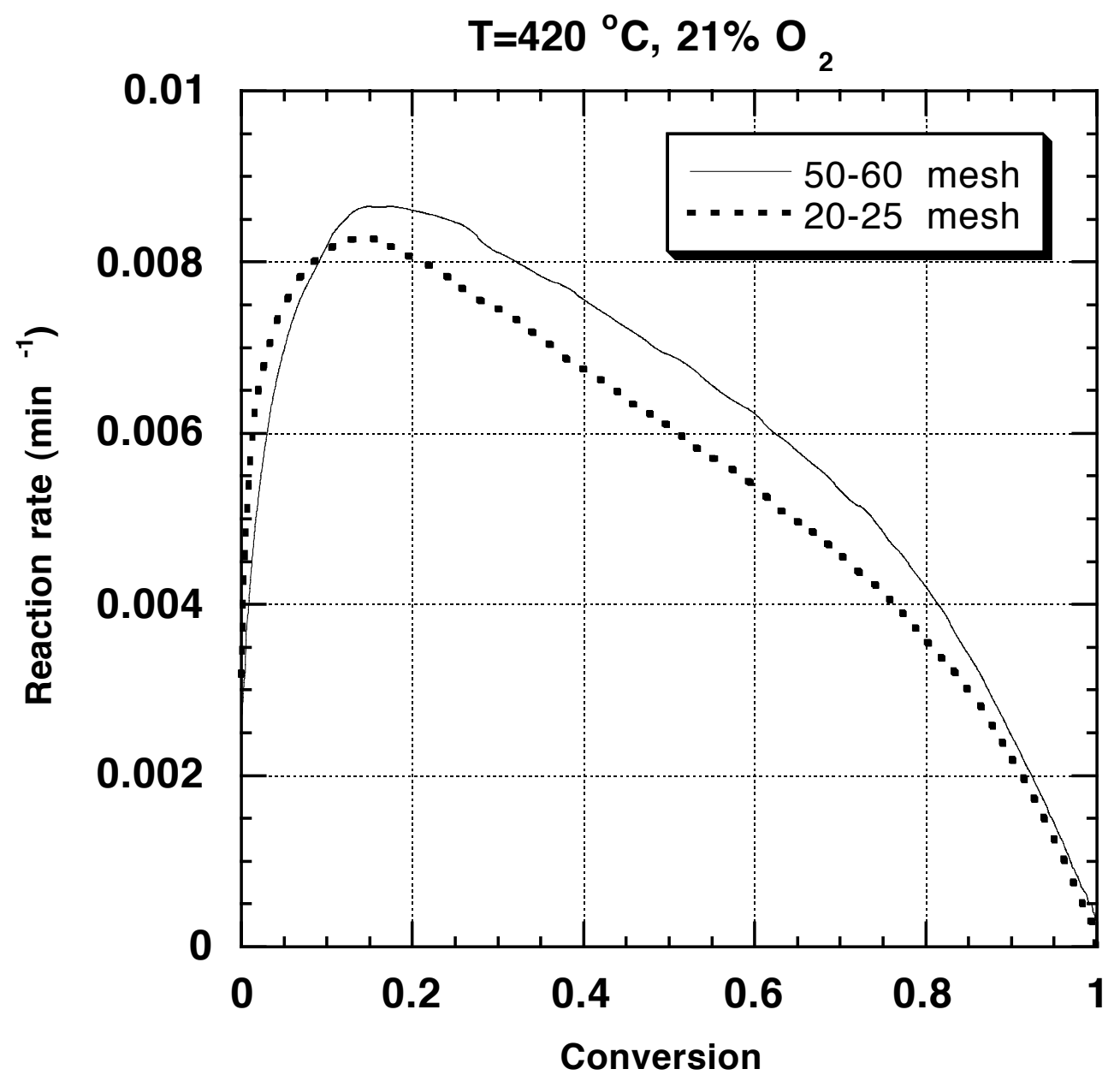

Figure 5.1: $\quad$ Effect coal particle size on char reactivity (Illinois \#6 coal).

Combustion Temperature $=420{ }^{\circ} \mathrm{C}$ - Oxygen concentration $=21 \%$ Pyrolysis Heating Rate $=1^{\circ} \mathrm{C} / \mathrm{Sec}$ - Staged Combustion

The reactivity curves are the averages of 3 runs for each size fraction 


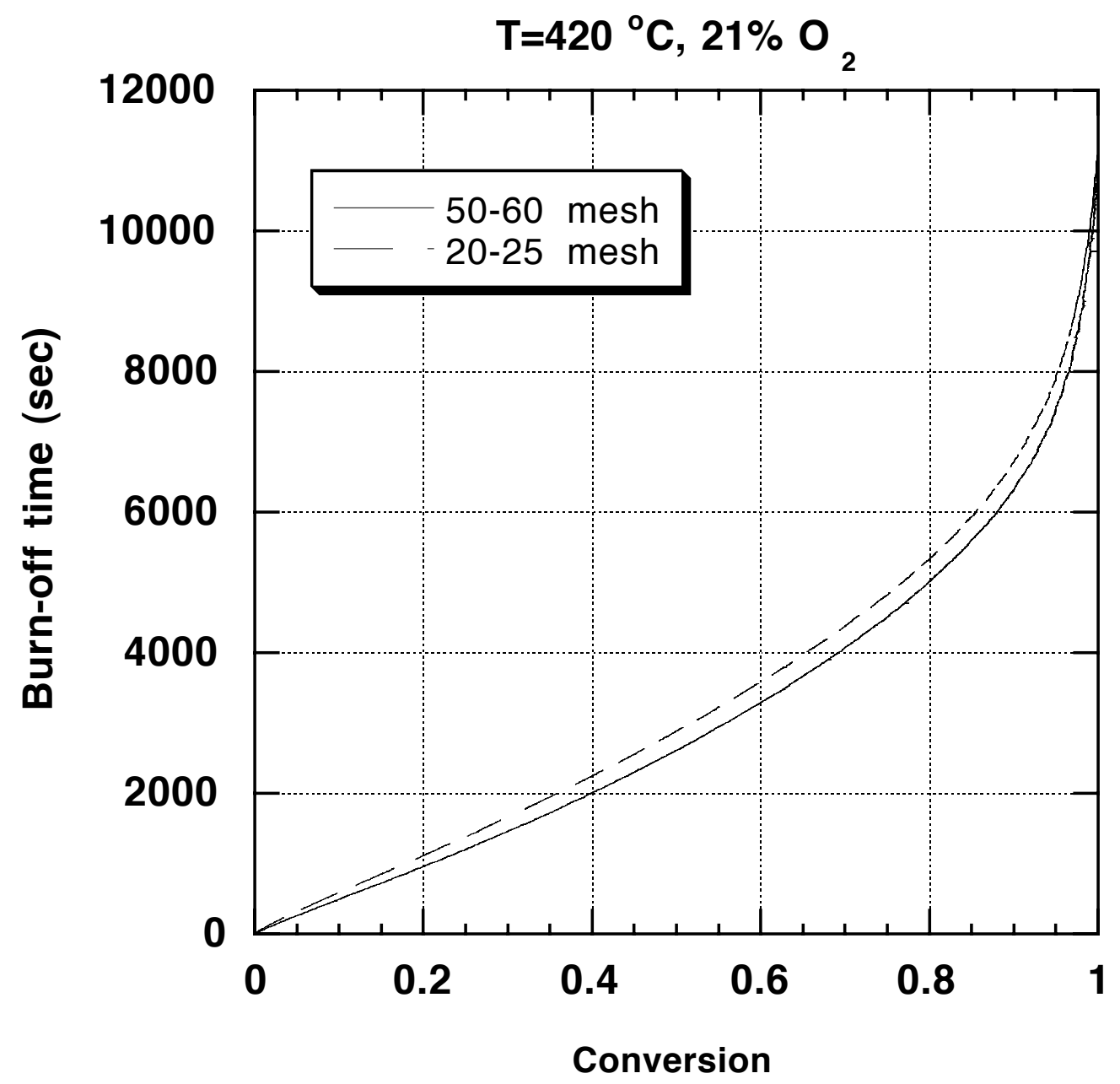

Figure 5.2: $\quad$ Effect of coal particle size on burn-off time of Illinois \#6 chars. Combustion Temperature $=420^{\circ} \mathrm{C}$ - Concentration of $\mathrm{O}_{2}=21 \%$ Pyrolysis Heating Rate $=1^{\circ} \mathrm{C} / \mathrm{Sec}$ - Staged Combustion The burn-off time curves are the averages of 3 runs for each size fraction. 


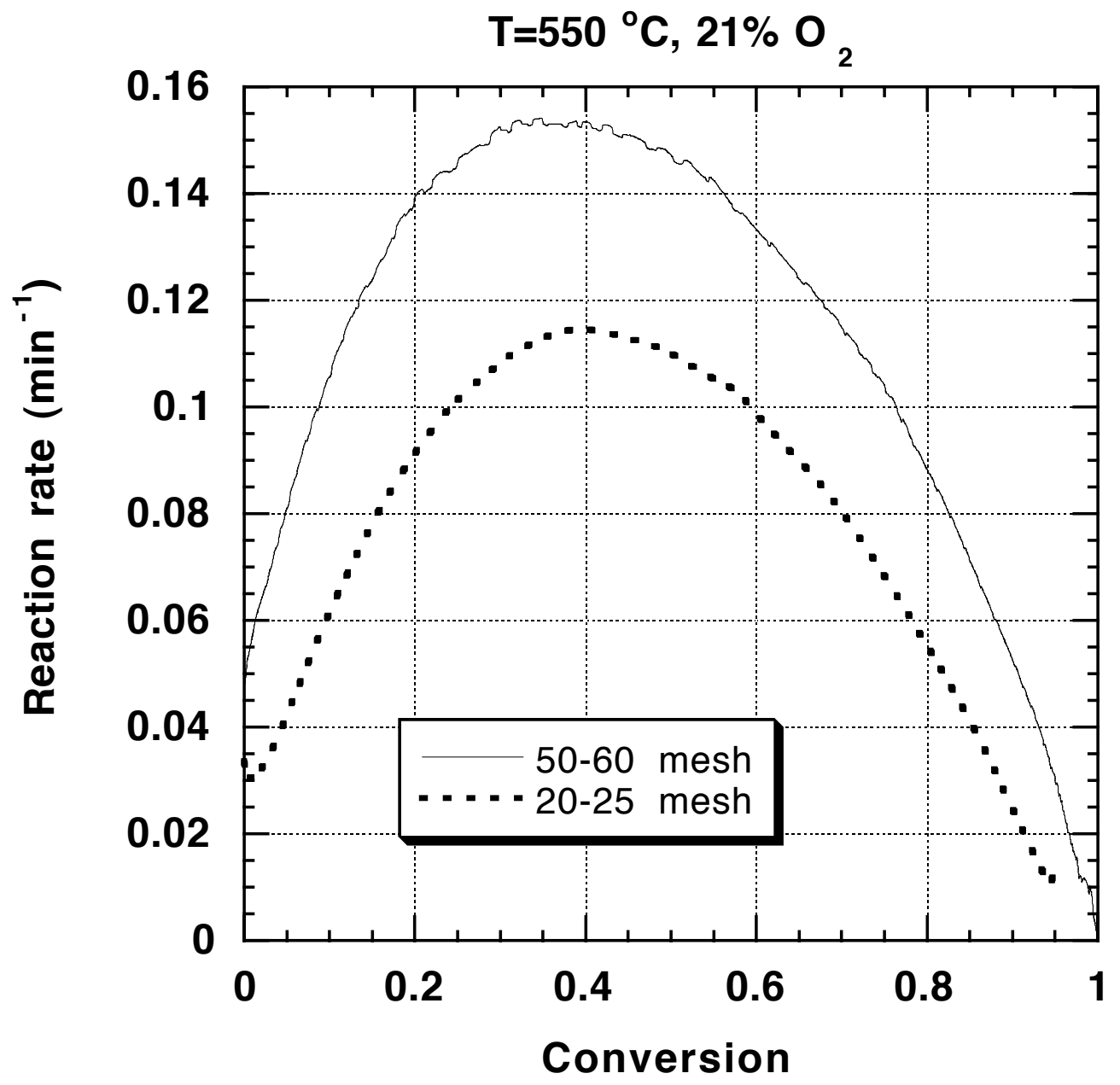

Figure 5.3: Effect of coal particle size on Illinois \#6 char reactivity. Combustion Temperature $=550{ }^{\circ} \mathrm{C}$ - Oxygen concentration $=21 \%$ Pyrolysis Heating Rate $=1^{\circ} \mathrm{C} / \mathrm{Sec}-$ Staged Combustion The reactivity curves are the averages of 3 runs for each size fraction 


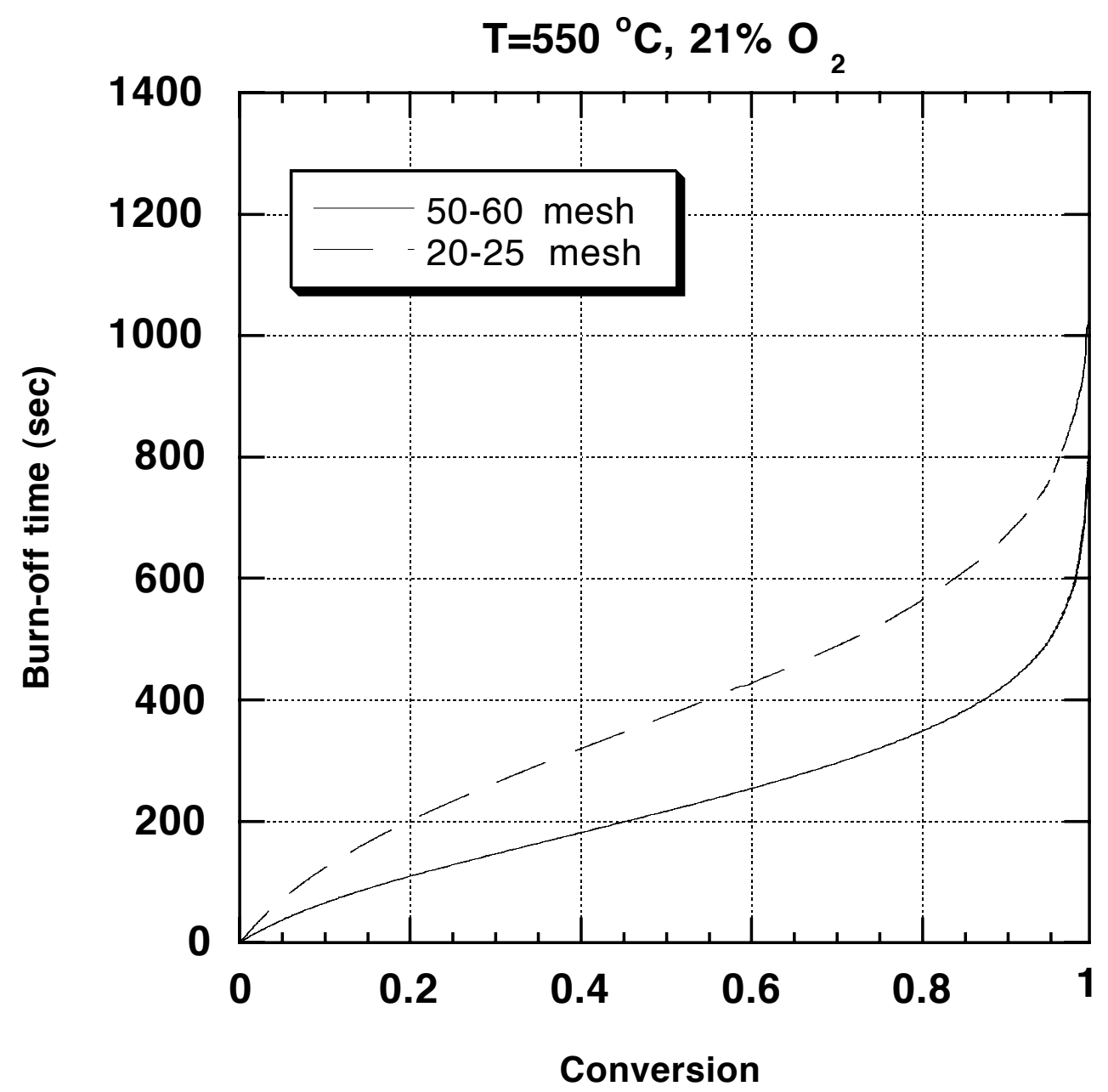

Figure 5.4: Effect of coal particle size on burn-off time of Illinois \#6 chars. Combustion Temperature $=550^{\circ} \mathrm{C}$ - Concentration of $\mathrm{O}_{2}=21 \%$ Pyrolysis Heating Rate $=1^{\circ} \mathrm{C} / \mathrm{Sec}-$ Staged Combustion The burn-off time curves are the averages of 3 runs for each size fraction. 


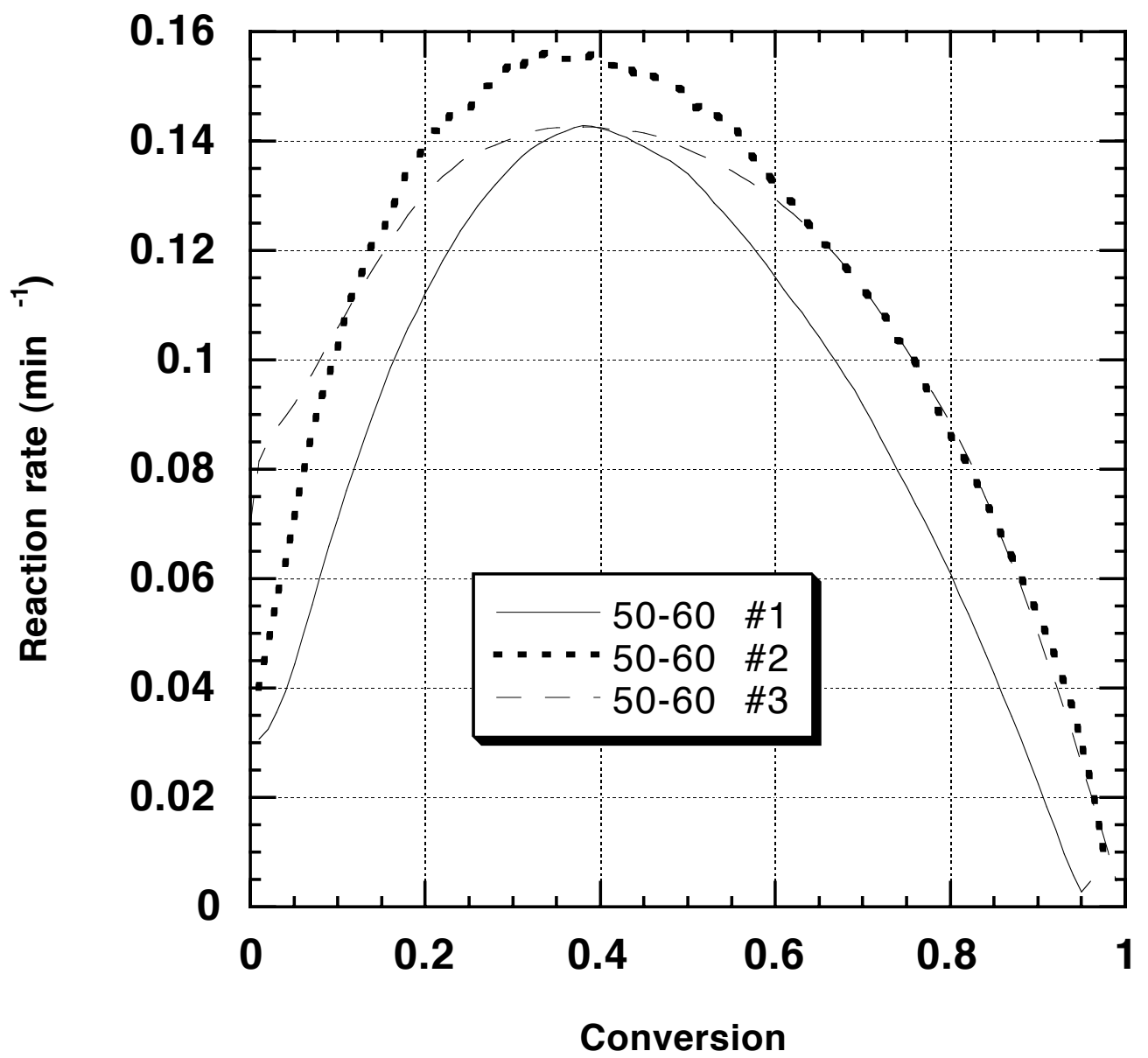

Figure 5.5: Repeatability of experimental results.

Combustion temperature $=550{ }^{\circ} \mathrm{C}$ - Concentration of $\mathrm{O}_{2}=21 \%$

Particle size $=50-60$ mesh - Pyrolysis heating rate $=1{ }^{\circ} \mathrm{C} / \mathrm{sec}$ 


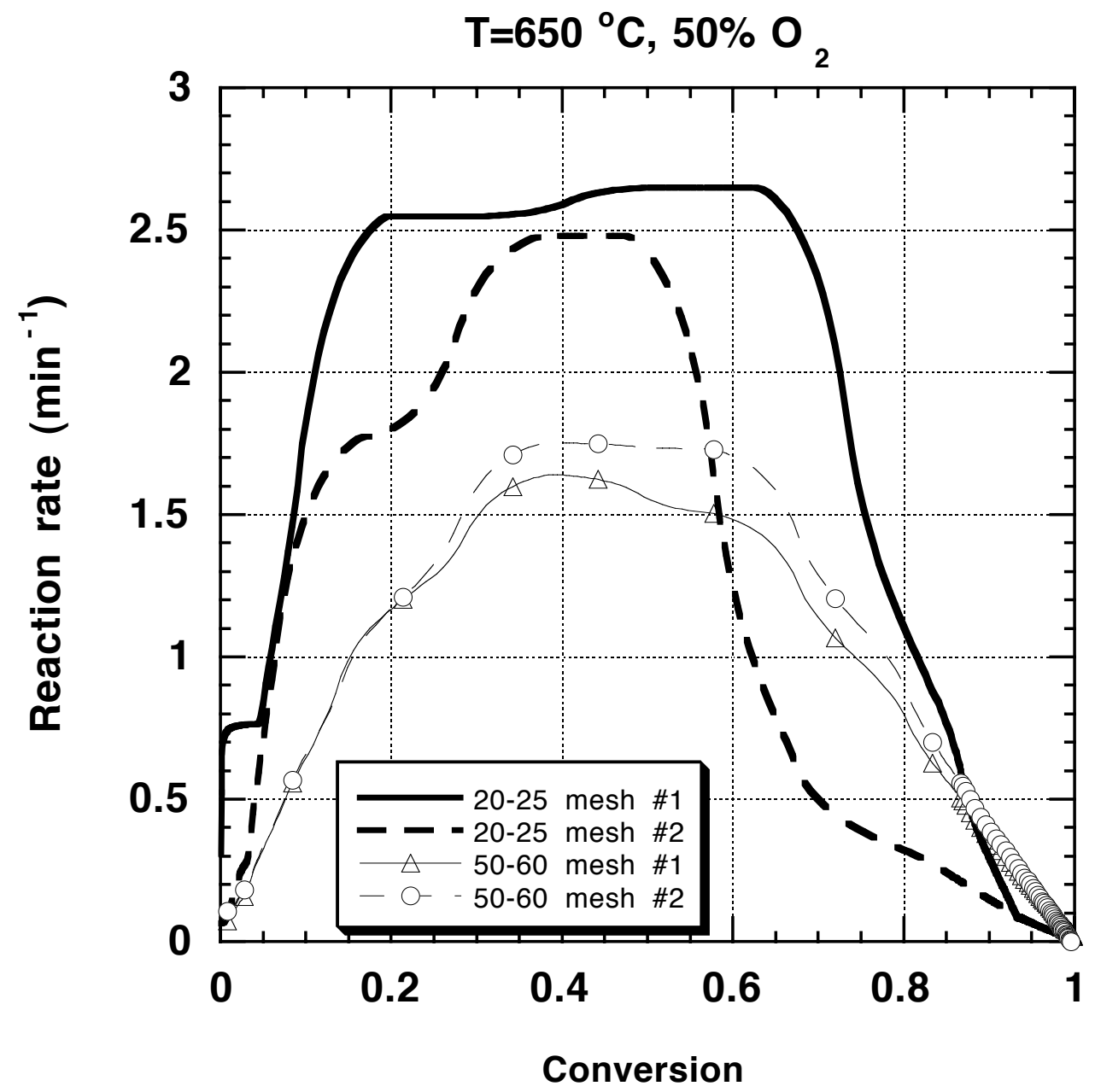

Figure 5.6: Effect of Illinois \#6 coal particle size on char reactivity. Combustion Temperature $=650{ }^{\circ} \mathrm{C}$ - Concentration of $\mathrm{O}_{2}=50 \%$ Pyrolysis Heating Rate $=1{ }^{\circ} \mathrm{C} / \mathrm{Sec}-$ Staged Combustion 


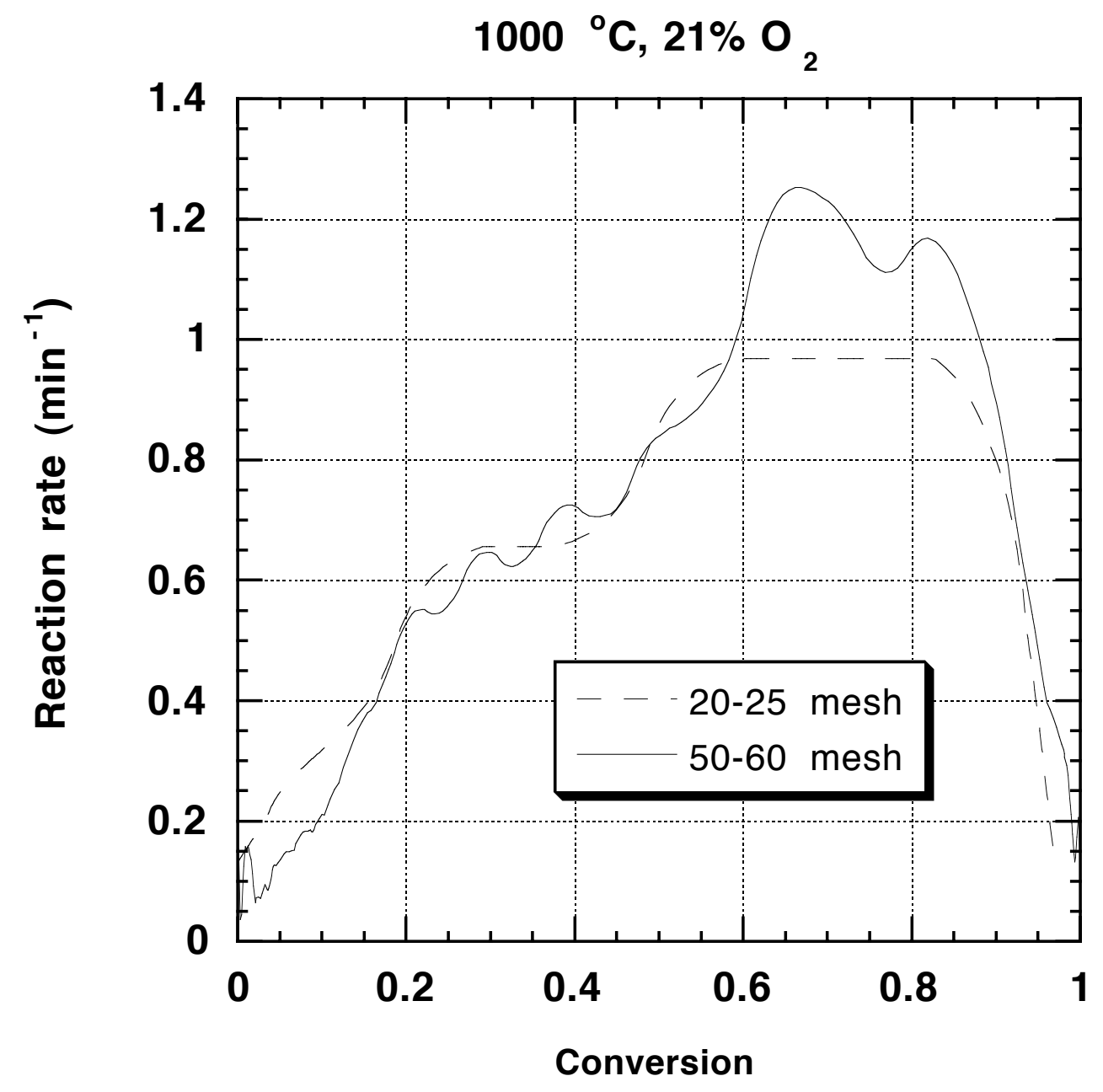

Figure 5.7: $\quad$ Effect of Illinois \#6 coal particle size on char reactivity.

Combustion Temperature $=1000{ }^{\circ} \mathrm{C}$ - Concentration of $\mathrm{O}_{2}=21 \%$

Pyrolysis Heating Rate $=1{ }^{\circ} \mathrm{C} / \mathrm{Sec}$ - Staged Combustion

The reactivity curves are the averages of 3 runs for each size fraction. 


\section{SECTION 6}

\section{DETECTION AND CHARACTERIZATION OF CHAR AND COAL PARTICLE IGNITIONS}

\subsection{Introduction}

The first studies of coal ignition were undertaken to prevent mine explosions like the one investigated by Faraday and Lyell in 1844 (Faraday and Lyell 1845). Since then, many experimental and theoretical studies have focused on the ignition characteristics of coal particles in an effort to optimize the operation of coal-fired power plants and industrial-scale utility boilers (Essenhigh, Misra et al. 1989). The detection of coal particle ignitions, however, remains a very challenging task. Although increasingly sophisticated experimental techniques have been employed to study this complex process, there are still many unanswered questions concerning the effect of important operating parameters on coal particle ignition and combustion.

Coal particle ignitions follow either a homogeneous or a heterogeneous mechanism. The first step of the homogeneous mechanism involves rapid release of volatiles upon heating of the coal particles. As the volatiles escape, they ignite and burn in the gaseous phase surrounding the particle. After this stage, heterogeneous combustion reactions continue to take place on the surface and in the interior of the particles until all the carbon is consumed. On the other hand, heterogeneous ignitions occur when heat generation rates due to combustion reactions are much higher than the heat removal rates. As a result, the particles rapidly reach temperatures that can be several hundred degrees above the ambient temperature (Semenov 1928) and they ignite often with bright light emissions.

Because of the importance of particle interactions in industrial coal combustion, most laboratory reactors employ designs which approximate these interactions. One common type of laboratory combustion reactor is the drop tube or entrained flow reactor, where multiple coal 
particles are pulsed or continuously flown through a tubular furnace. In this case, little information about the behavior of individual particles can be obtained. The same argument can be made for coal combustion studies in a fluidized bed. A common approach to ignition detection in these types of experiments is to measure the light emissions, with photomultipliers (Wall, Phong-Anant et al. 1988; Gupta, S. et al. 1990). Although this approach is useful for studying the role of particle interactions, it cannot distinguish individual particle ignitions nor can it determine whether the light emissions observed at a given time point come from one or more particles.

To accurately study ignition phenomena, many researchers have conducted single or isolated particle experiments. Here, a common approach to ignition detection and characterization is the use of two-color near infrared pyrometry (Levendis, Sahu et al. 1989) to measure particle temperatures. Using this technique, Levendis et al (Levendis, Sahu et al. 1989) observed that the ignition of char particles originated from localized "hot spots" on the particle surface before spreading across the entire particle. Gomez and coworkers studied ignitions by combining luminosity measurements with simultaneous analysis of the carbon monoxide and carbon dioxide produced when a single coal particle ignites and burns (Gomez and Vastola 1985). Since total luminosity measurements cannot distinguish between volatile matter ignition (homogeneous mechanism) and surface reaction (heterogeneous mechanism), the product gas was analyzed to determine the mechanism of ignition. To directly detect the combustion of volatiles in the region surrounding a coal particle, Huang and coworkers combined luminosity measurements with measurements of temperature profiles around coal particles (Huang, Vastola et al. 1988). This approach can provide useful information about the ignition mechanism by differentiating between volatile burning around the particle and reactions occurring at the surface or in the particle interior (Zhang and Wall 1994).

In contrast to total luminosity measurements, video microscopy is effective in tracking the fate of individual coal particles during pyrolysis and combustion experiments. Video microscopy techniques detect ignitions by directly observing light emissions from individual particles and are also useful for investigating ignition mechanisms. Yang and Tsai (Yang and Tsai 1990) utilized video techniques to visualize the ignition of coal particles with diameters ranging from 6 to 15 $\mathrm{mm}$. They concluded that particles ignited by both mechanisms and noted the appearance of luminous flames in the area surrounding the particle as well as on the particle surface. For 
experiments where ignitions result in easily observable emissions of light, video microscopy can be very effective for detection and mechanism identification. When used alone, however, we will show that even this technique may be inadequate for detecting ignitions where light emissions are faint.

Tognotti and his coworkers (Tognotti, Malotti et al. 1985) utilized thermogravimetric measurements to detect the ignition of coal particles. Their technique involved comparison of weight loss vs. temperature curves obtained by combusting coal in inert and reactive atmospheres. The ignition temperature was then determined as the temperature at which these two curves deviated (Chen, Fan et al. 1985; Wall, Gupta et al. 1991). Thus, the thermogravimetric technique provided information about the onset of combustion rather than ignition, only identifying ignition in cases where it was the first combustion event (Zhang and Wall 1994). Our studies have shown, however, that in many cases we may have significant extents of heterogeneous reactions before the particles ignite. This thermogravimetric ignition detection is also not effective for multiple particle experiments since it does not provide information about which or how many particles have ignited.

Other recent studies have utilized the electrodynamic balance to study the combustion behavior of levitated char particles (Cozzani, Petarca et al. 1995; Wong, Gavalas et al. 1995). In these experiments a single char particle is suspended in an electric field and heated by laser irradiation. Pyrometry measurements provide particle temperatures and video imaging provides images of the reacting particle. This type of study has proven itself very useful in studying heterogeneous reactions. The loss of particle charge when it ignites or reaches high temperatures, however, may cause the particle to drop out of view in the apparatus, complicating the observation of ignition phenomena.

From this discussion, it is apparent that experimental approaches to studying coal and char particle ignitions fall into one of two categories:

(1) Particle ensemble experiments that allow particle interactions, but provide little or no detail about individual particle ignitions.

(2) Single particle experiments that do not allow particle interactions, but provide great detail about individual particles. 
The need is thus apparent for an experimental approach that is effective in detecting and characterizing individual ignitions occurring during particle ensemble experiments. This study presents results showing that this objective can be achieved by combining thermogravimetric analysis and digital video microscopy. Such a combined approach can provide detailed information on individual particle ignitions while still allowing us to study particle interactions. The advantages and limitations of the new methodology are discussed by presenting and analyzing results from combustion experiments with ensembles of coal and char particles ranging in size from 250 to $840 \mathrm{~mm}$.

\subsection{Experimental Methods}

\subsubsection{Digital Video Microscopy}

Ignition experiments were conducted in a thermogravimetric reactor with in-situ video microscopy imaging (TGA/VMI) that was described in detail in an earlier communication (Matzakos and Zygourakis 1993). Briefly, the TGA/VMI reactor is a modified thermogravimetric analyzer (Perkin-Elmer, TGS-2) having a micro balance with a sensitivity of $0.1 \mathrm{mg}$. Coal or char samples placed in the balance pan are viewed with a high-magnification, extra-long working distance microscope (JENA, Model 121), equipped with a video camera (Javelin, Chromachip II). A computer-activated video timer inserts on the video signal the time elapsed since the beginning of an experiment. This allows us to relate visual observations to changes in sample reactivity or reactor temperature.

This apparatus was used to record on video tape the pyrolysis and combustion of multiparticle coal or char samples. The reacting samples were illuminated with a fiber optic light source (Dolan-Jenner, Fiber Lite) which allows for intensity adjustment. To improve the sensitivity of our video detection method, the illumination source was usually turned off and, in

this case, ignitions appeared as flashes of light in a dark background. This approach allowed us to detect "faint" ignitions that would not be visible if the illumination source were on.

The video tapes of combustion experiments were analyzed off-line. For each experiment, a sequence of digital images was acquired at fixed time intervals using a frame grabber (Data Translation, QuickCapture). The digital images had a resolution of 640x480 8-bit pixels (256 
intensity levels). These sequences of images were digitally processed to obtain time-resolved intensity traces for specified regions of interest (ROI) corresponding to particle locations or the entire pan.

The following procedure was followed to determine the appropriate ROI's for experiments conducted without external illumination. Before switching off the illumination source, a reference image was acquired to determine the precise location of each particle in the pan. Using information from the reference image, we defined regions of interest such that each ROI included only one particle. Every image in a combustion sequence was then processed to (a) isolate the ROI for each particle and (b) measure the maximum light intensity observed in it. The trace of this intensity allowed us to determine if a particle ignited and to measure the beginning and duration of each particle ignition. Char particles rarely moved during combustion experiments. If particle movement occurred, however, we simply monitored intensity across the entire pan. All steps of the image analysis procedure developed to obtain light intensity traces were performed using NIH Image, a public-domain image processing software package (available by anonymous ftp from zippy.nimh.nih.gov).

Figure 6.1 shows a digitized image from a combustion experiment with an ensemble of four particles. The time elapsed since the beginning of this experiment is shown in the upper right hand corner of Figure 6.1. Using the reference image, the four ROI's shown by the white circles were determined so that each ROI contained one particle. At the time this image was acquired, no light emissions can be seen in ROI's C and D. ROI's A and B, however, contain particles which react in an ignited state with bright (ROI B) or faint (ROI A) light emissions.

\subsubsection{Combustion and Pyrolysis Experiments}

The experiments discussed here were carried out with Illinois \#6 coal obtained from the Argonne Premium Coal Sample Program (Vorres 1990). Three coal particle sizes were used: 5060 mesh $(250-300 \mu \mathrm{m}), 28-32$ mesh $(500-600 \mathrm{~mm})$, and 20-24 mesh $(710-840 \mathrm{~mm})$. For each run, we placed several coal particles in the sample pan of the TGA/VMI reactor: 10-20 particles of the 50-60 mesh size, 4-5 particles of the 28-32 mesh size, and 2-3 particles of the 20-24 mesh size.

For sequential pyrolysis-combustion experiments, char samples were first prepared by heating the coal particles in pure nitrogen to various final heat treatment temperatures (HTT) at 
heating rates ranging from 0.1 to $20^{\circ} \mathrm{C} / \mathrm{sec}$. After holding the temperature at the HTT for a soak time of either 0 or 3 minutes, the char sample was quickly quenched to $200{ }^{\circ} \mathrm{C}$. Without removing the char sample, the appropriate mixture of $\mathrm{O}_{2}$ and $\mathrm{N}_{2}$ was then introduced to the TGA/VMI reactor and the char particles were heated to the final combustion temperature at a rate of $20^{\circ} \mathrm{C} / \mathrm{sec}$. For coal combustion runs, the TGA/VMI was loaded with coal particles and the sample was heated at rates varying between 0.1 and $20^{\circ} \mathrm{C} / \mathrm{sec}$ to the final combustion temperature in the presence of $\mathrm{O}_{2}$.

The sample weight and reactor temperature were continuously monitored using a data acquisition and control computer (Apple Computer, Macintosh Quadra 900). Data were collected at sampling rates as high as $20 \mathrm{~Hz}$ and recorded in a file. Sample weight was sampled at high rates since the duration of some ignitions was shorter than 0.25 seconds. Sample reactivity was determined by calculating the reaction rate per unit mass of initial solid $\left(R_{o}\right)$ according to the equation:

$$
R_{o}(t)=\frac{d x}{d t}=-\frac{1}{m_{o}}\left(\frac{d m(t)}{d t}\right)
$$

where $x$ is the conversion of the solid, $m_{o}$ is the initial mass of the solid in ash-free basis, and $m(t)$ is the mass (ash free) of char remaining unreacted at time $t$.

\subsection{Results and Discussion}

\subsubsection{Homogeneous and Heterogeneous Ignitions}

The video imaging capabilities of our TGA/VMI reactor were essential in identifying the ignition mechanism of coal and char particles. Figure 6.2 shows a typical sequence of digital images obtained during combustion of two 28-32 mesh Illinois \#6 coal particles. The particle in the upper part of the image appears to ignite heterogeneously at first with a flame originating from a "hot-spot" on its surface (frames $2 \mathrm{~A}$ and $2 \mathrm{~B}$ ). This particle is then engulfed by a flame that appears to extend slightly beyond the original particle boundary in a few places (frame 2C), indicating the presence of a small volatile combustion front close to the particle surface. The next 
frame (frame 2D obtained $0.3 \mathrm{~s}$ after $2 \mathrm{~A}$ ) shows that volatiles emitted from the bottom particle have clearly ignited with a large luminous flame emanating from the particle surface. This flame seems to ignite volatiles released by the other particle and a second flame emanating from the top particle now joins the original flame (frame 1E). Both particles continue to glow in the last frame (frame $1 \mathrm{~F}$ obtained $0.5 \mathrm{~s}$ after $2 \mathrm{~A}$ ) indicating that heterogeneous reactions continue to take place on the particle surfaces (and the particle interiors) after the volatile flames have been extinguished.

Our observations agree with literature results reporting that coal particles ignite with a combination of homogeneous and heterogeneous mechanisms, depending on the flow velocities of reactant gases(Huang, Vastola et al. 1988; Yang and Tsai 1990). We must note, however, that the image sequence of Figure 6.2 also shows interactions among neighboring particles with one particle triggering the homogeneous ignition of another one. Such interactions must be important in actual combustors, but will remain undetected in experiments that use a single coal particle. Our studies have revealed that occurrence of this homogeneous mechanism is aided by high oxygen concentrations, high combustion temperatures, and, most notably, the presence of multiple particles during a combustion run. The presence of multiple particles is perhaps the most crucial of these factors because it increases the chances of having highly combustible volatiles in the gas surrounding an igniting particle.

Although Figure 6.2 clearly indicates a homogeneous ignition mechanism, we have also observed ignitions in which only the surface of the coal particles becomes illuminated and the bright ignition regions never exceed the particle boundaries. This transition to a predominantly heterogeneous ignition mechanism occurs when we lower the oxygen concentration in the gas flowing through the TGA/VMI reactor.

On the other hand, char particles appear to always ignite heterogeneously, with bright ignition regions that never exceed the boundary of the particle. Ignitions of the type shown in Figure 6.2 have never been observed with char particles. This observation is consistent with the accepted mechanism of heterogeneous ignitions since chars produced with our experimental protocols contain insignificant amounts of volatiles. Figure 6.3 shows a typical ignition sequence for char particles. The char used for this run was prepared from 28-32 mesh Illinois \#6 coal particles pyrolyzed at $5{ }^{\circ} \mathrm{C} / \mathrm{s}$ to a final heat treatment temperature of $700{ }^{\circ} \mathrm{C}$. In frame $3 \mathrm{~B}$, the left particle has ignited and its entire surface is glowing. Ignition of the other particle starts from a 
"hot-spot" localized in the leftmost part of the particle (frame 3B) and propagates over the entire particle surface (frames 3C and 3D). The glowing zone, however, never exceeds the particle boundary. By frame 2D (obtained $1.9 \mathrm{~s}$ after frame $3 \mathrm{~A}$ ), the ignition of the left particle appears quenched. But, large holes (seen as dark spots) appear on the surface of the right particle indicating the opening to the exterior of large internal cavities (macropores) that have formed during pyrolysis (Zygourakis 1993).

\subsubsection{Detection of Char Particle Ignitions}

As stated previously, our approach to ignition detection involves the combination of thermogravimetric measurements and video microscopy. To discuss the effectiveness of this approach for ignition detection, we will consider first two different types of heterogeneous char particle ignitions.

Ignitions characterized by high particle temperatures are accompanied by bright emissions of light. When this occurs, the ignition is easily observed on video tape regardless of the intensity of the light source which illuminates the reacting char sample. We will refer to such ignitions as type I ignitions. When, on the other hand, the particle temperature is not significantly elevated during a heterogeneous ignition, the intensity of light emission from the particle is low. Such ignitions may be difficult to detect with video microscopy, particularly when the external illumination of the sample is on. Ignitions associated with faint light emissions will be referred to as type II ignitions.

With type I ignitions, video microscopy is always effective in detecting the ignition of individual particles. We have also found that ignitions are accompanied by peaks in the reactivity curve caused by the sharp rise and drop of solid temperature as the particles ignite, react and are extinguished. Figure 6.4a shows the reactivity plot obtained for a type I ignition when only one of the particles in the char sample ignites. This peak in reactivity corresponds to ignition of one 1 of the 5 particles present in the reactor as shown by the accompanying light intensity trace (Figure 6.4b).

When multiple particles ignite, however, we may not be able to distinguish the different ignition phenomena using only reactivity data. Figure 6.5 a presents the reactivity plot for an experiment for which video microscopy shows that 4 out of the 5 char particles in the sample ignited. Despite the fact that 4 ignitions occurred, only 3 peaks are observed in reactivity. The 
light intensity trace of Figure 6.5b shows that the third peak is a result of 2 separate particle ignitions. When ignitions are separated by short time intervals, the associated reactivity peaks overlap and video microscopy becomes the only means of determining which particles ignited and when these ignitions took place.

The video microscopy method has its limitations, however, and may not be sufficient to detect all particle ignitions of type II that are associated with faint light emissions. Typical ignition experiments are carried out with the external illumination source turned off to enhance the sensitivity of our video microscopy system for detecting ignitions. Even in the absence of external illumination, however, some type II ignitions may not be visible. In such cases, spikes in reactivity patterns obtained through weight measurements can help us detect ignitions.

To illustrate the sensitivity of the weight measurements, Figure 6.6 presents the reactivity patterns from 2 experiments conducted at a combustion temperature of $550{ }^{\circ} \mathrm{C}$ and without external illumination. No ignitions were observed during the first experiment. During the second experiment, however, one of the 11 particles present in the sample exhibited a type II ignition that was barely visible on video tape and would have undoubtedly been invisible if the external illumination were turned on. The image analysis procedure used to obtain an intensity trace for this particle was not able to distinguish the light emission from the image background. However, Figure 6.6 shows a sharp peak in reactivity that clearly distinguishes this reactivity pattern for the pattern obtained from the non-ignited sample. Reactivity data are thus necessary to effectively detect particle ignitions of type II. While isolated type II ignitions can be detected using reactivity data, the detection of multiple type II ignitions is much more difficult. This is because reactivity patterns alone may not allow us to tell how many and which particles have ignited, if the ignitions are separated by short time intervals.

Figure 6.7 presents another possible problem with ignition detection. The light intensity trace given in Figure 6.7b represents the maximum observed light intensity for the entire sample pan. Comparison with the reactivity plot shows that the first spike in reactivity is the result of one particle ignition. The second peak in reactivity, however, is more difficult to explain. This peak may be due to one or several type II ignitions, however because ignitions were not detected their existence can only be proposed. In fact, this peak may be a result of the opening of the internal pore structure of the particle through heterogeneous reaction (Sundback, Beer et al. 1984). The pore structure of devolatilized coal is characterized by a bimodal size distribution with small 
micropores and large macropores (Zygourakis 1993). As the reaction proceeds, the opening of previously inaccessible porosity can lead to a sharp increase in the surface area available to reactants and, thus, to a sudden jump in particle reactivity.

Finally, our setup enabled us to observe that some char particles ignited multiple times in the same combustion sequence. These secondary ignitions commonly occur at high oxygen concentrations. Secondary ignitions produce a separate reactivity peak provided that they are sufficiently separated from the primary ignitions. An example of the detection of secondary ignitions with our setup is presented in Figures 6.8a and 6.8b. In this experiment, 5 particles were placed in the reactor pan. The first peak in reactivity shown in Figure 6.8a, corresponds to the ignition of 4 of the 5 particles in the reactor within a span of about 3 seconds. Six seconds after the first group of ignitions, 3 of the previously ignited 4 particles ignited again and the new group of ignitions produced a second distinct peak. The light intensity traces of Figure $6.8 \mathrm{~b}$ demonstrate the ability of video microscopy to distinguish between the primary and secondary ignitions. In this case, the secondary ignitions were delayed enough to produce a separate reactivity peak. In many cases, however, the secondary ignitions occur very soon after the primary ignitions and video microscopy is the only means of detection.

Up to this point, we have focused on the effectiveness of ignition detection at a combustion temperature of $550{ }^{\circ} \mathrm{C}$. When the combustion temperature is raised, ignitions become more frequent and overlapping of individual ignitions is more likely. Figure 6.9a presents a typical reactivity curve for a combustion run conducted at $750{ }^{\circ} \mathrm{C}$. The accompanying light intensity trace (Figure 6.9b) shows that all 5 particles in the sample ignited. The shape of the reactivity curves is much smoother than those at $550{ }^{\circ} \mathrm{C}$, it does not exhibit the same sharp ignition peaks. When reactivity is plotted versus conversion as in Figure 6.10, the curves at $750{ }^{\circ} \mathrm{C}$ bear more of a resemblance to those obtained at $450{ }^{\circ} \mathrm{C}$, a temperature at which ignitions do not occur.

The reason the reactivity curves at $750{ }^{\circ} \mathrm{C}$ look more similar to $450{ }^{\circ} \mathrm{C}$ curves than $550{ }^{\circ} \mathrm{C}$ is not because particle ignitions do not occur. Particle ignitions are, in fact, much more common at $750{ }^{\circ} \mathrm{C}$. When multiple particles in the sample ignite however, individual ignition peaks blend together, as discussed earlier.

Because of this behavior, ignition detection at higher combustion temperatures will rely more heavily on observation of ignitions with video microscopy than on reactivity data. Furthermore, 
the detection of faint particle ignitions (type II) will be much more difficult since reactivity data is not as available to complement video microscopy.

\subsubsection{Detection of Coal Particle Ignitions}

Many of the issues we discussed above also apply to the detection of coal particle ignitions. Studies on the combustion of coal particles, however, have revealed that at heating rates equal to or above $10{ }^{\circ} \mathrm{C} / \mathrm{sec}$ the devolatilization rates are large enough to produce peaks in $\mathrm{R}_{\mathrm{O}}$ quite similar to ignition peaks. Figure 6.10 shows the reactivities measured for a series of coal combustion experiments conducted at heating rates between 0.1 and $20{ }^{\circ} \mathrm{C} / \mathrm{sec}$. The two highest heating rates each reveal two reactivity peaks, one at a low conversion and another at a higher conversion. Without the aid of video microscopy, this might be interpreted as two distinct ignitions. However, comparison of the reactivity plots versus time and the video tapes clearly shows that the first reactivity peaks which are observed at lower conversions correspond to the devolatilization of the coal particle. Devolatilization is visible due to the plastic behavior of the Illinois \#6 coal. High heating rates result in increased devolatilization rates and produced the primary peaks observed in Figure 6.9. Similar peaks are observed when pyrolyzing coal particles in pure $\mathrm{N}_{2}$ (see Figure 6.11).

Video tapes from these coal combustion experiments revealed that the second peaks observed for 10 and $20{ }^{\circ} \mathrm{C} / \mathrm{sec}$ heating rates (see Figure 6.10) were overlapping peaks from multiple particle ignitions. Again, video microscopy is necessary in this case to provide information about individual particle ignitions. No ignitions were observed at a heating rate of $0.1{ }^{\circ} \mathrm{C} / \mathrm{sec}$. This is confirmed by the flat reactivity curve.

The video tape for the $1{ }^{\circ} \mathrm{C} / \mathrm{sec}$ experiment revealed that several very faint ignitions occurred on one of the four particles. The faint emission of light by these ignitions is in agreement with the relatively low reactivity of this sample. Since these experiments were conducted without external illumination, it was possible to detect the faint ignitions. If image analysis had not detected any ignitions for this experiment, reactivity data could still provide evidence of the occurrence of ignitions, though not enough to determine that the same particle ignited more than once.

The devolatilization peaks of Figures 6.10 and 6.11 occur regardless of whether the particles ignite or not, provided that the heating rate is $10^{\circ} \mathrm{C} / \mathrm{sec}$ or higher. We should note, however, that 
the temperatures at which these first peaks occur (about $600{ }^{\circ} \mathrm{C}$ for 10 and $20{ }^{\circ} \mathrm{C} / \mathrm{sec}$ heating rates when combusted at $700{ }^{\circ} \mathrm{C}$ ) do suggest that heterogeneous reactions may contribute to the weight loss associated with this peak.

\subsection{Conclusions}

The TGA/VMI reactor allows us to observe and record the structural transformations of individual coal and char particles during pyrolysis and combustion. Post-processing of the video tapes enabled us to characterize important ignition phenomena including the mechanism of particle ignitions. Devolatilized char particles were observed to ignite heterogeneously, while coal particles ignited heterogeneously, homogeneously, or through a combination of both mechanisms.

The combination of video microscopy, digital image analysis and thermogravimetry is a very efficient method to detect ignitions under a wide variety of conditions that may lead to light emissions ranging from very bright to faint. While allowing us to study the interactions among the many particles of a coal or char sample, the technique presented in this study provides timeresolved light intensity traces that can be compared to the sample reactivity pattern.

Combining the video tape analysis with simultaneous weight loss data provides comprehensive ignition detection. The TGA/VMI reactor provides detailed information on individual particle ignitions while still allowing particle interactions, thus combining the qualities of single and multiple particle experiments.

\subsection{References for Section 6}

Chen, M. R., L. S. Fan, et al. (1985). Prediction and measurement of ignition temperatures of coal particles. Symp. (Int.) Combust., [Proc.], Volume Date 1984, 20th, 1513-21.

Cozzani, V., L. Petarca, et al. (1995). "Ignition and combustion of single, levitated char particles." Combustion and Flame 103: 181-193. 
Essenhigh, R. H., M. K. Misra, et al. (1989). "Ignition of coal particles: a review." Combust. Flame 77(1): 3-30.

Faraday, M. and C. Lyell (1845). "Explosions in coal mines.” Philos. Mag. 26: 16-21.

Gomez, C. O. and F. J. Vastola (1985). "Ignition and combustion of single coal and char particles. A quantitative differential approach." Fuel 64(4): 558-63.

Gupta, R. P., G. V. S., et al. (1990). "Ignition temperature of pulverized coal particles: Expreimental techniques and coal-related influences." Combustion and Flame 79: 333-339.

Huang, G., F. J. Vastola, et al. (1988). "Temperature gradients in the gas phase surrounding pyrolyzing and burning coal particles.” Energy \& Fuels 2: 385-390.

Levendis, Y. A., R. Sahu, et al. (1989). "Post-ignition transients in the combustion of single char particles.” Fuel 68(7): 849-55.

Matzakos, A. N. and K. Zygourakis (1993). "Computerized thermogravimetric reactor with video microscopy imaging system for coal pyrolysis and combustion studies." Rev. Sci. Instrum. 64(6): 1541-1548.

Semenov, N. (1928). “Zur theorie des verbrennungsprozesses.” Z. Physik 48: 571-582.

Sundback, C. A., J. M. Beer, et al. (1984). Fragmentation behavior of single coal particles in a fluidized bed. 20th International Symposium on Combustion, Ann Arbor, MI.

Tognotti, L., A. Malotti, et al. (1985). "Measurement of ignition temperature of coal particles using a thermogravimetric technique." Combust. Sci. Technol. 44(1-2): 15-28. 
Vorres, K. S. (1990). “The Argonne premium coal sample program.” Energy \& Fuels 4(5): 420426.

Wall, T. F., R. P. Gupta, et al. (1991). "The ignition of coal particles.” Fuel 70(September): 1011-1016.

Wall, T. F., D. Phong-Anant, et al. (1988). "Indicators of ignition for clouds of pulverized coal." Combust. Flame 72(2): 111-18.

Wong, B. A., G. R. Gavalas, et al. (1995). “Laser ignition of levitated char particles.” Energy \& Fuels 9(3): 484-492.

Yang, J.-T. and G.-T. Tsai (1990). "Ignition mechanism of subbituminous coal combustion in the stretched-flow field." Fuel 69(6): 696-701.

Zhang, D.-k. and T. F. Wall (1994). "Ignition of coal particles: the influence of experimental technique." Fuel 73: 1114-1119.

Zygourakis, K. (1993). "Effect of pyrolysis conditions on the macropore structure of coalderived chars." Energy \& Fuels 7(1): 33-41. 


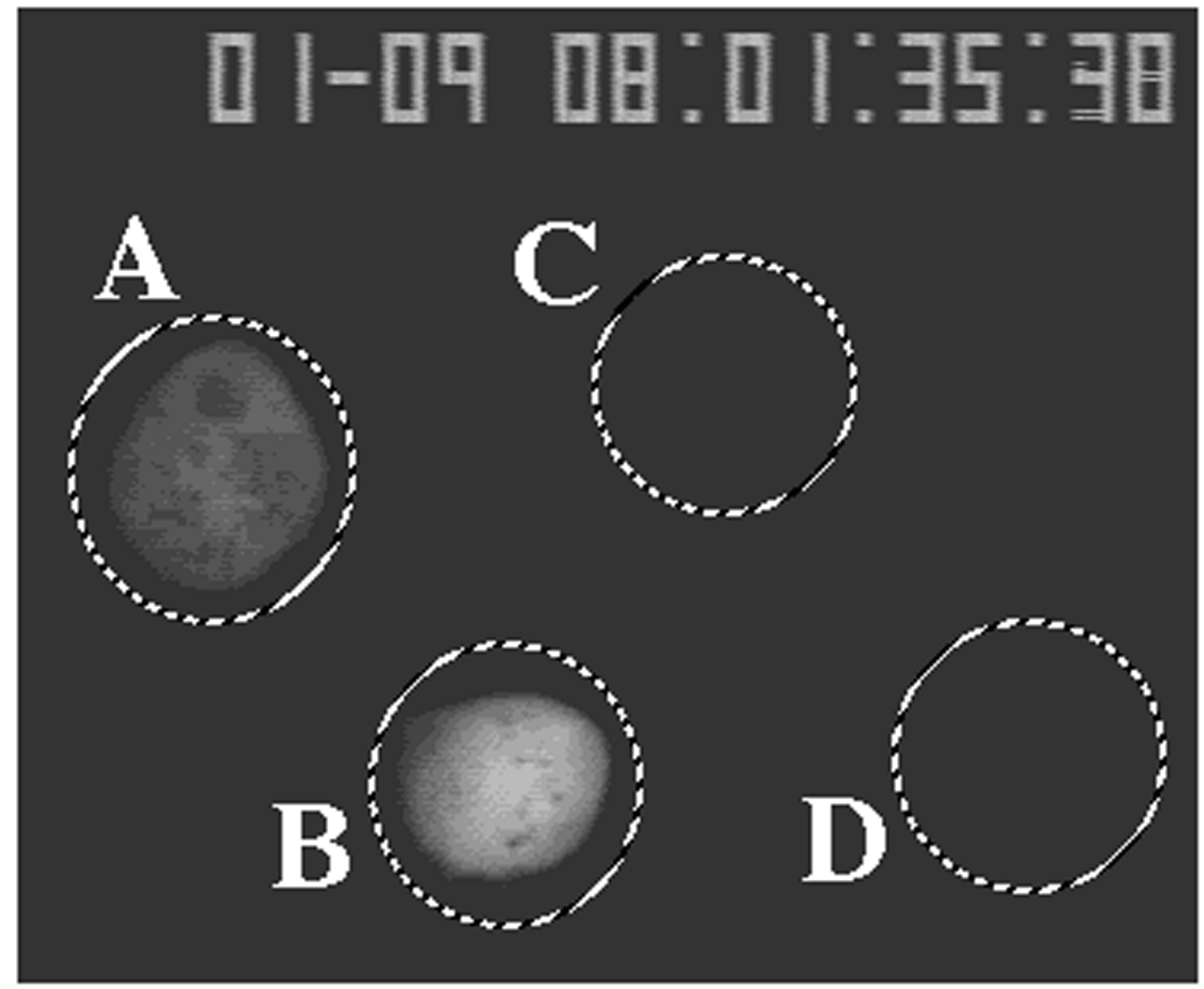

Figure $6.1 \quad$ (198)Frame from a digitized experiment showing 4 regions of interest (ROI) which are centered around char particles and are being monitored to determine maximum light intensity. 

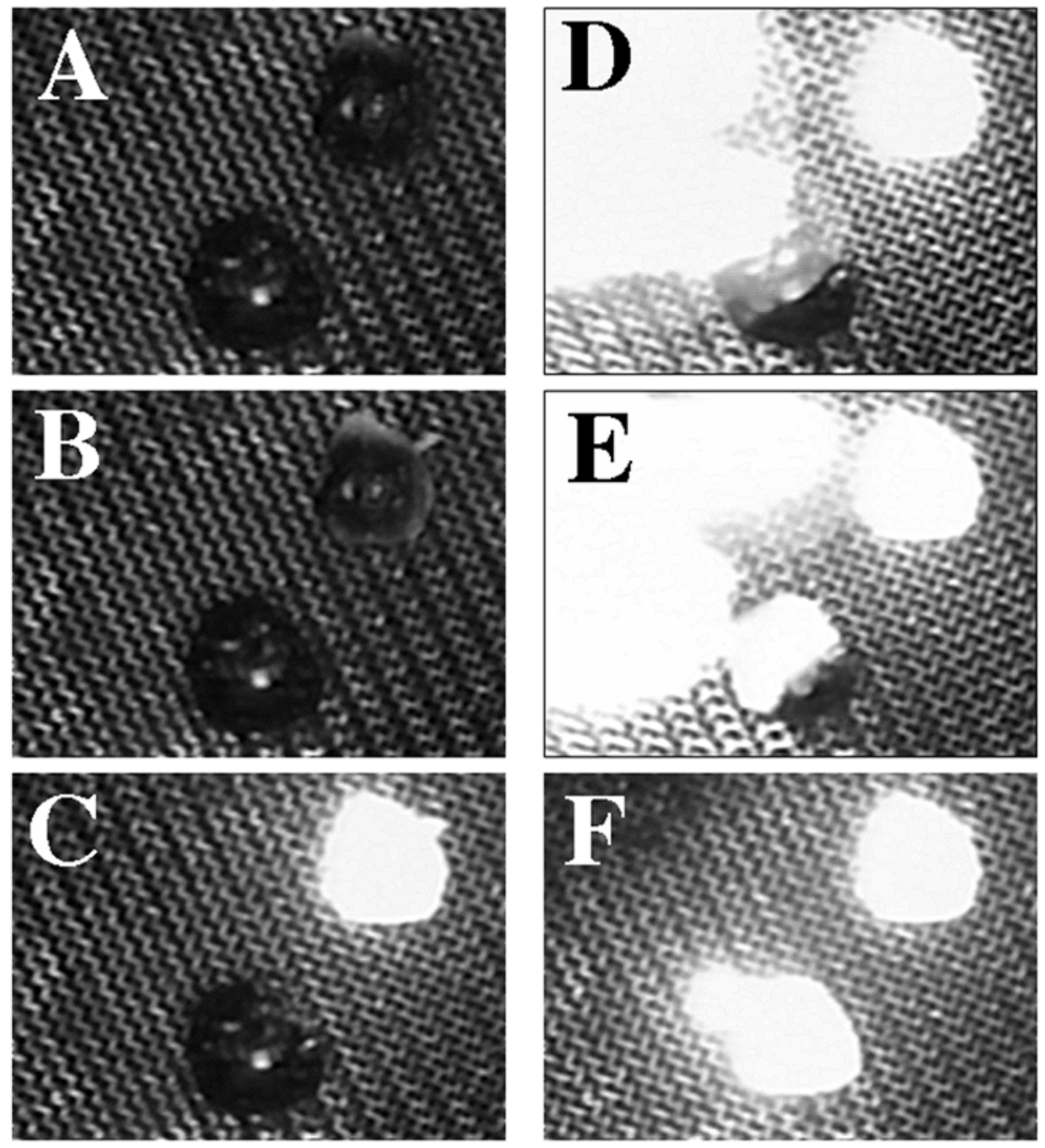

Figure 6.2 (48)Sequence of digital images from a coal combustion experiment. For this run, 28-32 mesh Illinois \#6 particles were heated at $5{ }^{\circ} \mathrm{C} / \mathrm{sec}$ to a final combustion temperature of $750{ }^{\circ} \mathrm{C}$. The oxygen concentration was $50 \%$. Elapsed time in seconds of respective frames A-F: 0.0, 0.1, 0.2, 0.3, 0.4, 0.5. 

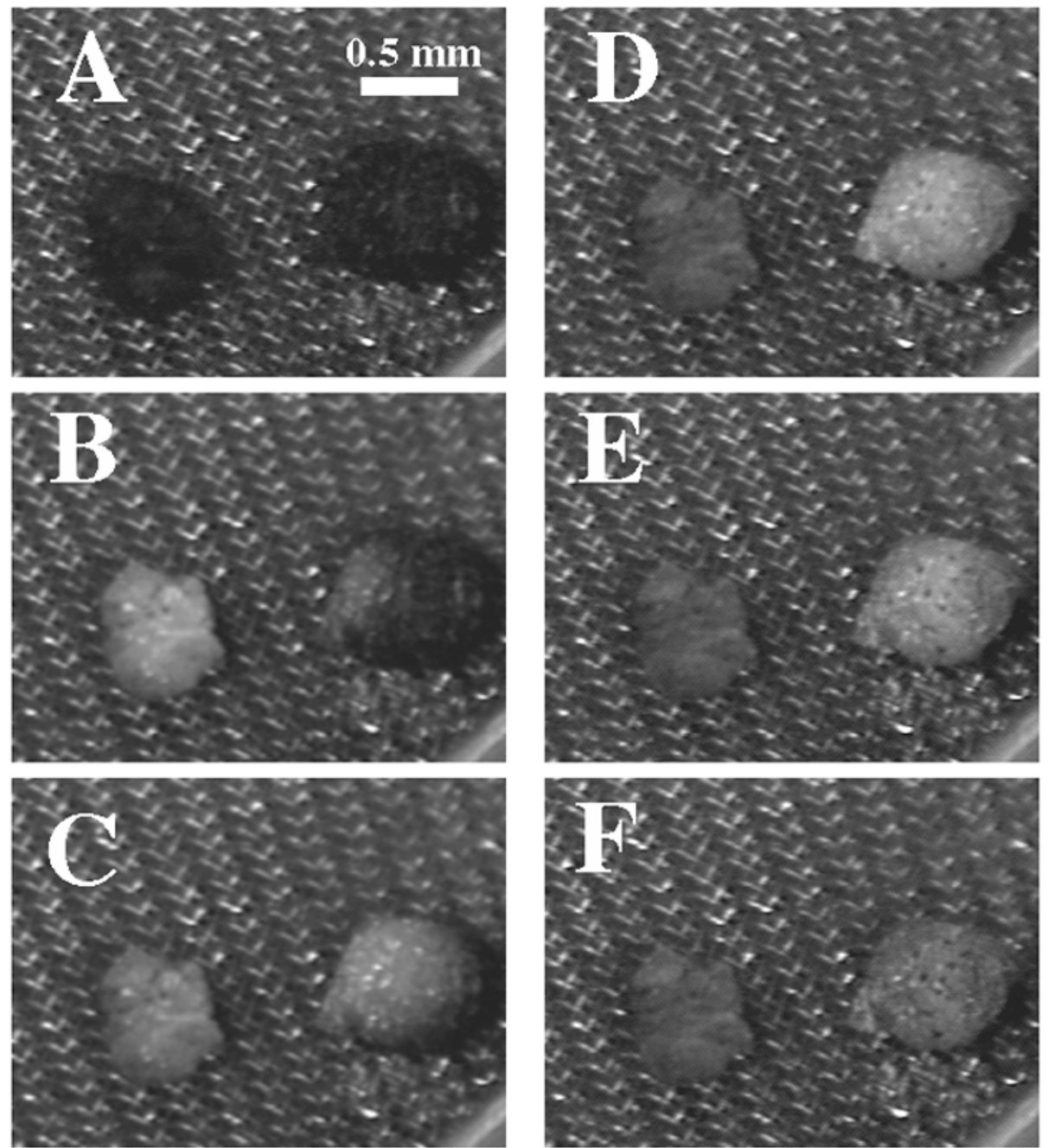

Figure 6.3 (54)Sequence of digital images from a char combustion experiment. The chars were prepared from 28-32 mesh Illinois \#6 particles heated under pure nitrogen at $5{ }^{\circ} \mathrm{C} / \mathrm{sec}$ to a HTT of $700{ }^{\circ} \mathrm{C}$. Combustion was carried out at an ambient temperature of $700{ }^{\circ} \mathrm{C}$ under flowing gas containing $50 \% \mathrm{O}_{2}$. Elapsed time in seconds of respective frames A-F: 0.0, $1.0,1.1,1.9,2.2,2.5$. 


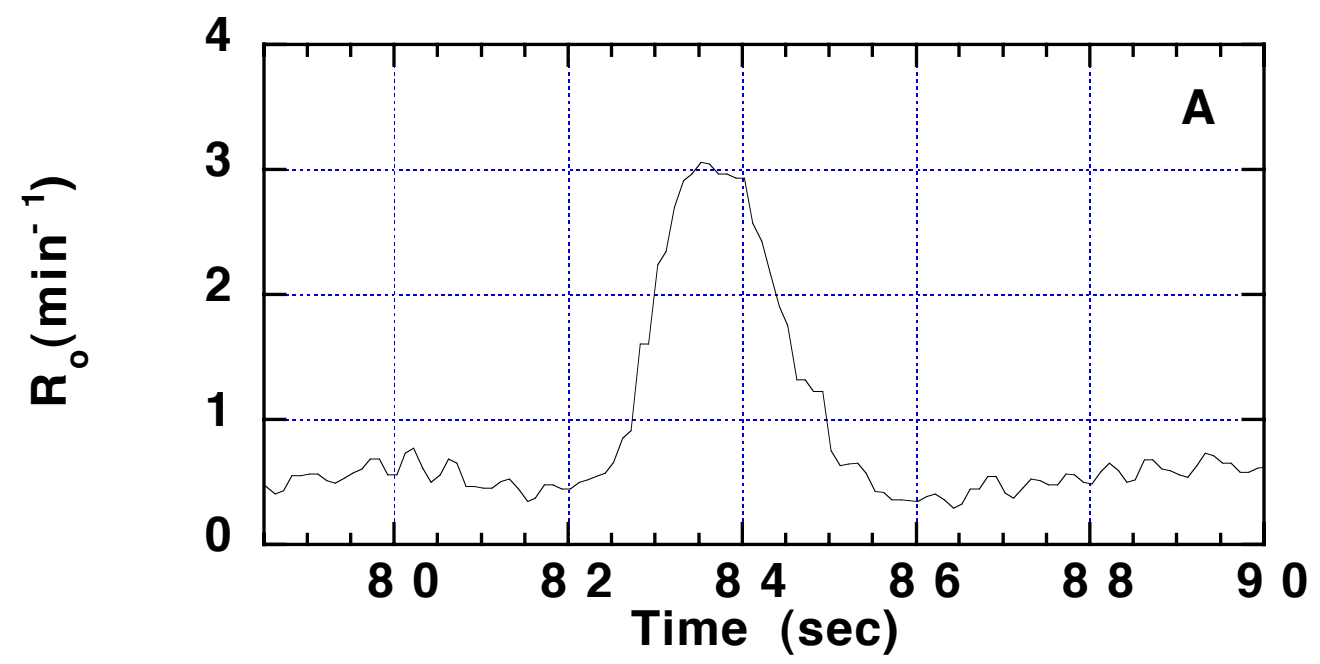

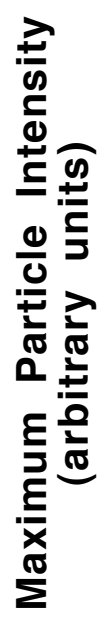

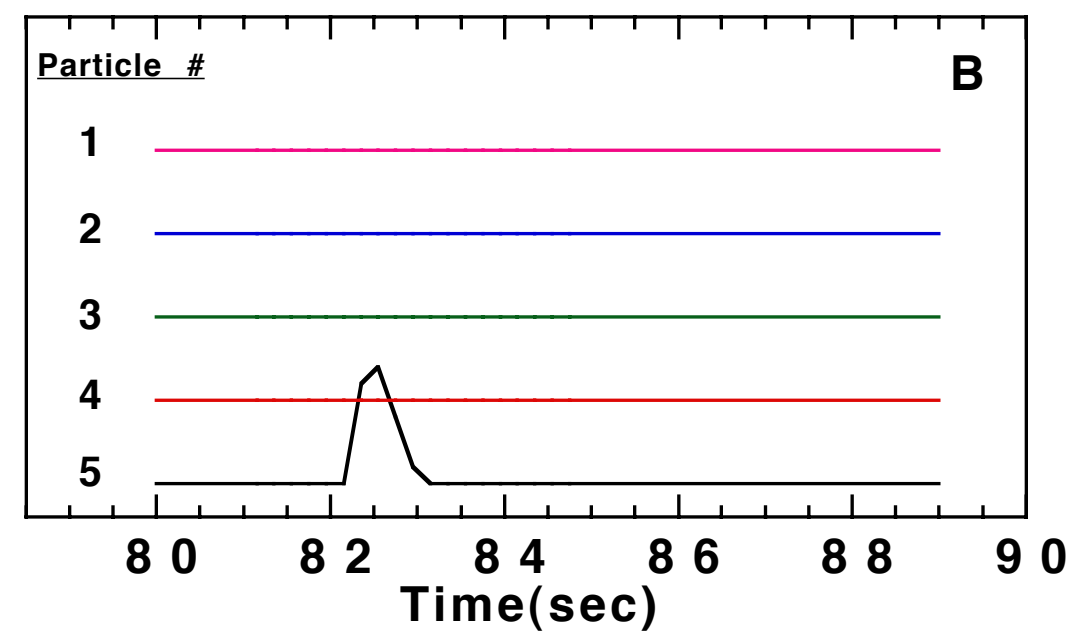

Figure 6.4 (236) Reactivity pattern [A] and accompanying light intensity trace [B] obtained for a char combustion run during which 1 out of the 5 char particles ignited.

Conditions: 28-32 mesh Illinois \#6, pyrolysis heating rate: $10{ }^{\circ} \mathrm{C} / \mathrm{sec}$, HTT: 700 ${ }^{\circ} \mathrm{C}$, combustion Temp.: $550{ }^{\circ} \mathrm{C}, 33 \% \mathrm{O}_{2}$. 

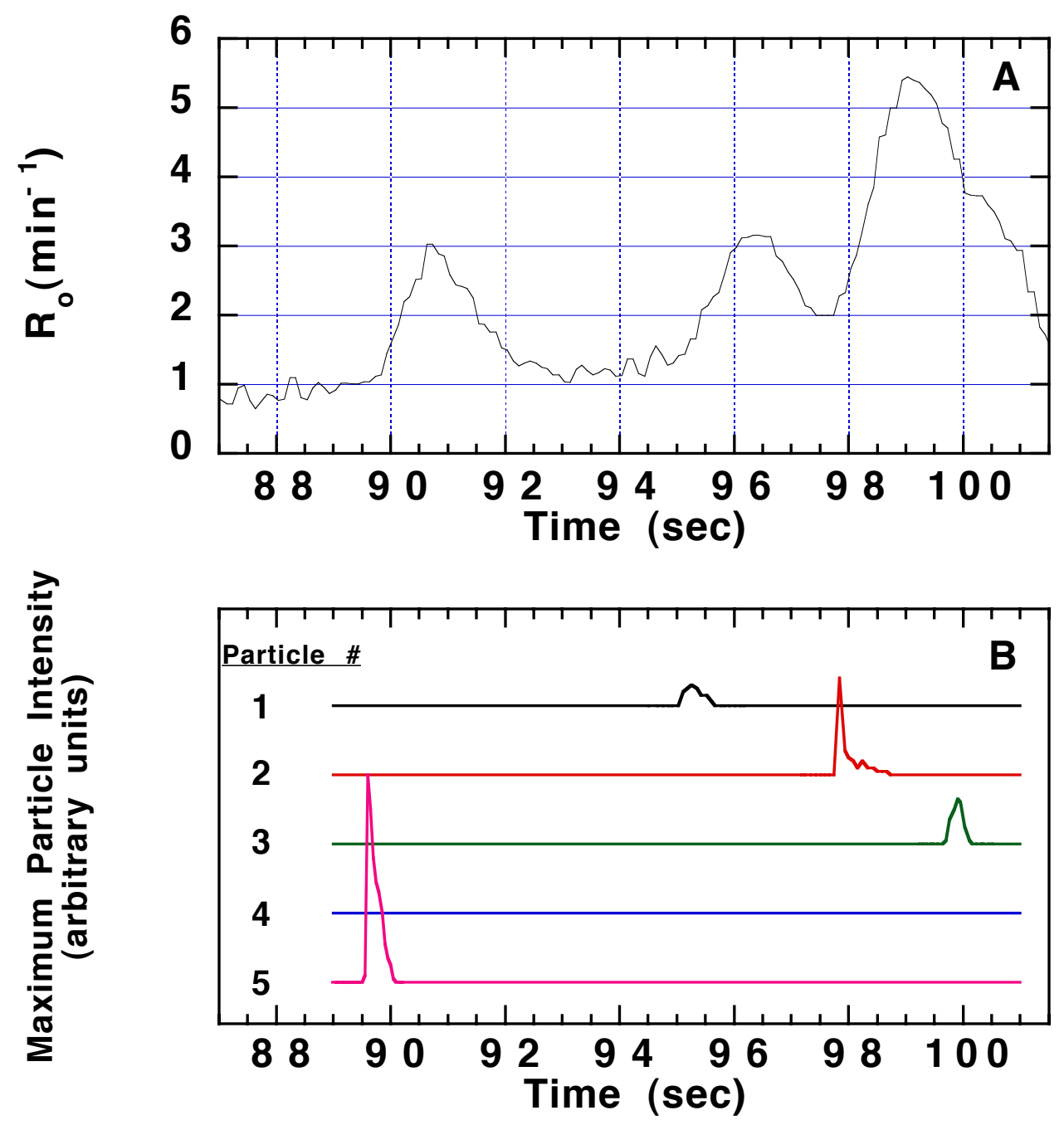

Figure 6.5 (230)Reactivity pattern [A] and accompanying light intensity trace [B] obtained for a char combustion run during which 4 out of the 5 char particles ignited. Conditions: 28-32 mesh Illinois \#6 particles, pyrolysis heating rate: $1.0{ }^{\circ} \mathrm{C} / \mathrm{sec}$, HTT: $700{ }^{\circ} \mathrm{C}$, combustion Temp.: $550{ }^{\circ} \mathrm{C}, 33 \% \mathrm{O}_{2}$. 


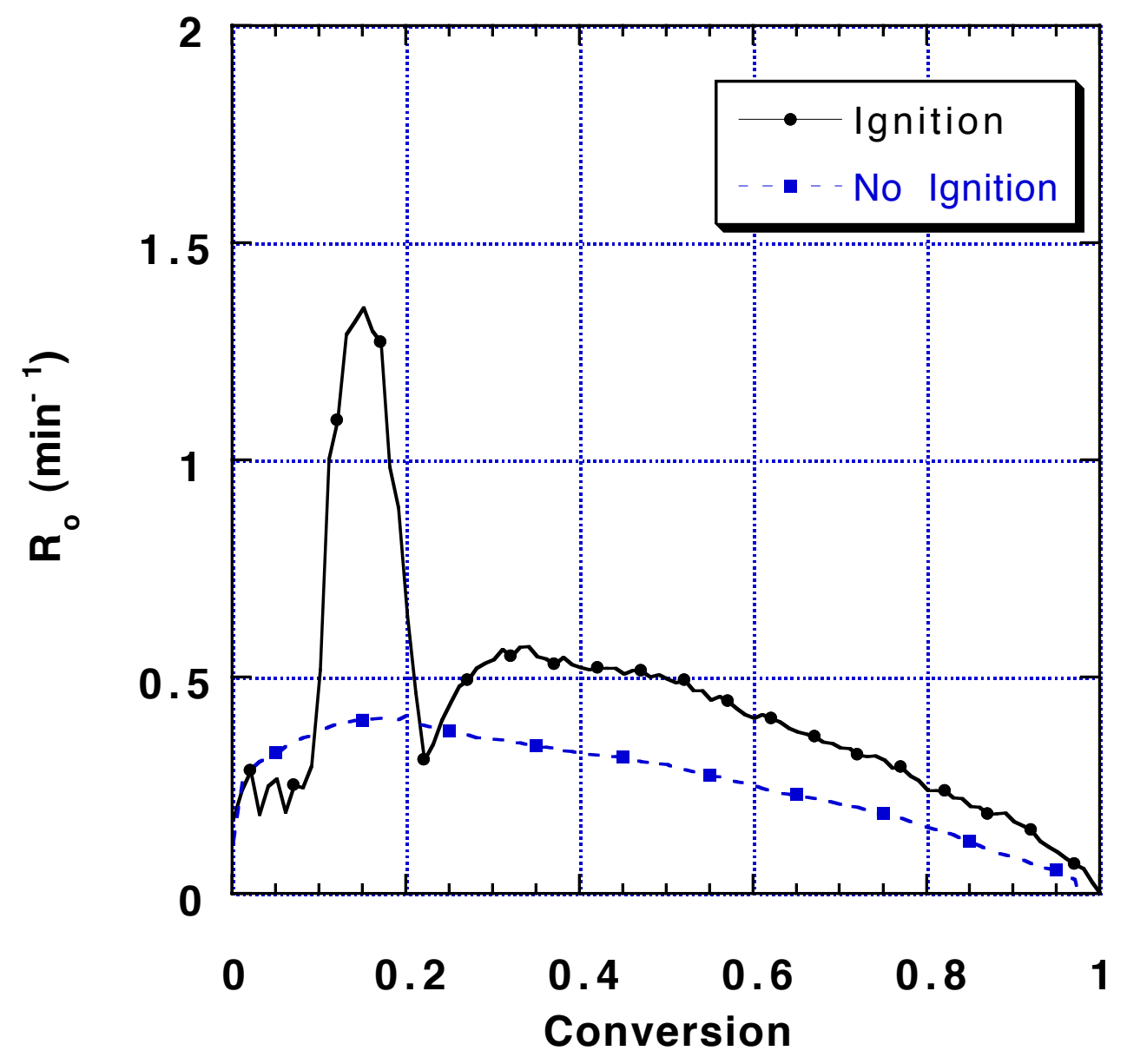

Figure $6.6 \quad(69,115)$ Reactivity patterns for 2 char combustion runs. During one, a faint ignition was observed for 1 out of the 11 particles in the sample. Conditions for both: 50-60 mesh Illinois \#6 particles, pyrolysis heating rate: $10^{\circ} \mathrm{C} / \mathrm{sec}, \mathrm{HTT}: 700$ ${ }^{\circ} \mathrm{C}$, combustion temp.: $550{ }^{\circ} \mathrm{C}, 21 \% \mathrm{O}_{2}$. 


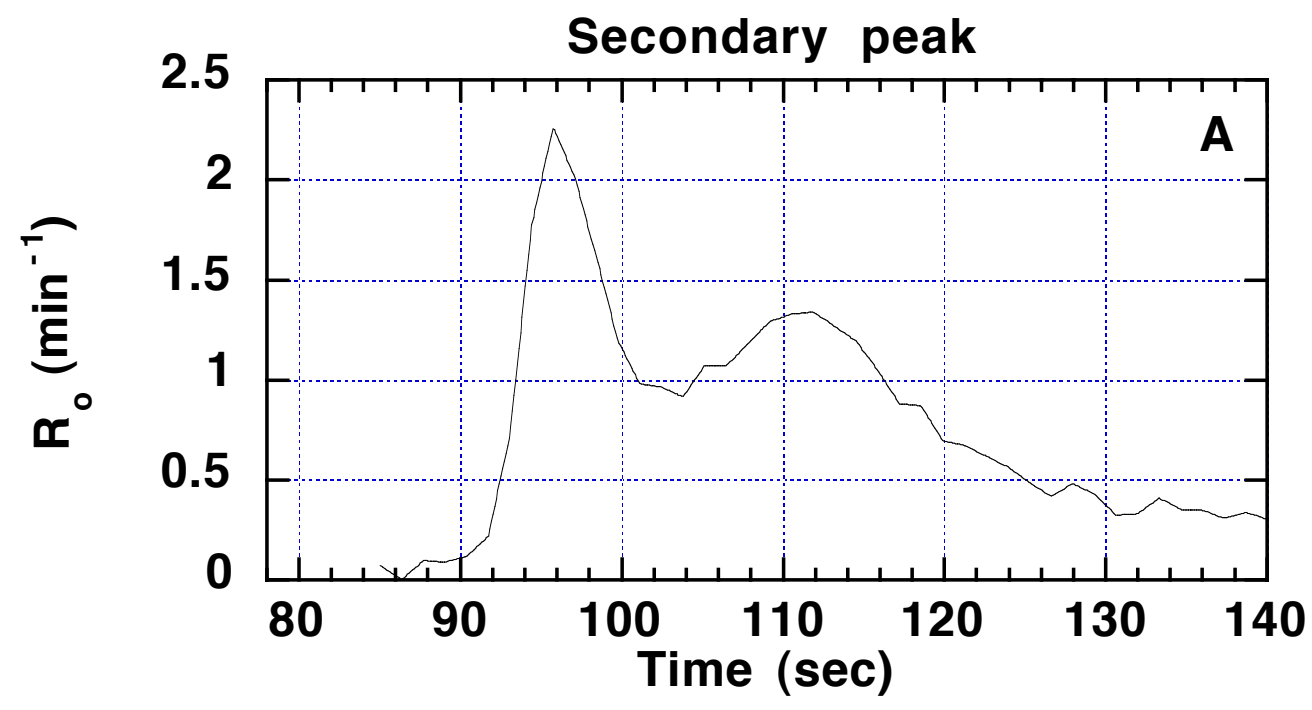

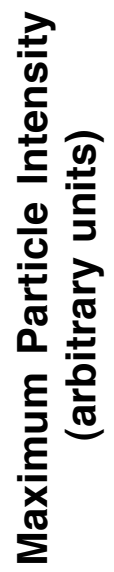

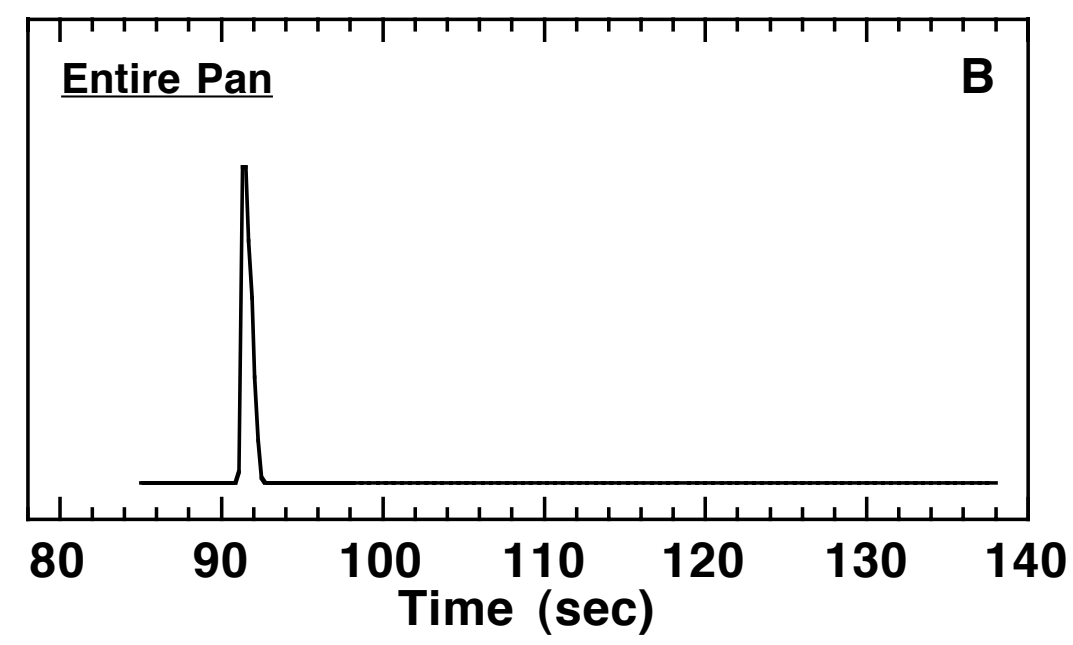

Figure 6.7 (97)Reactivity pattern [A] and accompanying light intensity trace [B] showing secondary peak which may not be due to ignition. Conditions: 28-32 mesh Illinois \#6 particles, pyrolysis heating rate: $10^{\circ} \mathrm{C} / \mathrm{sec}$, HTT: $625^{\circ} \mathrm{C}$, combustion temp.: $550{ }^{\circ} \mathrm{C}, 33 \% \mathrm{O}_{2}$. 

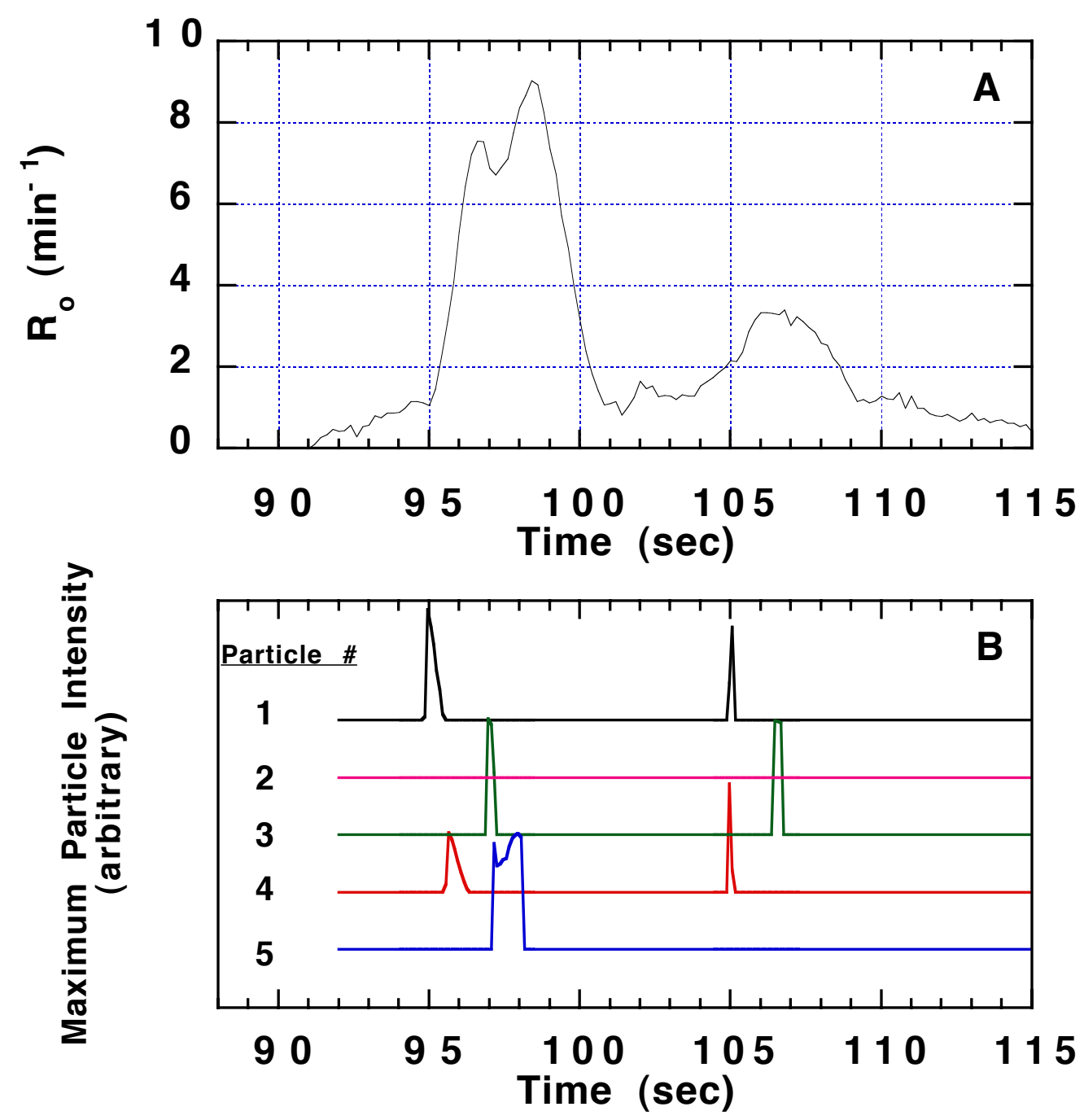

Figure 6.8 (197)Reactivity pattern [A] and accompanying light intensity trace [B] showing primary and secondary peaks, illustrating the detection of secondary ignitions. Conditions: $28-32$ mesh Illinois \#6 particles, pyrolysis heating rate: $10{ }^{\circ} \mathrm{C} / \mathrm{sec}$, HTT: $700{ }^{\circ} \mathrm{C}$, combustion temp.: $700{ }^{\circ} \mathrm{C}, 50 \% \mathrm{O}_{2}$. 

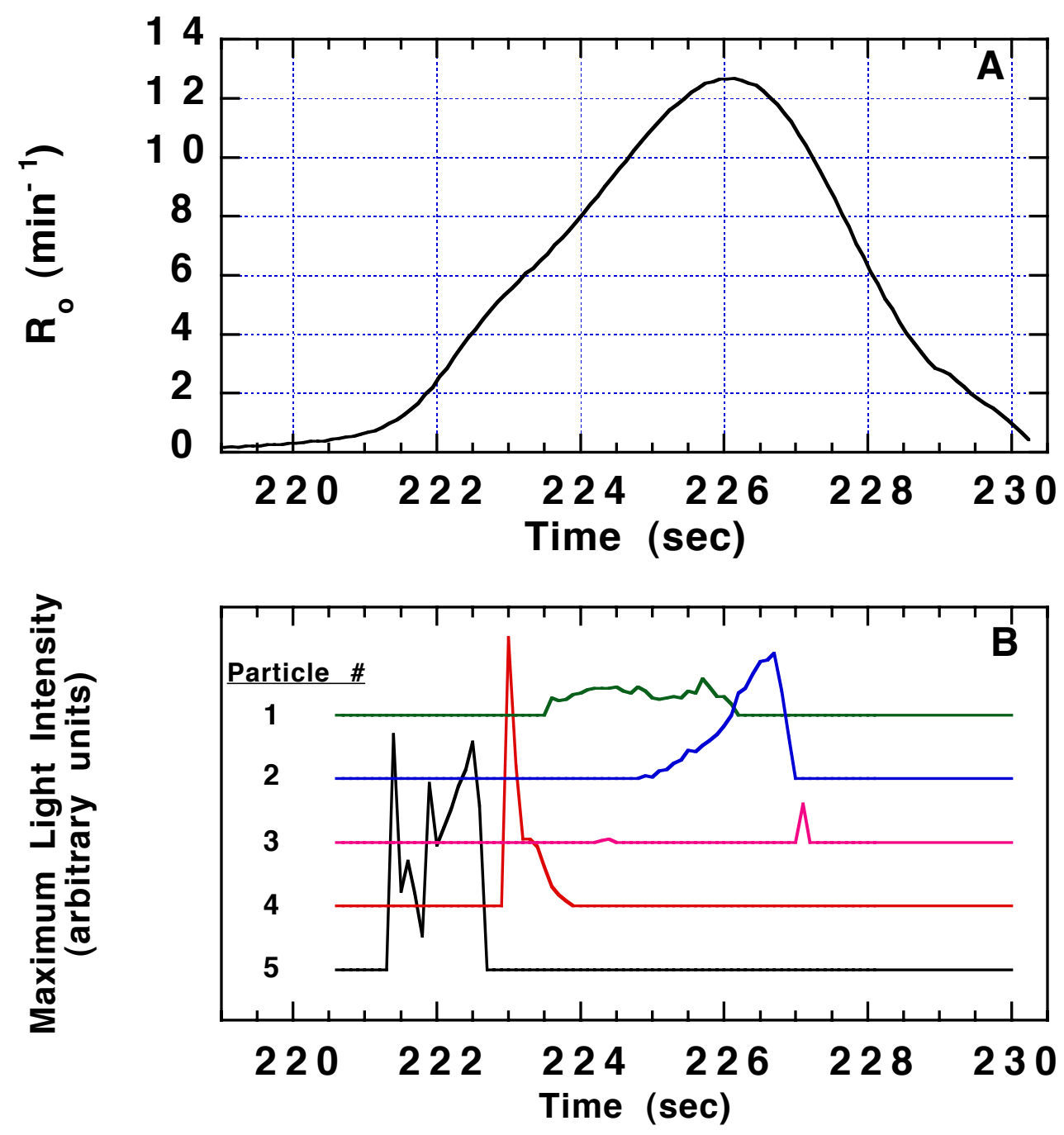

Figure 6.9 (293)Reactivity pattern [A] and accompanying light intensity trace [B] for char combustion run in which all five sample particles ignite. Conditions: $28-32$ mesh Illinois \#6 particles, pyrolysis heating rate: $500{ }^{\circ} \mathrm{C} / \mathrm{sec}$, HTT: $700{ }^{\circ} \mathrm{C}$, combustion temp.: $750{ }^{\circ} \mathrm{C}, 33 \% \mathrm{O}_{2}$. 


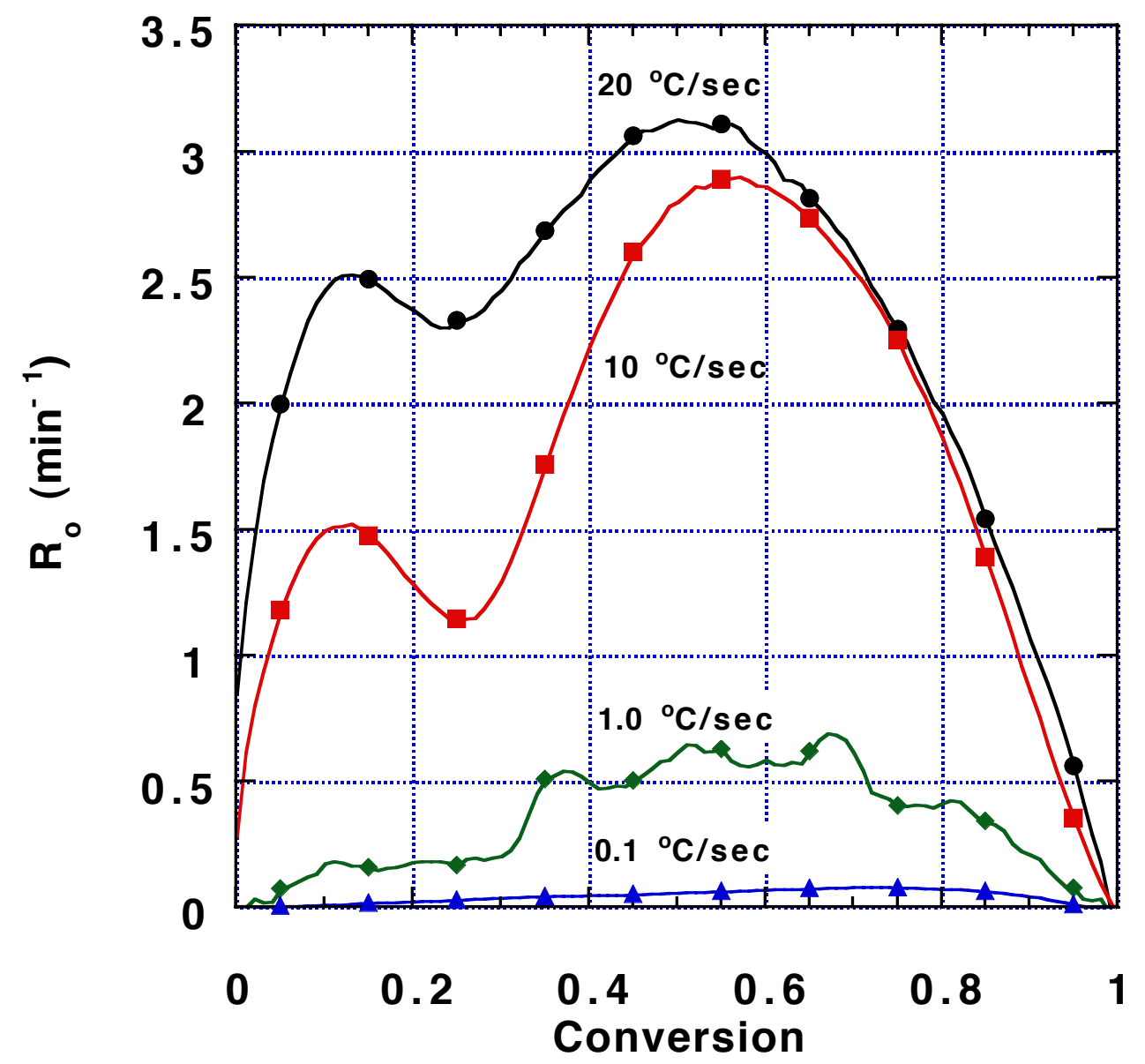

Figure 6.10 Series of coal combustion experiments showing the presence of a devolatilization peak as well as a blended ignition peak for higher heating rates. Conditions: 28-32 mesh Illinois \#6 particles, combustion temp.: $700{ }^{\circ} \mathrm{C}, 21 \% \mathrm{O}_{2}$. 


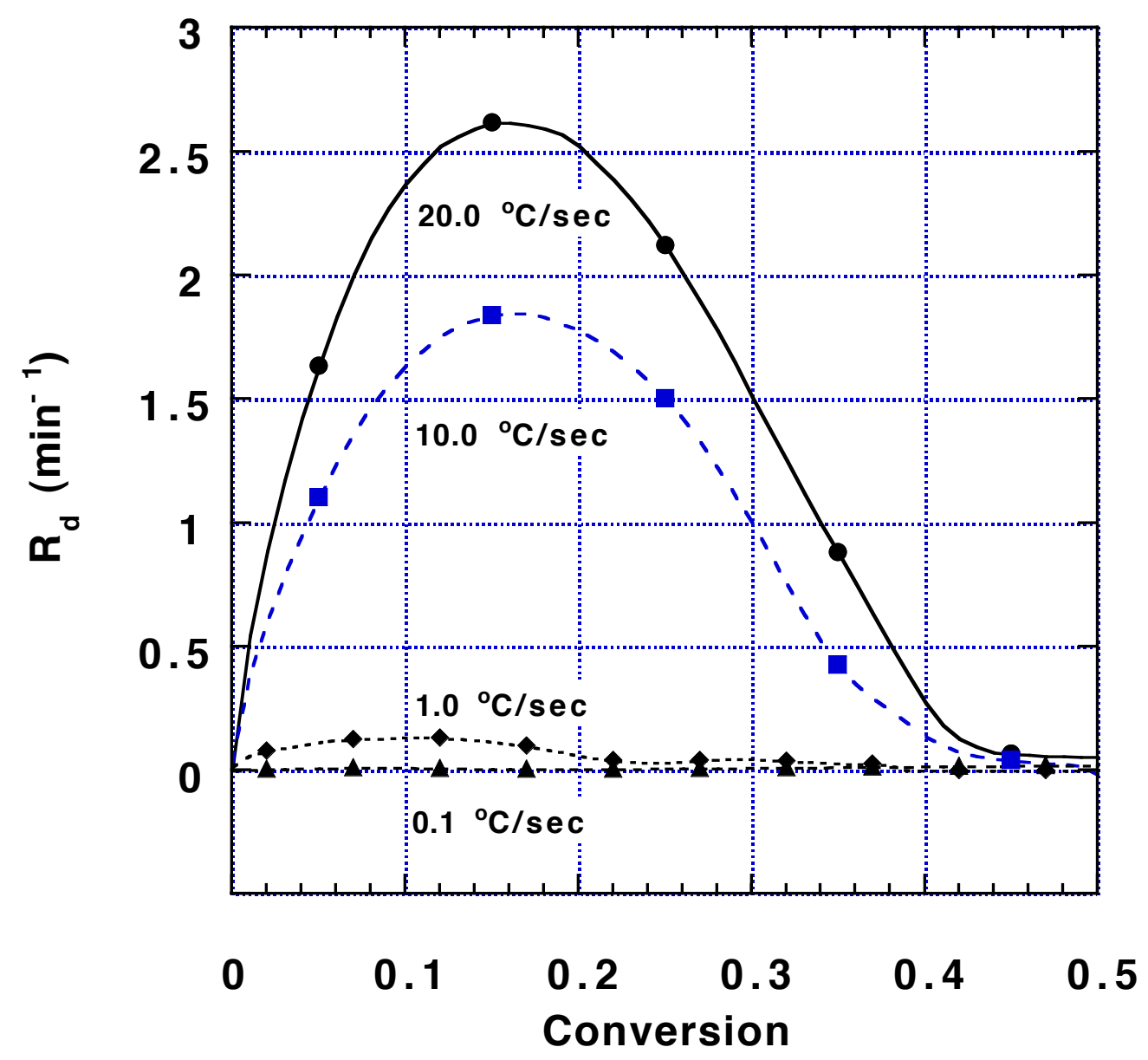

Figure 6.11 Series of coal pyrolysis experiments illustrating the peak in devolatilization rate occurring in pure $\mathrm{N}_{2}$. Conditions: $28-32$ mesh Illinois \#6 particles, HTT: $700{ }^{\circ} \mathrm{C}$. 


\section{SECTION 7}

\section{MODELING THE IGNITION OF CHAR PARTICLES}

\subsection{Model Development}

The combustion of carbon in oxygen involves the following heterogeneous reactions:

$$
\begin{aligned}
& \mathrm{C}+\frac{1}{2} \mathrm{O}_{2} \rightarrow \mathrm{CO} \\
& \mathrm{C}+\mathrm{O}_{2} \rightarrow \mathrm{CO}_{2}
\end{aligned}
$$

Both reactions are exothermic with heats of reaction equal to $221.0 \mathrm{~J} /\left(\mathrm{mol} \mathrm{O}_{2}\right)$ and $393.5 \mathrm{~J} /\left(\mathrm{mol} \mathrm{O}_{2}\right)$ resper (Arthur 1951). It was found that CO is the primary reaction product at higher temperatures. At higher temperatures, the carbon surface undergoes endothermic reaction with $\mathrm{CO}_{2}$ :

$$
\mathrm{C}+\mathrm{CO}_{2} \rightarrow 2 \mathrm{CO}
$$

From our experimental reactivity measurements, we have data on the rate of carbon reaction. To relate the carbon reactivity to the consumption of oxygen, we have utilized the stoichiometry of reactions 1 and 2. For example, the stoichiometry of reaction 1 indicates that two moles of carbon are consumed for each mole of oxygen. Reaction 3 has been neglected since it prevents simplifying assumptions about the reaction order. Utilizing our kinetic data and the stoichiometry of the reaction between oxygen and carbon, we have related the reaction of oxygen to the reaction of carbon: 


$$
R_{O_{2}}=v_{O_{2}} \cdot R_{C}=\frac{\left(V_{P} \rho_{P} f_{c}\right)_{o} v_{O_{2}}}{M_{c}} A e^{-\left(\frac{E}{R T_{s}}\right)} C_{s}
$$

where $\mathrm{M}_{\mathrm{c}}$ is the molecular weight of carbon, $\mathrm{vo}_{2}$ is the stoichiometric coefficient for oxygen in the chemical reactions with carbon. A and E are the pre-exponential factor and activation energy determined previously. The units of $\mathrm{R}_{\mathrm{c}}$ are grams of carbon per initial grams of carbon per second. In our experimental results, we have simply presented these units as inverse minutes, ignoring the grams of carbon per initial grams of carbon. Since this reactivity data was based on the initial mass of char present, the reactivity is multiplied by the product of initial particle volume and density. This product is then multiplied by the initial carbon content, $\mathrm{f}_{\mathrm{co}}$ to obtain the ash free carbon mass.

The relative rates of formation of $\mathrm{CO}$ versus $\mathrm{CO}_{2}$ are not only of importance due to the different heats of reaction. The stoichiometric coefficient of oxygen in each reaction is different. Thus, the relative rates of these reactions determine the stoichiometric coefficient of oxygen. At high temperatures, where $\mathrm{CO}$ is the primary reaction product, $\mathrm{vo}_{2}$ is constant at $1 / 2$.

Since reactions (7.1) and (7.2) involve heterogeneous reaction of oxygen and carbon, model equations must be solved in both solid and gas phases. This particular model does not consider gas phase homogeneous reactions of oxygen with heterogeneous reaction products such as carbon monoxide. These reactions have been considered extensively by Sotirchos and Amundson (Sotirchos, Srinivas et al. 1984; Sotirchos and Amundson 1984a; Sotirchos and Amundson 1984b; Sotirchos and Amundson 1984c; Sotirchos and Amundson 1984d; Sotirchos and Burganos 1986).

\subsubsection{Governing equations}

The primary equations that make up the system are mass balances on reacting oxygen (7.5) and carbon (7.6), and a solid energy balance (7.7) which determines the particle temperature: 


$$
\begin{gathered}
V_{p} \varepsilon \frac{d C_{s}}{d t}=a_{x} k_{g}\left(C_{f}-C_{s}\right)-V_{p} \varepsilon R_{O_{2}} \eta \\
\frac{d}{d t}\left(V_{p} \rho_{p}\right)=\left(V_{p} \rho_{p}\right)_{0} R_{c} \\
V_{p} \rho_{s} C p_{s}(1-\varepsilon) \frac{d T_{s}}{d t}=\sum_{i}\left(-\Delta H_{n}\right)_{i} R_{O_{2}} \eta-a_{x} h\left(T_{s}-T_{f}\right)-a_{x} \sigma e\left(T_{s}^{4}-T_{f}^{4}\right)
\end{gathered}
$$

with the initial conditions:

$$
\begin{aligned}
& T_{s, o}=T_{s}(0) \\
& C_{s, o}=C_{s}(0)
\end{aligned}
$$

where ax and $\mathrm{V}_{\mathrm{p}}$ are the external surface area and volume of the char particle respectively; $\mathrm{Cp}_{\mathrm{s}}$ is the solid heat capacity and $\rho$ s is the solid density. The porosity or void volume of the particle is given by $\varepsilon$. Subscript $s$ denotes solid properties and subscript $f$ denotes properties of the surrounding fluid. $\mathrm{kg}$ and $\mathrm{h}$ are the mass and heat transfer coefficients respectively. In the radiation term of the energy balance, e is the particle emissivity and $\sigma$ is the Boltzmann constant. The emissivity of the char particle was taken to be 0.9 , the same value used by Sotirchos and Amundson (Sotirchos, Srinivas et al. 1984; Sotirchos and Amundson 1984a; Sotirchos and Amundson 1984b; Sotirchos and Amundson 1984c; Sotirchos and Amundson 1984d; Sotirchos and Burganos 1986). General values of the emissivity of Carbon are presented by Perry, et al.(Perry, Green et al. 1984). The exothermic heat of the reaction is denoted by $(-\Delta \mathrm{HR})$, and $\eta$ is the effectiveness factor.

In these equations, we have neglected spatial variations in all properties. The equations are highly coupled since both the particle temperature and oxygen concentration determine the reaction rates, and reaction rate terms are found in both equations. In the energy balance, the reaction rate determines the amount of heat generated by the exothermic reaction. 


\subsubsection{Effectiveness factors}

The effectiveness factor, $\eta$, was calculated by a method developed by Mingle and Smith (Mingle and Smith 1961) and outlined by Froment and Bischoff (Froment and Bischoff 1979). The method takes into account the strongly bimodal pore distribution that exists in char particles. Assuming the micropores are cylindrical and that the reactions are first order with respect to oxygen, the mass balance for reacting oxygen has the form:

$$
D_{\mu} \frac{d^{2} C_{\mu}}{d z^{2}}=\frac{2}{r_{\mu}} \frac{k_{o}}{\rho_{p} S_{g}} C_{\mu}
$$

where $D_{\mu}$ is the micropore diffusion coefficient, $z$ is the axial coordinate, $r_{\mu}$ is the micropore radius, and $\mathrm{C}_{\mu}$ is the oxygen concentration in the micropores. Boundary conditions for this equation assume that each closed micropore originates from a macropore:

$$
\begin{aligned}
& \frac{d C_{\mu}}{d z}=0 \ldots \ldots \ldots @ z=0 \\
& C_{\mu}=C_{m} \ldots \ldots . . @ z=L_{\mu}
\end{aligned}
$$

where $\mathrm{L}_{\mu}$ is the micropore length and $\mathrm{Cm}$ is the concentration of oxygen in the macropores, located at the end of each micropore. If reaction 3 was also considered it is apparent that analytical solution of 9 would not be possible since the reaction order would no longer be 1 . Solution of the micropore balance (7.9) with boundary conditions (7.10) yields an effectiveness factor for the micropores of the form:

$$
\eta_{\mu}=\frac{\tanh \left(\phi_{\mu}\right)}{\phi_{\mu}}
$$


where $\phi_{\mu}$ is the Thiele modulus for the micropores defined by:

$$
\phi_{\mu}=L_{\mu} \sqrt{\frac{2 k_{o}}{\rho_{p} S_{g} r_{\mu} D_{\mu}}}
$$

where $k_{0}$ is the reaction rate constant and $S_{g}$ is the total surface area $\left(\mathrm{cm}^{2} / \mathrm{g}\right)$. The micropore radius, $\mathrm{r} \mu$, is a parameter and was assigned an average value of $5 \AA$. This value corresponds to the size separating the micropores from the sub-micropores. The micropore diffusion coefficient, $\mathrm{D}_{\mu}$, was calculated using the micropore radius and assuming Knudsen diffusion. The micropore length, $\mathrm{L}_{\mu}$, was estimated by the ratio of the particle volume to macropore surface area as follows:

$$
L_{\mu}=\frac{1}{(1-\varepsilon) S_{m g}}
$$

where $S_{\mathrm{mg}}$ is the macropore surface area per unit of solid volume $\left(\mathrm{cm}^{2} / \mathrm{cm}^{3}\right.$ solid). The porosity, $\varepsilon$, has units of $\mathrm{cm}^{3}$ void $/ \mathrm{cm}^{3}$ particle.

The oxygen balance for the macropores resembles an overall spherical particle balance:

$$
D_{e f f} \frac{d^{2} C_{m}}{d r^{2}}=k_{o} \eta_{\mu} C_{m}
$$

where Deff is the effective diffusivity in the macropores, $r$ is the particle radius, and $\eta_{\mu}$ is the effectiveness factor obtained for the micropores. The boundary conditions for the macropores are:

$$
\begin{aligned}
& \frac{d C_{m}}{d r}=0 \ldots \ldots \ldots @ r=0 \\
& C_{m}=C_{s} \ldots \ldots . . @ r=R_{p}
\end{aligned}
$$


where $C_{s}$ is the oxygen concentration at the particle surface, and $R_{p}$ is the particle radius. Solution of the macropore mass balance leads to an expression of the effectiveness factor for the macropores:

$$
\eta_{m}=\frac{\tanh \left(\phi_{m}\right)}{\phi_{m}}
$$

where the macropore Thiele moduli is defined by:

$$
\phi_{m}=\frac{R_{p}}{3} \sqrt{\frac{k_{o} \eta_{\mu}}{D_{e f f}}}
$$

In the macropores, the bulk diffusion coefficient was used for $\mathrm{D}_{\text {eff }}$ since the macropore radii are typically larger than $1000 \AA$ (Boissiere 1993). Finally, the overall effectiveness factor is determined as the product of the macro and micro effectiveness factors.

$$
\eta=\eta_{\mu} \cdot \eta_{m}
$$

\subsubsection{Transport properties}

To determine the heat and mass transfer coefficients found in equations 5 and 7, correlations for forced convection around a sphere were used (Bird, Stewart et al. 1960):

$$
\begin{aligned}
& \frac{h(2 R)}{k_{f}}=2.0+0.6 \operatorname{Re}^{1 / 2} \operatorname{Pr}^{1 / 3} \\
& \frac{k_{g}(2 R)}{D_{A B}}=2.0+0.6 \operatorname{Re}^{1 / 2} S c^{1 / 3}
\end{aligned}
$$


where Re, Pr, and Sc are the Reynolds, Prandtl, and Schmidt dimensionless numbers respectively, defined by:

$$
\begin{gathered}
\operatorname{Re}=\frac{(2 R) V_{\infty} \rho_{f}}{\mu_{f}} \\
\operatorname{Pr}=\frac{C_{p} \mu_{f}}{k_{f}} \\
S c=\frac{\mu_{f}}{\rho_{f} D_{A B}}
\end{gathered}
$$

where $\mathrm{R}$ is the particle radius and $\mathrm{v}_{\infty}$ is the gas flow velocity. $\mathrm{Cp}, \mu, \rho$, and $\mathrm{k}$ are the heat capacity, viscosity, density, and thermal conductivity of the fluid; and $\mathrm{D}_{\mathrm{AB}}$ is the binary diffusion coefficient. Pure component viscosity was calculated by a method proposed by Thodos and coworkers (Perry, Green et al. 1984). The mixture viscosity was then estimated by a series expression developed by Wilke (Perry, Green et al. 1984). Fluid heat capacity was determined as a function of temperature based on coefficients given by Felder and Rousseau (Felder and Rousseau 1978). Pure component thermal conductivity was calculated by averaging values obtained from the Eucken and modified Eucken correlation (Perry, Green et al. 1984). A similar series expression was used to calculate mixture thermal conductivity. The binary diffusion coefficient was estimated using the Fuller, Schettler, and Giddings relation (Perry, Green et al. 1984). Fluid density was determined by assuming ideal gas relations.

\subsubsection{Solid properties}

As mentioned earlier, consideration must be given to the dependence on conversion of solid properties such as particle size, surface area, and porosity. While many investigators make assumptions in determining these relationships, our experimental studies have been very useful 
in providing this information. Earlier sections of this report presented results on experiments designed to obtain information about the changes of particle diameter and surface area with conversion in both the kinetic control and diffusion limited regime. Since conditions that lead to particle ignitions are inherently in the diffusion limited regime, data on changes in normalized diameter from this regime were used.

To account for the variation in surface area with conversion, normalized reactivity data obtained previously for reacting chars in the kinetic control regime was used as input to the model. Kinetic control regime data was used since diffusion control is accounted for by the effectiveness factors. As mentioned in earlier sections, normalized reactivity plots describe the change in internal surface area with conversion with respect the value at $10 \%$ conversion. In general, this variation of surface area could be taken to describe the change in reactive or total surface area. This depends on what value is assigned to the surface area at $10 \%$ conversion. Since measurements of the reactive surface area were not made, we have chosen to normalize reactivity by the total surface area, similar to many other investigators. To estimate the surface area at $10 \%$ conversion from initial data, it was assumed that the internal surface area was consumed uniformly with conversion in this range.

We must also take into account the presence of ash material in the char particle. In this study, we focused on chars prepared from Illinois \#6 coal, which has a high ash content. Precursors of ash in char particles are clays and minerals such as quartz, pyrite, and calcite. As conversion proceeds, these minerals are oxidized to compounds such as $\mathrm{SiO}_{2}, \mathrm{CaO}_{2} \mathrm{Al}_{2} \mathrm{O}_{3}, \mathrm{Fe}_{2} \mathrm{O}_{3}$, and a small amount of $\mathrm{SO}_{3}$, which make up the majority of Illinois \#6 ash present at late conversions (Vorres 1989). In determining the particle density and heat capacity, contributions must come from both the char carbon and ash material. As conversion progresses, the contribution due to ash becomes more significant.

Correlations developed by Kirov (Kirov 1965), were used for char and ash heat capacity dependence on temperature. True Illinois \#6 char density has been measured by Ballal (Ballal 1985). From the measured ash content of the char measured and the density of the ash, we determined the contribution of the char carbon itself to the true density to be $1.8 \mathrm{~g} / \mathrm{cc}$. Estimation of the true mineral and ash density for Illinois \#6 chars is made by determining the densities of the major components listed in the previous paragraph. Since the estimated true density for Illinois \#6 char minerals $(3.18 \mathrm{~g} / \mathrm{cc})$ and ash $(3.32 \mathrm{~g} / \mathrm{cc})$ are similar, an average value 
was used $(3.25 \mathrm{~g} / \mathrm{cc})$ instead of taking into account the gradual conversion of mineral to ash during combustion. Ash fusion at high temperatures was not taken into account in the current model.

\subsection{Comparison with Experimental Results}

To compare the model results with experimental data on char ignitions, it would be useful to have a definition of ignition that applies to the model results. Ignitions occur when the particle undergoes a transition from an unignited state to an ignited state. This transition is detected by sharp changes in particle temperature with time.

In the experimental case, ignitions were defined as visible emissions of light, or peaks in the reactivity data. These two phenomena resulted from particles reacting at temperatures much higher than the ambient. Unfortunately, our current experimental set-up does not allow for measurements of particle temperature. Furthermore, our reactivity measurements represent average reactivities for multiple particles while model results yield single particle reactivity. Choosing a model criterion for ignition which we could relate to experimental results, such as a minimum reactivity or temperature, would therefore be somewhat arbitrary.

Instead of choosing an arbitrary threshold for ignition, we will present data on maximum particle temperatures. Since maximum particle temperatures are achieved during ignition, maximum particle temperature data should provide information about the relative frequency of ignition at various conditions.

Boissiere (Boissiere 1993) measured the particle size, macroporosity, and macropore surface areas of chars prepared from 28-32 mesh Illinois \#6 coals under various pyrolysis conditions. Pyrolysis conditions such as heat treatment temperature, soak time, and gas composition, were identical to those utilized here. Macropore surface areas measured by Boissiere and Zygourakis (Boissiere 1993; Zygourakis 1993) utilized digital image processing techniques on char particle cross sections. Pyrolyzed char particles were embedded in an epoxy resin and cross sections were polished and exposed. The cross sections were imaged with a polarizing microscope. Due to the limi to traditional macropore values. It is expected that true macropore surface areas are larger than 
these values. In Table 7.1, we again present the measurements of Boissiere (Boissiere 1993) obtained at different pyrolysis heating rates:

Table 7.1

Structural data for 28-32 mesh Illinois \#6 chars

\begin{tabular}{|c|c|c|c|}
\hline $\begin{array}{c}\text { Heating Rate } \\
\left({ }^{\circ} \mathbf{C} / \mathbf{s e c}\right)\end{array}$ & $\begin{array}{c}\text { Radius } \\
(\mathbf{m m})\end{array}$ & Macroporosity & $\begin{array}{c}\text { Macropore SA } \\
\left(\mathbf{c m}^{2} / \mathbf{c m}^{\mathbf{3}}\right)\end{array}$ \\
\hline 0.1 & 0.317 & $0.592 \pm 0.030$ & $865 \pm 73$ \\
\hline 1.0 & 0.325 & $0.595 \pm 0.025$ & $1244 \pm 98$ \\
\hline 10.0 & 0.407 & $0.648 \pm 0.025$ & $1040 \pm 85$ \\
\hline
\end{tabular}

From this data, we were able to make direct relations between pyrolysis conditions and model parameters involving these char structural properties. Figure 7.1 shows the model results when the parameters listed in Table 7.1 were used for a combustion run at $550{ }^{\circ} \mathrm{C}$ in $33 \%$ oxygen. From the plot of particle temperature versus conversion we see that chars prepared at 1.0 and $10.0{ }^{\circ} \mathrm{C} / \mathrm{sec}$ exhibit the highest particle temperatures. Since higher particle temperatures lead to higher reactivities, these chars are more reactive. Confirmation of this is given in Figure 7.2, which shows the associated reactivity plot for this run. At $550{ }^{\circ} \mathrm{C}$, the model predicts a peak in reactivity for chars prepared at $1.0{ }^{\circ} \mathrm{C} / \mathrm{sec}$. This is in direct agreement with the experimental results at heating rates below $20{ }^{\circ} \mathrm{C} / \mathrm{sec}$.

In earlier sections, we presented results showing that chars with larger macropore surface areas exhibit higher reactivity in the diffusion control regime. From the data of Table 7.1, we see that chars prepared at $1.0{ }^{\circ} \mathrm{C} / \mathrm{sec}$ exhibited the highest macropore surface areas. Although chars prepared at $10.0{ }^{\circ} \mathrm{C} / \mathrm{sec}$ are larger, the increase in macropore surface area accounts for the observed and predicted increases in reactivity.

It should be noted that since the model results are for individual particles, peaks in reactivity appear much higher than experimental values. This is because experimental reactivities are averages of all particles present. Thus, if four particles are reacting at a rate of $0.25 \mathrm{~min}^{-1}$, and the fifth is igniting with a reactivity rate of $4.0 \mathrm{~min}^{-1}$, the overall reactivity is only $1.0 \mathrm{~min}^{-1}$. Due 
to the limitations of the TGA/VMI microbalance, it was not possible to accurately determine individual particle reactivities experimentally.

The same parameters were used to run the model for combustion at $750^{\circ} \mathrm{C}$ in $33 \%$ oxygen. The particle temperature and reactivity plots are shown in Figures 7.3 and 7.4 respectively. The same trends in reactivity are observed at $750{ }^{\circ} \mathrm{C}$ as those predicted at $550{ }^{\circ} \mathrm{C}$. At $750{ }^{\circ} \mathrm{C}$, diffusional limitations become more extreme. Therefore, the effect of macropore surface area becomes more important since higher macropore surface areas reduce the effects of diffusional limitations. For this reason, it is not surprising that the model predicts the same trends in reactivity at $750{ }^{\circ} \mathrm{C}$.

Experimentally observed differences in reactivity for these heating rates were almost indistinguishable at $750{ }^{\circ} \mathrm{C}$. This supports a contention that the diffusional limitations were underestimated by the model. However, it is not reasonable to suggest that all char particles exhibit the exact structural properties given by Table 7.1. At this point, we have not considered the standard deviations given in Table 7.1. These standard deviations will be considered in the next section.

As discussed in the beginning of this section, very sharp increases in particle temperature are attributed to the transition from the unignited to the ignited state. In Figure 7.5, one of the particle temperatures obtained in Figure 7.3 is plotted versus time. The sharp increase in particle temperature is evidence of the transition to the ignited branch of the solution structure.

It is important to note that the transition, or ignition, often occurs after significant conversion is achieved. Initially, the conditions are such that the particle reacts in the unignited state. As conversion progresses, however, the properties of the char change. Thus, the solution structure is modified until the particle must react in the ignited state.

\subsection{References for Section 7}

Arthur, J. R. (1951). "Reactions between Carbon and Oxygen." Trans. Faraday Society 47: 164178.

Ballal, G. D. (1985). "A study of char gasification reactions," Ph.D. Thesis, Rice University. 
Bird, R. B., W. E. Stewart, et al. (1960). Transport Phenomena. New York, John Wiley and Sons.

Boissiere, F. (1993). "Influence of pyrolysis conditions on the macropore structure of char particles," M.S. Thesis, Rice University.

Felder, R. M. and R. W. Rousseau (1978). Elementary Principles of Chemical Processes. New York, John Wiley and Sons.

Froment, G. F. and K. B. Bischoff (1979). Chemical Reactor Analysis and Design. New York, John Wiley and Sons.

Kirov, N. Y. (1965). "Specific heats and total heat contents of coals and related materials at elevated temperatures.” Br. Coal Util. Res. Assoc. Mon. Bull. 29: 33-57.

Mingle, J. O. and J. M. Smith (1961). "Effectiveness factors for porous catalysts." AIChE J. 7(2): 243-249.

Perry, R. H., D. W. Green, et al. (1984). Perry's Chemical Engineers' Handbook. New York, McGraw-Hill.

Sotirchos, S. V. and N. R. Amundson (1984a). "Diffusion and reaction in a char particle and in the surrounding gas phase. A continuous model." Ind. Eng. Chem. Fundam. 23(2): 191-201.

Sotirchos, S. V. and N. R. Amundson (1984b). "Diffusion and reaction in a char particle and in the surrounding gas phase. Two limiting models." Ind. Eng. Chem. Fundam. 23(2): 180-91.

Sotirchos, S. V. and N. R. Amundson (1984c). "Dynamic behavior of a porous char particle burning in an oxygen-containing environment. Part I: Constant particle radius." AIChE J. 30(4): 537-549.

Sotirchos, S. V. and N. R. Amundson (1984d). "Dynamic behavior of a porous char particle burning in an oxygen-containing environment. Part II: Transient analysis of a shrinking particle." AIChE J. 30(4): 549-556.

Sotirchos, S. V. and V. N. Burganos (1986). "Intraparticle diffusion and char combustion." Chem. Eng. Sci. 41(6): 1599-1609.

Sotirchos, S. V., B. Srinivas, et al. (1984). "Modeling of the combustion of single char particles." Rev. Chem. Eng. 2(3-4): 175-236.

Vorres, K. S. (1989). Users handbook for the Argonne premium coal program, Argonne National Laboratory.

Zygourakis, K. (1993). "Effect of pyrolysis conditions on the macropore structure of coalderived chars." Energy \& Fuels 7(1): 33-41. 


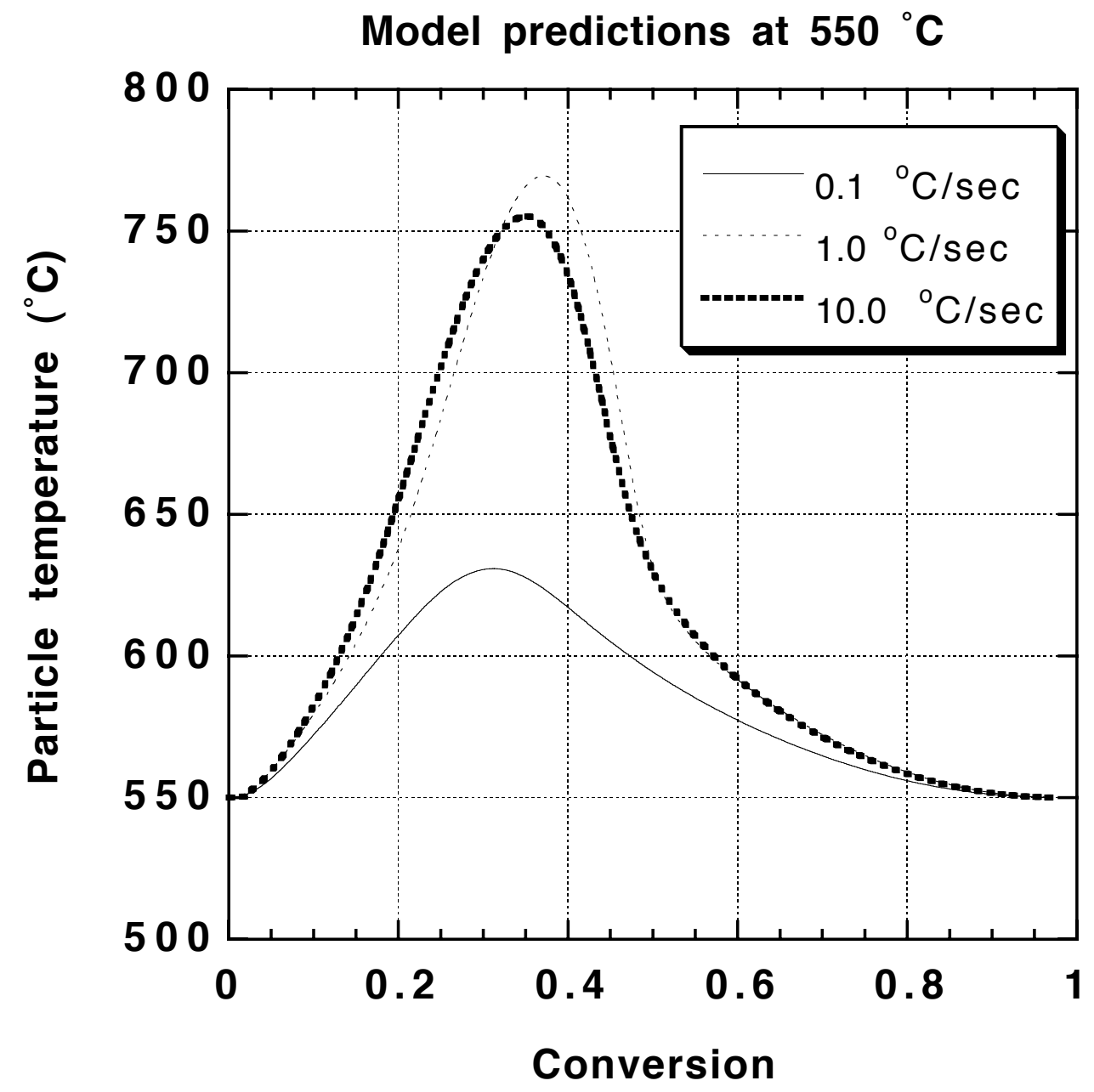

Figure 7.1: Model predictions of particle temperature versus conversion for chars with structural properties from Table 1 combusted at $750{ }^{\circ} \mathrm{C}$ and $33 \% \mathrm{O}_{2}$. 


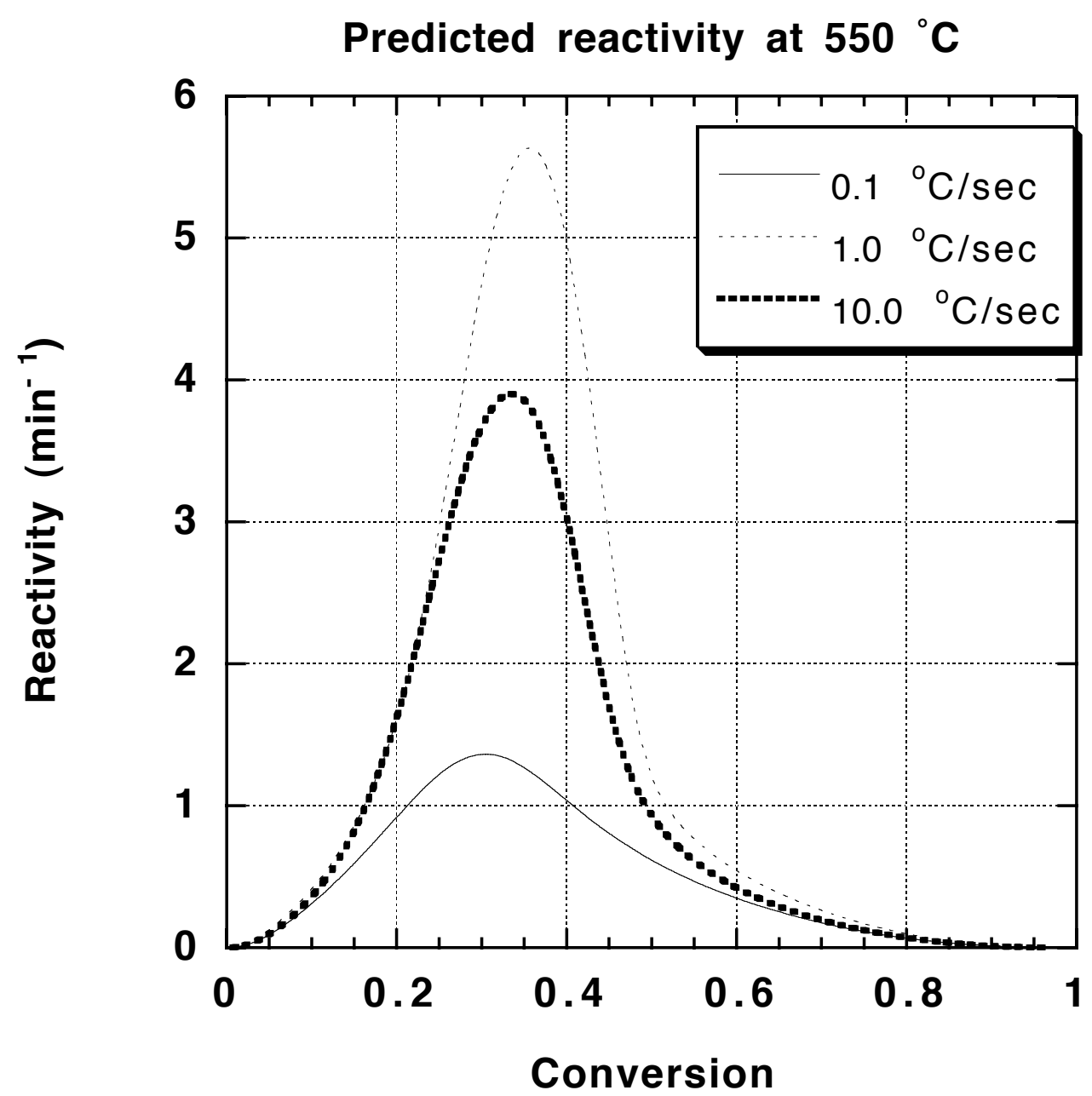

Figure 7.2: $\quad$ Model predictions of reactivity of individual chars with structural properties from Table 1 combusted at $550{ }^{\circ} \mathrm{C}$ and $33 \% \mathrm{O}_{2}$. 


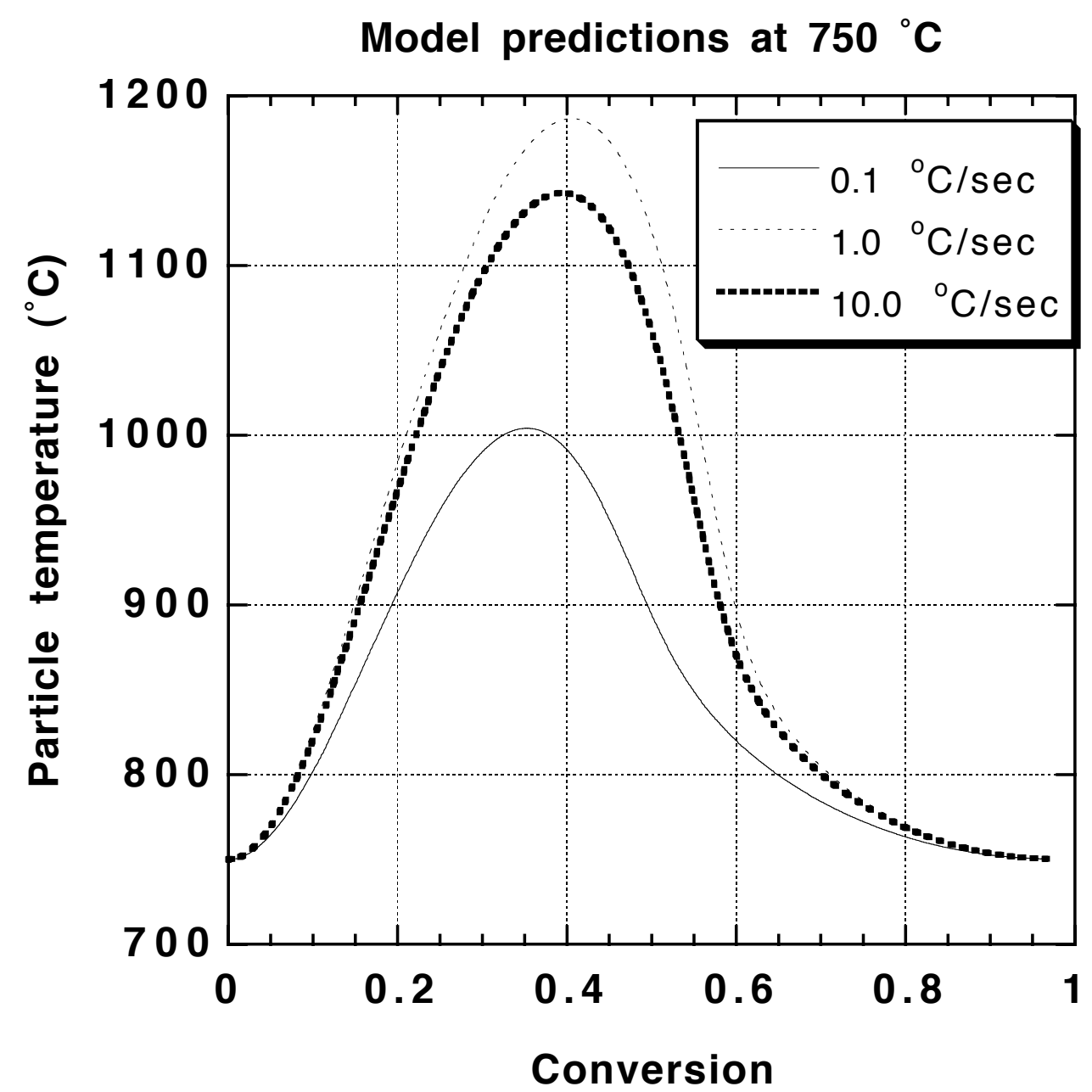

Figure 7.3: Model predictions of particle temperature versus conversion for chars with structural properties from Table 1 combusted at $750{ }^{\circ} \mathrm{C}$ and $33 \% \mathrm{O}_{2}$. 


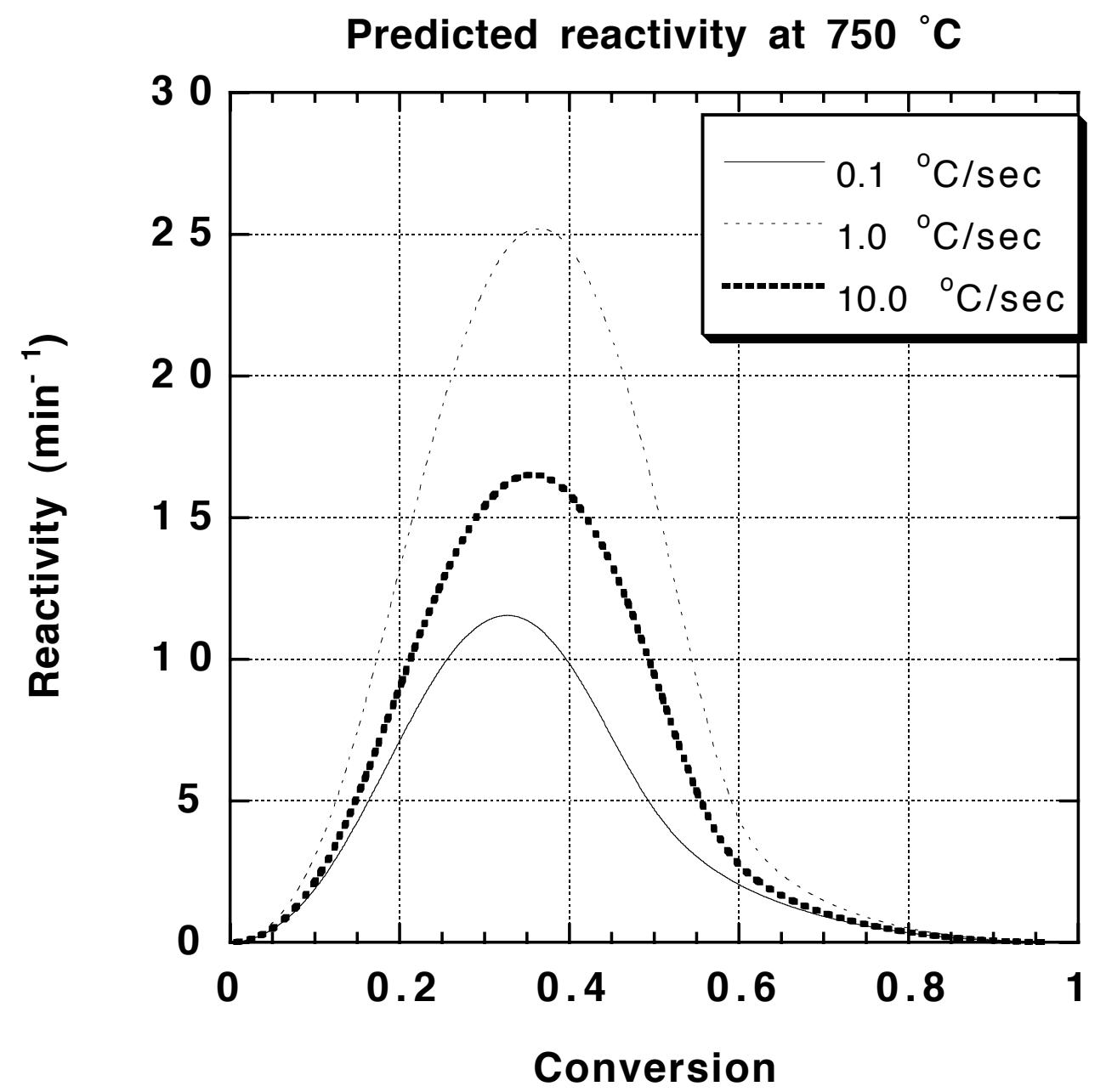

Figure 7.4: Model predictions of reactivity of individual chars with structural properties from Table 1 combusted at $750{ }^{\circ} \mathrm{C}$ and $33 \% \mathrm{O}_{2}$. 


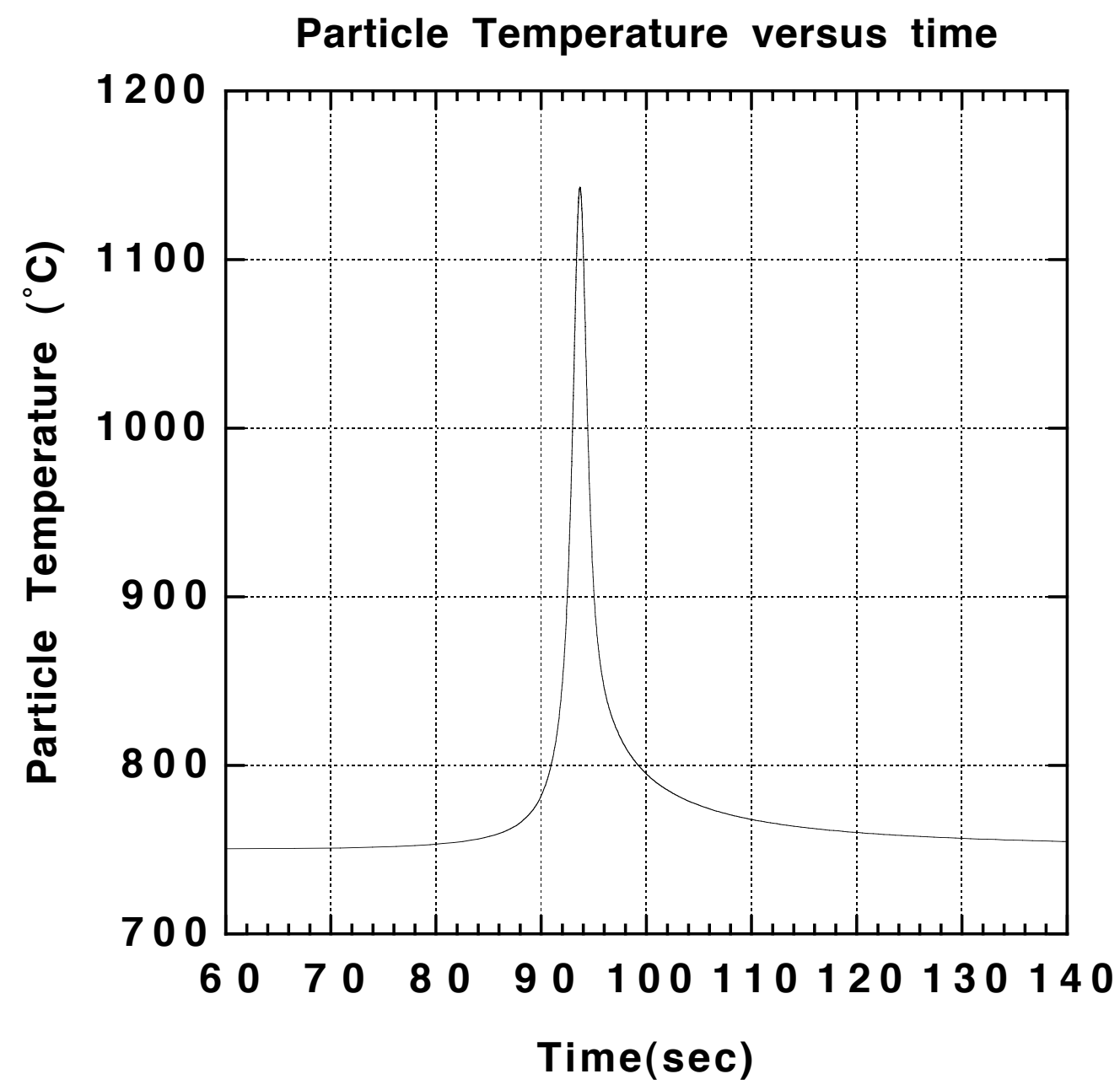

Figure 7.5: Plot of particle temperature versus time for char prepared at $10.0{ }^{\circ} \mathrm{C} / \mathrm{sec}$ and combusted at $750{ }^{\circ} \mathrm{C}$ and $33 \% \mathrm{O}_{2}$. 


\section{SECTION 8}

\section{EFFECT OF REACTION CONDITIONS AND PORE STRUCTURAL PARAMETERS ON CHAR PARTICLE IGNITIONS}

\subsection{Introduction}

This section presents a systematic analysis of the ability of our ignition model to predict the trends identified by our experimental combustion studies. Using the pore structure data obtained in our laboratory, we carry out a systematic parametric study that investigates how particle ignitions are affected by combustion temperature, oxygen concentration, micropore size, pore surface area, pore volume and particle size. The effects of ambient gas velocity and particle ash content are also investigated. Finally, we carry out several experiments to determine how random variations of structural properties might affect the reactivity of small ensembles of particles. The presented results clearly demonstrate that the transient combustion model captures the essential features of the ignition process.

\subsection{Parametric Study}

To thoroughly determine the effects of model parameters, a parametric study was conducted. In this study, base values were chosen for each model parameter. To study the effects of a certain parameter, all other parameters were kept at their base value while the parameter of interest took values in a specified range. Any possible correlations among the parameters in this study were ignored in order to isolate the effect of each parameter. However, correlations between the 
particle radius, porosity, and macropore surface area are very important. The sensitivity of the model to individual parameters may change when correlations are taken into account. Tables 8.1 and 8.2 summarize our pore structural measurements for Illinois \#6 chars and the parameter choices respectively.

Table 8.1

Structural data for 28-32 mesh Illinois \#6 chars

\begin{tabular}{|c|c|c|c|}
\hline $\begin{array}{c}\text { Heating Rate } \\
\left({ }^{\circ} \mathbf{C} / \mathbf{s e c}\right)\end{array}$ & $\begin{array}{c}\text { Radius } \\
(\mathbf{m m})\end{array}$ & Macroporosity & $\begin{array}{c}\text { Macropore SA } \\
\left(\mathbf{c m}^{\mathbf{2}} / \mathbf{c m}^{\mathbf{3}}\right)\end{array}$ \\
\hline 0.1 & 0.317 & $0.592 \pm 0.030$ & $865 \pm 73$ \\
\hline 1.0 & 0.325 & $0.595 \pm 0.025$ & $1244 \pm 98$ \\
\hline 10.0 & 0.407 & $0.648 \pm 0.025$ & $1040 \pm 85$ \\
\hline
\end{tabular}

Table 8.2

Base and range values for the parametric study.

\begin{tabular}{|l|l|l|}
\hline Parameter & Base Value & Range \\
\hline Combustion Temperature $\left({ }^{\circ} \mathrm{C}\right)$ & 550 & $450-750$ \\
\hline Oxygen composition & $33 \%$ & $21-50 \%$ \\
\hline Total Surface Area $\left(\mathrm{m}^{2} / \mathrm{g}\right)$ & 530.8 & $200-1000$ \\
\hline Macropore S.A. $\left(\mathrm{cm}^{2} / \mathrm{cm}^{3}\right)$ & 1200 & $700-2900$ \\
\hline Porosity & 0.6 & $0.5-0.7$ \\
\hline Particle radius $(\mathrm{mm})$ & 0.325 & $0.16-0.48$ \\
\hline Micropore diameter $(\AA)$ & 5.0 & $4.0-6.0$ \\
\hline Gas velocity $(\mathrm{cm} / \mathrm{sec})$ & 1.0 & $0.0-10.0 \mathrm{~cm} / \mathrm{sec}$ \\
\hline Ash content & $17 \%$ & $5-45 \%$ \\
\hline
\end{tabular}


With the exception of micropore radius, all base values for parameters describing physical properties of the coal were chosen based on measurements made in our laboratory. Illinois \#6 char surface area was measured by Ballal using $\mathrm{CO}_{2}$ adsorption (Ballal 1985). The char particle radii, porosity, and macropore surface areas were measured by Boissiere and Zygourakis (Boissiere 1993; Zygourakis 1993). Since the macropores account for nearly all the internal porosity, we assumed that the measured values of macroporosity also correspond to total porosity. The chosen values for particle radii roughly correspond to values for chars prepared from (50-60), (28-32), and (20-24) mesh sized Illinois \#6 coals. The gas velocity present in the TGA/VMI reactor was estimated to be approximately $1.0 \mathrm{~cm} / \mathrm{sec}$. The range of values chosen for the char ash content correspond to measurements from combustion experiments.

\subsubsection{Combustion temperature}

Figure 8.1 shows the effects of varying the combustion temperature on the ignition behavior of char particles. When chars having the base structural properties listed in Table 8.2 were combusted at $450{ }^{\circ} \mathrm{C}$ in $33 \%$ oxygen, particle temperatures were approximately equal to the ambient. As the temperature was raised, the particles began to react at temperatures well above the ambient. As discussed previously, we decided not to define an arbitrary threshold for ignition to interpret the model results. Thus, we will discuss only the maximum particle temperatures, which should exhibit very similar trends to particle ignitions.

\subsubsection{Oxygen composition}

The effects of oxygen concentration are presented in Figure 8.2. As expected, particle temperatures were increased at higher oxygen concentrations. For the base conditions chosen in this study, chars combusted at $550{ }^{\circ} \mathrm{C}$ in $21 \%$ oxygen reacted at temperatures only slightly higher than the ambient. At higher oxygen concentrations, char particles reached higher temperatures. These higher particle temperatures are directly associated with higher reactivities. At 50\% oxygen, particle temperatures greatly exceeded the ambient.

\subsubsection{Total surface area}

Chars with higher surface areas increase the accessibility of oxygen to reactive sites. Thus chars with higher surface areas exhibit increased reaction rates and these reactions generate more 
heat. This is supported by Figure 8.3, showing the effects of increasing surface area on char particle ignitions. Particle temperatures were greatly increased in chars with higher surface areas.

\subsubsection{Macropore surface area}

In the regime of diffusion limitations, macropores act as major pathways allowing oxygen to reach the micropore surface area. Thus, we expect that chars with higher macropore surface area will exhibit higher reactivity and will ignite more often. Figure 8.4 confirms this effect, showing that chars with higher macropore surface areas exhibited much larger increases in particle temperature.

\subsubsection{Porosity}

Figure 8.5 indicates that higher porosity leads to less reactive chars. In a sense, this result is intuitive since more porous char particles have smaller solid volumes to accommodate internal reaction and heat generation. However, this result is quite misleading. Pyrolysis conditions which lead to highly porous chars also lead to increased particle radii and higher macropore surface areas. Since we have neglected correlations among the model parameters, the effects of particle radius and macropore surface area have been ignored.

\subsubsection{Particle radius}

As discussed previously, increasing particle size is expected to favor ignitions because of the trade off between heat generation inside the particle and heat removal from the surface. For spherical particles, the volume of the particle is proportional to $\mathrm{R}^{3}$ while the external surface area is proportional to $\mathrm{R}^{2}$. Thus, increasing the particle radius leads to more volume for heat generation with a smaller increase in heat transfer capacity. Figure 8.6 agrees with this prediction by showing that larger particles reached much higher temperatures. Just as before, we have neglected the associated effects of porosity and macropore surface area. Nonetheless, the purpose of this parametric study is to isolate the effects of individual parameters.

\subsubsection{Micropore diameter}

The size of the micropores of a char particle are instrumental in determining the degree of diffusional limitations encountered. This dependence is reflected in equation (7.12) of the 
transient model, which shows that the micropore Thiele modulus is inversely proportional to the micropore diameter. Since increasing Thiele moduli lead to greater diffusional limitations, smaller micropore diameters should have the same effect. Figure 8.7 shows this behavior for three different micropore diameters. The char with the largest micropore diameter was most accessible to oxygen and therefore exhibited the highest particle temperature.

\subsubsection{Gas velocity}

The velocity of the gas flowing past a reacting char particle certainly plays a key role in the removal of heat from the particle. Increased air velocities lead to greater heat removal rates and thus should lead to lower particle temperatures. This behavior is shown in Figure 8.8, which shows that ignition was most favored by lower gas velocities.

\subsubsection{Ash content}

The effect of char ash content on ignition can be very complicated. In the present model, we have not accounted for any catalytic effects of ash in enhancing the rates of chemical reactions. Another effect of the presence of ash in char is a modification of the physical properties such as heat capacity and density. Illinois \#6 ash has a much higher density and heat capacity than char. In addition, the difference in heat capacity is increased at higher temperatures. Also, since ash is inorganic in nature, including ash at the expense of reactive char should result in a decrease in char reactivity.

Figure 8.9 shows that the maximum particle temperature was achieved at an intermediate ash content of $18 \%$ before decreasing for higher ash contents. Initial increases in char reactivity with increasing ash content are likely due to the effect of heat capacity. Chars with higher heat capacity due to their higher ash content can achieve higher particle temperatures. This effect is eventually overtaken at very high ash contents where the reactivity decreases due to the large amounts of inert ash.

\subsection{Random Variation of Char Properties}

As mentioned earlier, we do not propose that all chars produced at the specified heating 
rates exhibit the exact structural properties of Table 8.1. Due to the heterogeneous nature of coal, we expect deviations from these values. For this reason, we have assumed that at each pyrolysis heating rate, the structural properties of the char varied according to a standard normal probability distribution. The mean of each distribution was taken to be the values in Table 8.1. Standard deviations in particle radius, macropore surface area, and porosity given in Table 8.1 were used for the distributions. For other model parameters, we assumed a standard deviation equal to $3 \%$ of the mean value in each case. In the case of ash content, we do have experimental data. Thus, the average ash content (17.8\%) and standard deviation (9.74\%) calculated from experimental results were used for the distribution.

To select the model parameters for a given run, multiple sets of pseudo random numbers were generated from the given probability distribution for each parameter. The data was set up to run the model 30 times, with char structural properties varying for each run. Average reactivities for each run were calculated by the same procedure used on experimental data. Calculating average reactivities for multiple model runs on individual particles effectively averages individual particle reactivities similar to what occurs in obtaining experimental reactivity.

It is important to note that in this analysis we have not necessarily preserved the correlations between char structural parameters. Although the correlations are preserved for the mean values in the distributions for each parameter, choosing random values from these distributions ignores any possible correlations.

In Figure 8.10, the average reactivity data from the model runs and from experiments are presented for the 3 heating rates. As discussed earlier, for heating rates below $20{ }^{\circ} \mathrm{C} / \mathrm{sec}$, chars prepared at $1.0{ }^{\circ} \mathrm{C} / \mathrm{sec}$ exhibited the highest reactivity when combusted at $550{ }^{\circ} \mathrm{C}$. The random model results agree quite well with the experimental findings. Just as in the experimental results, the peak in reactivity is observed for chars prepared at $1.0{ }^{\circ} \mathrm{C} / \mathrm{sec}$. However, considering the standard deviations of Table 8.1 leads to large differences in reactivity, as observed by the standard deviations of Figure 8.10.

Figures $11 \mathrm{a}$ and $11 \mathrm{~b}$ compare the number of experimentally detected ignitions with the average maximum achieved particle temperatures for combustion at $550{ }^{\circ} \mathrm{C}$. Since we do not have experimental data on ignited particle temperatures, interpretation of the model results is limited to evaluating the predicted trends in particle ignitions rather than determining the actual number of particles which ignited. The model predicts little difference in average maximum 
particle temperatures for chars prepared at 1.0 and $10.0{ }^{\circ} \mathrm{C} / \mathrm{sec}$.

Figures $12 \mathrm{a}$ and $12 \mathrm{~b}$ compare the number of experimentally detected ignitions with the average maximum achieved particle temperatures for combustion at $750{ }^{\circ} \mathrm{C}$. Again, trends between model and experiment are in agreement. As discussed in earlier sections, ignition detection at $750{ }^{\circ} \mathrm{C}$ is much more difficult. The actual number of particle ignitions may be incorrect due to the inefficiency in detecting faint ignitions at $750{ }^{\circ} \mathrm{C}$, but the trends should be preserved.

Figure 8.13 compares the average reactivity versus heating rate for model and experiment at a combustion temperature of $750{ }^{\circ} \mathrm{C}$. The model results basically show the same trends observed at $550{ }^{\circ} \mathrm{C}$. Chars prepared at $1.0{ }^{\circ} \mathrm{C} / \mathrm{sec}$ again exhibit the highest reactivity. The model again predicts large variations in reactivity when allowing the initial char structural properties to vary randomly. Inclusion of these variations in the model leads to more similar reactivities for chars prepared at 1.0 and $10.0{ }^{\circ} \mathrm{C} / \mathrm{sec}$.

\subsubsection{Extrapolation of results to higher heating rates}

Unfortunately, structural data is not available for 28-32 mesh Illinois \#6 chars prepared at heating rates above $10{ }^{\circ} \mathrm{C} / \mathrm{sec}$. However, based on what we have learned about the effects of various parameters and the trends observed below $20{ }^{\circ} \mathrm{C} / \mathrm{sec}$, we can make an educated attempt to explain the high reactivity of chars prepared at higher heating rates. Chars prepared at heating rates approaching $1000{ }^{\circ} \mathrm{C} / \mathrm{sec}$ are expected to have much larger macropore surface areas. This is confirmed by our earlier measurements (Boissiere 1993; Zygourakis 1993), who measured the structural properties of chars prepared at heating rates approaching $1000{ }^{\circ} \mathrm{C} / \mathrm{sec}$.

\subsection{References for Section 8}

Ballal, G. D. (1985). "A study of char gasification reactions," Ph.D. Thesis, Rice University.

Boissiere, F. (1993). "Influence of pyrolysis conditions on the macropore structure of char particles," M.S. Thesis, Rice University. 
Zygourakis, K. (1993). "Effect of pyrolysis conditions on the macropore structure of coalderived chars." Energy \& Fuels 7(1): 33-41. 


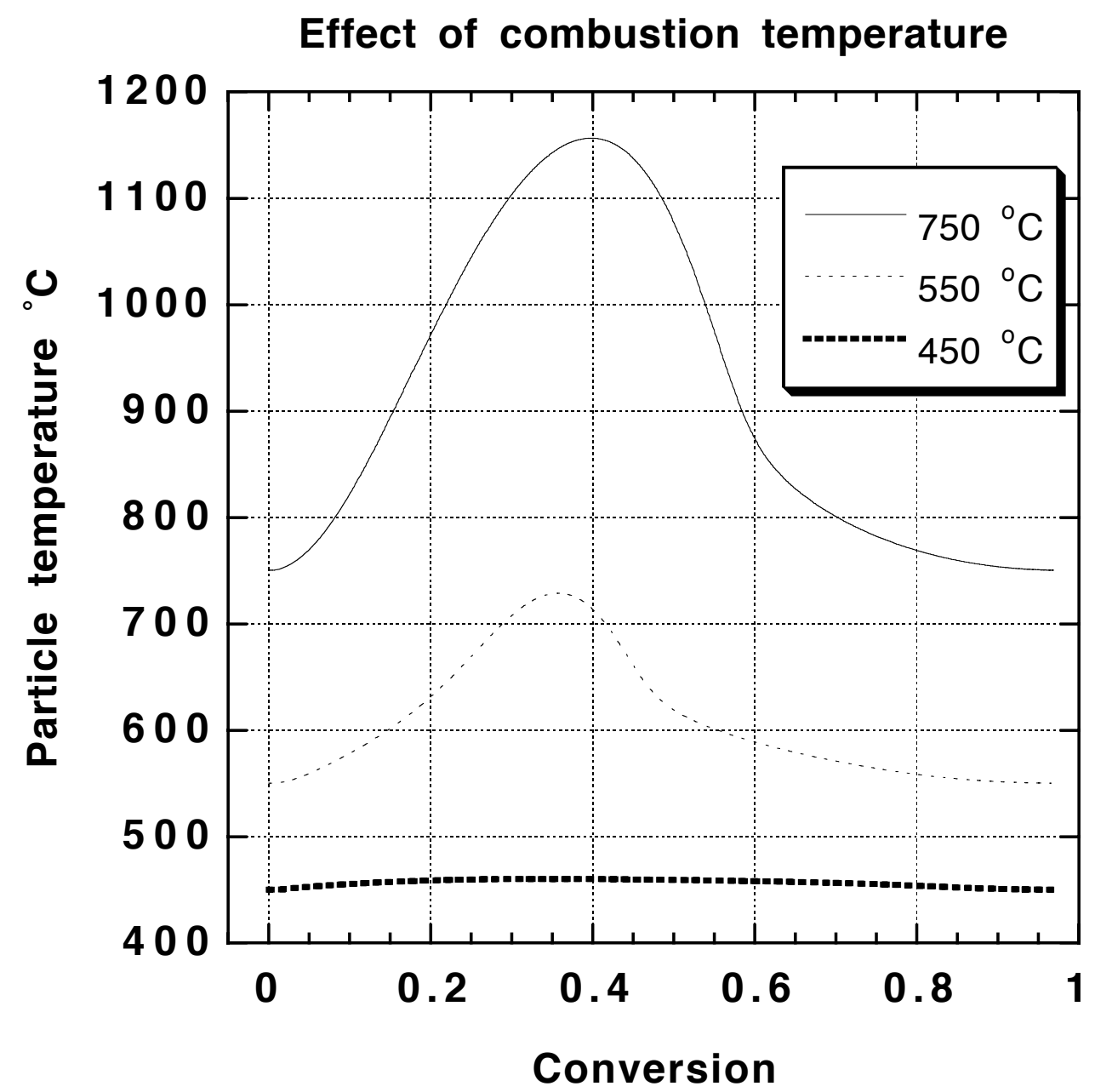

Figure 8.1: Effects of combustion temperature on char ignition behavior for an oxygen concentration of $33 \%$. 


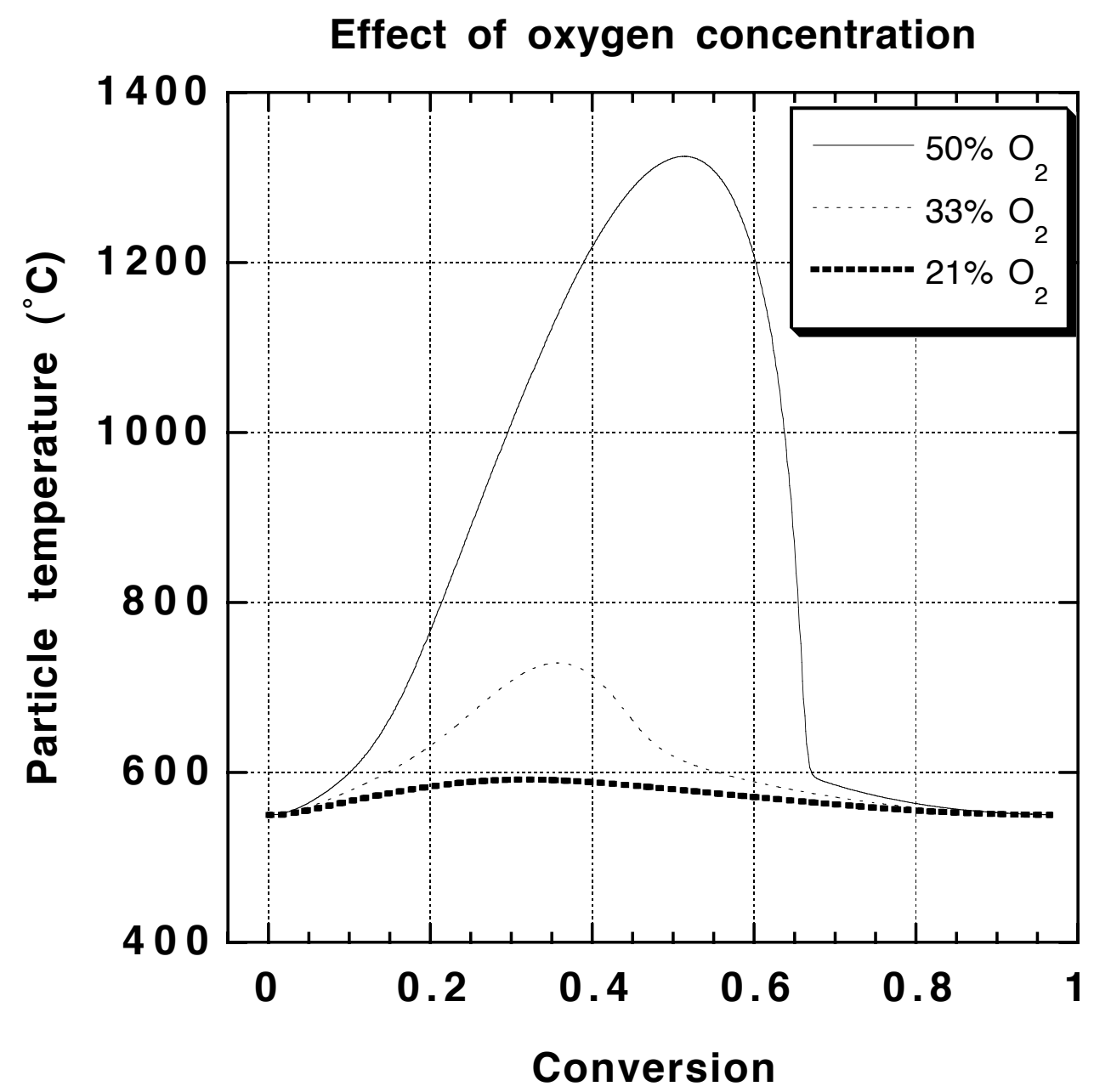

Figure 8.2: Effects of oxygen concentration on char ignition behavior for a combustion temperature of $550{ }^{\circ} \mathrm{C}$. 


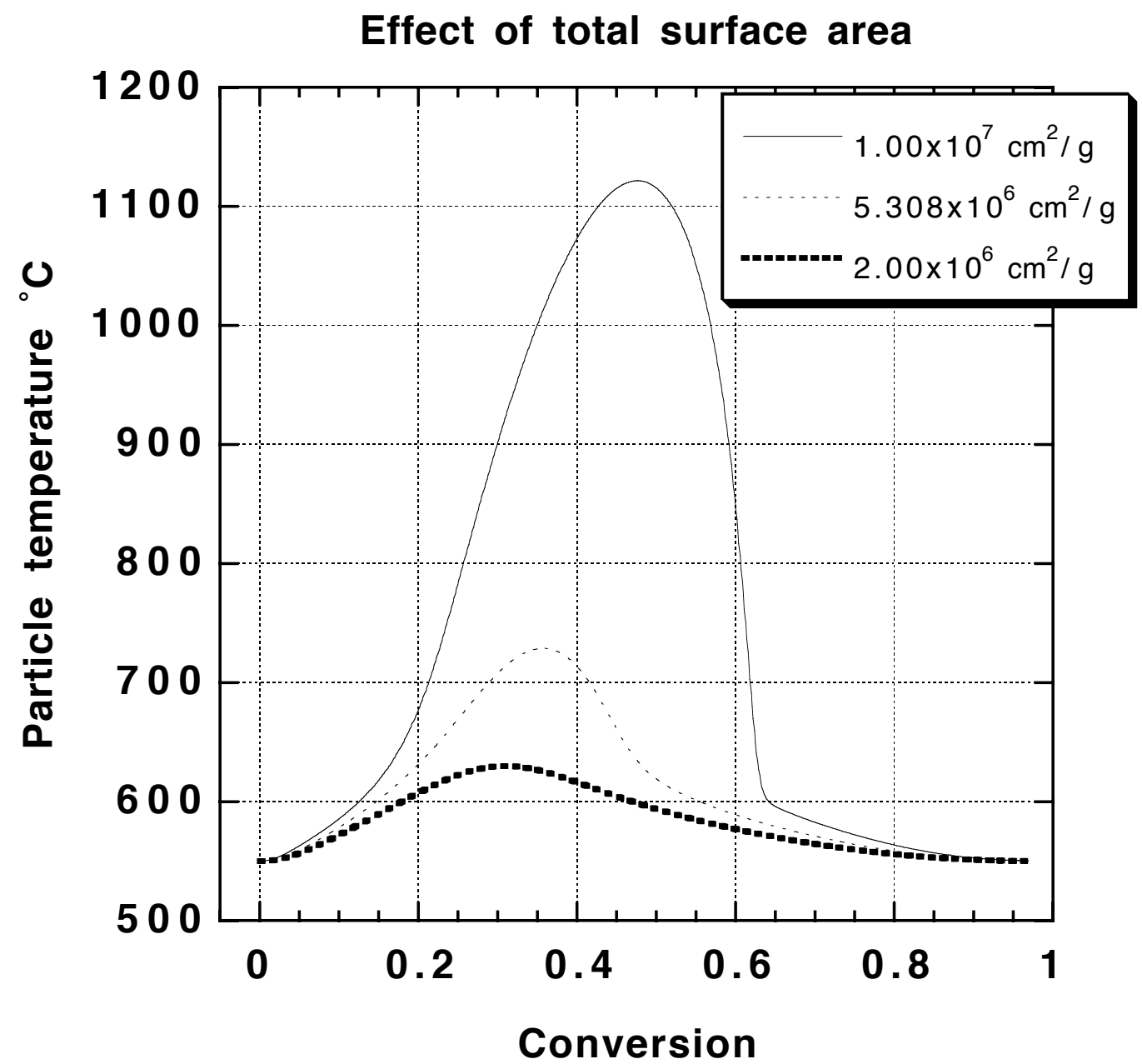

Figure 8.3: Effects of total surface area on char ignition behavior at $550{ }^{\circ} \mathrm{C}$ in $33 \% \mathrm{O}_{2}$. 


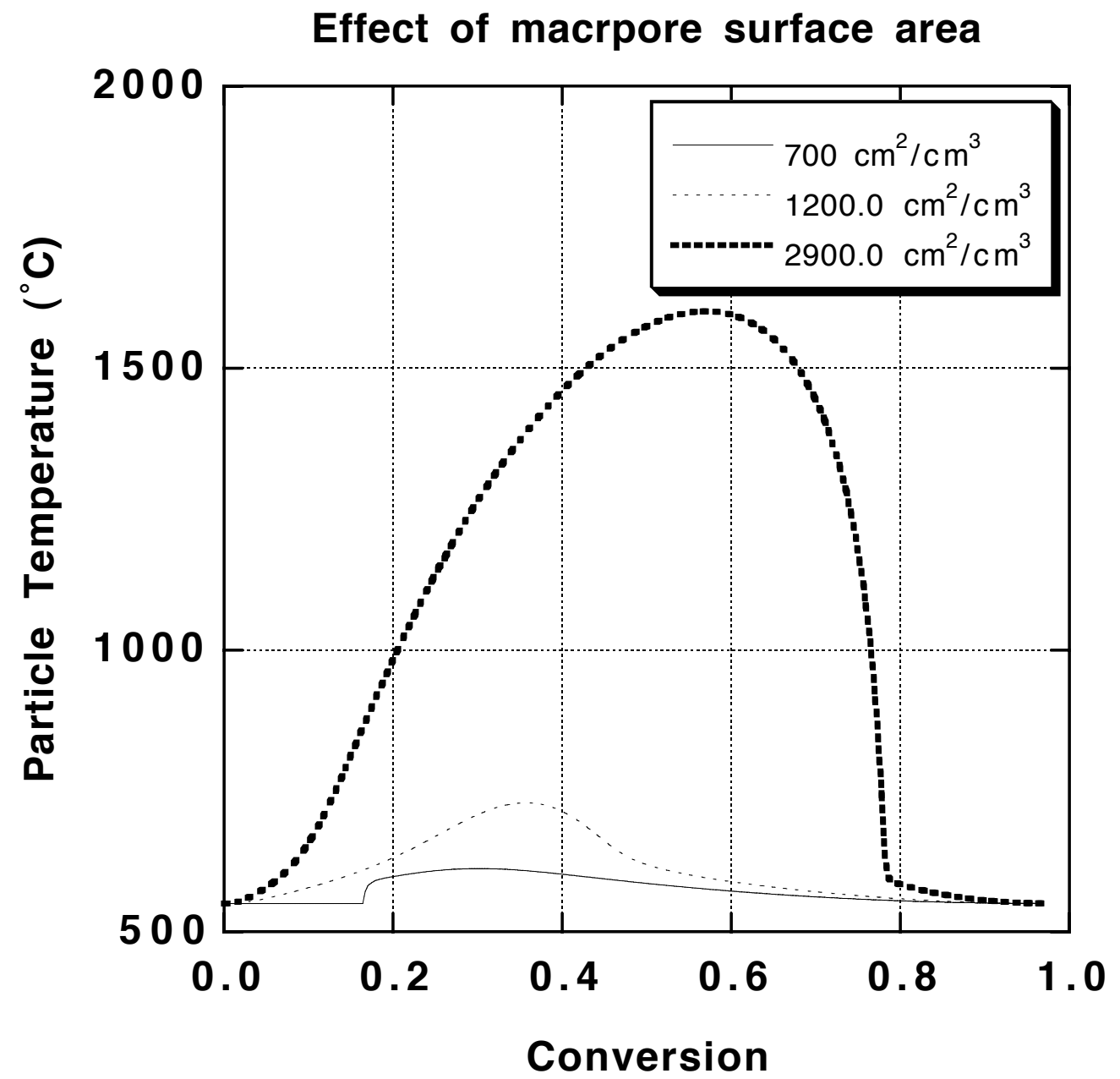

Figure 8.4: $\quad$ Effects of macropore surface area on char ignition behavior at $550{ }^{\circ} \mathrm{C}$ in $33 \% \mathrm{O}_{2}$. 


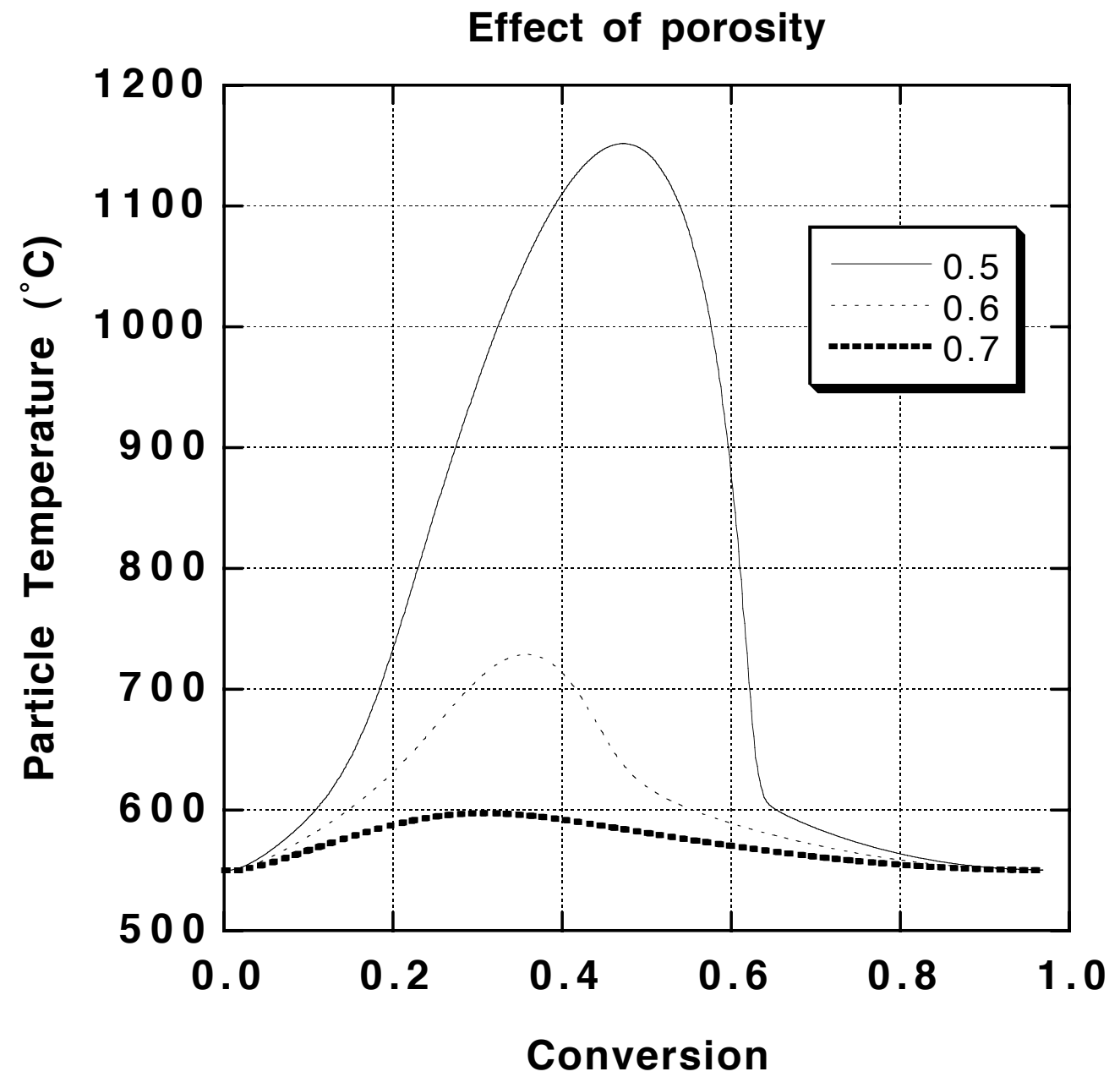

Figure 8.5: Effects of porosity on char ignition behavior at $550{ }^{\circ} \mathrm{C}$ in $33 \% \mathrm{O}_{2}$. 


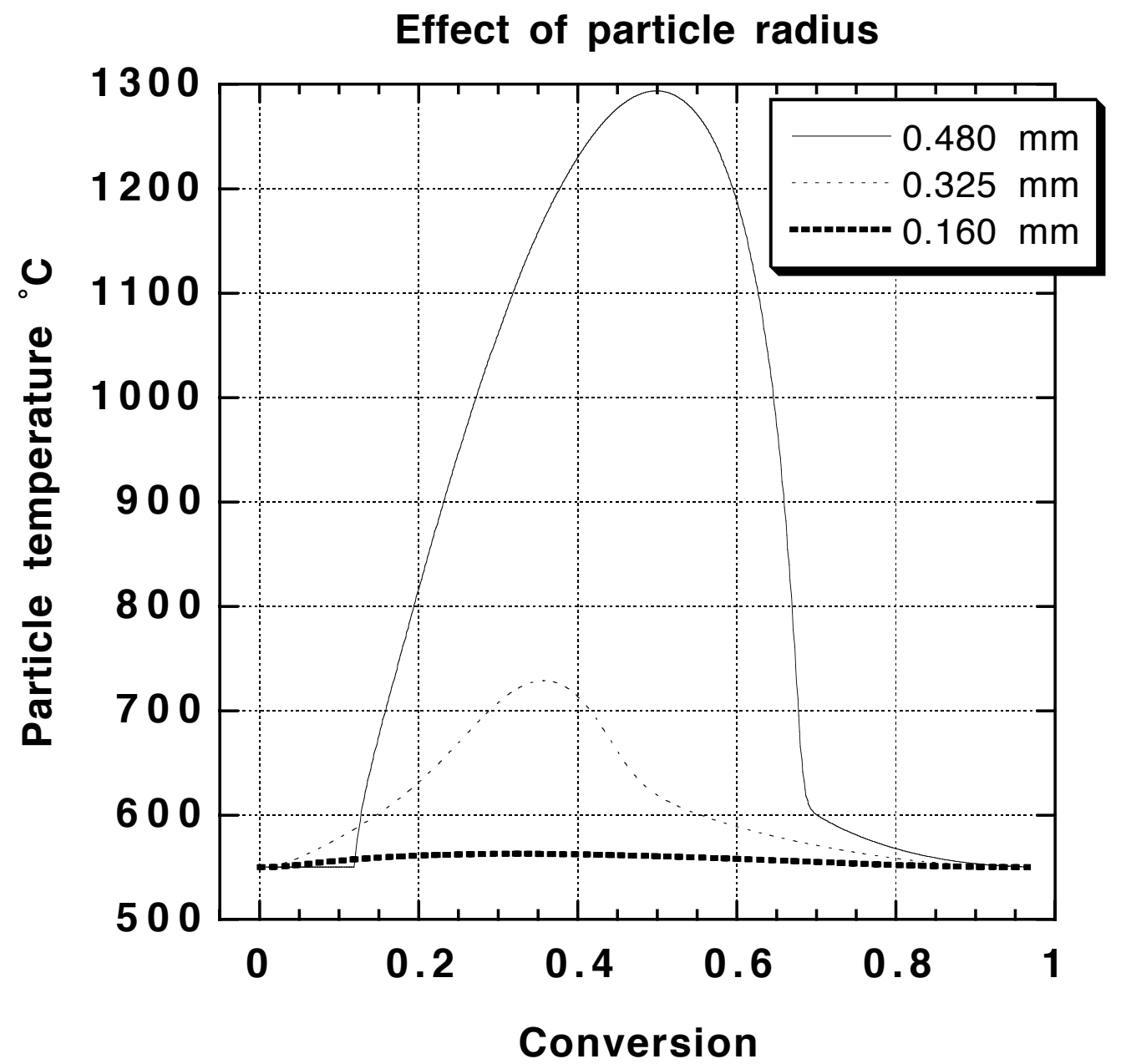

Figure 8.6: Effects of char particle radius on char ignition behavior at $550{ }^{\circ} \mathrm{C}$ in $33 \% \mathrm{O}_{2}$. 


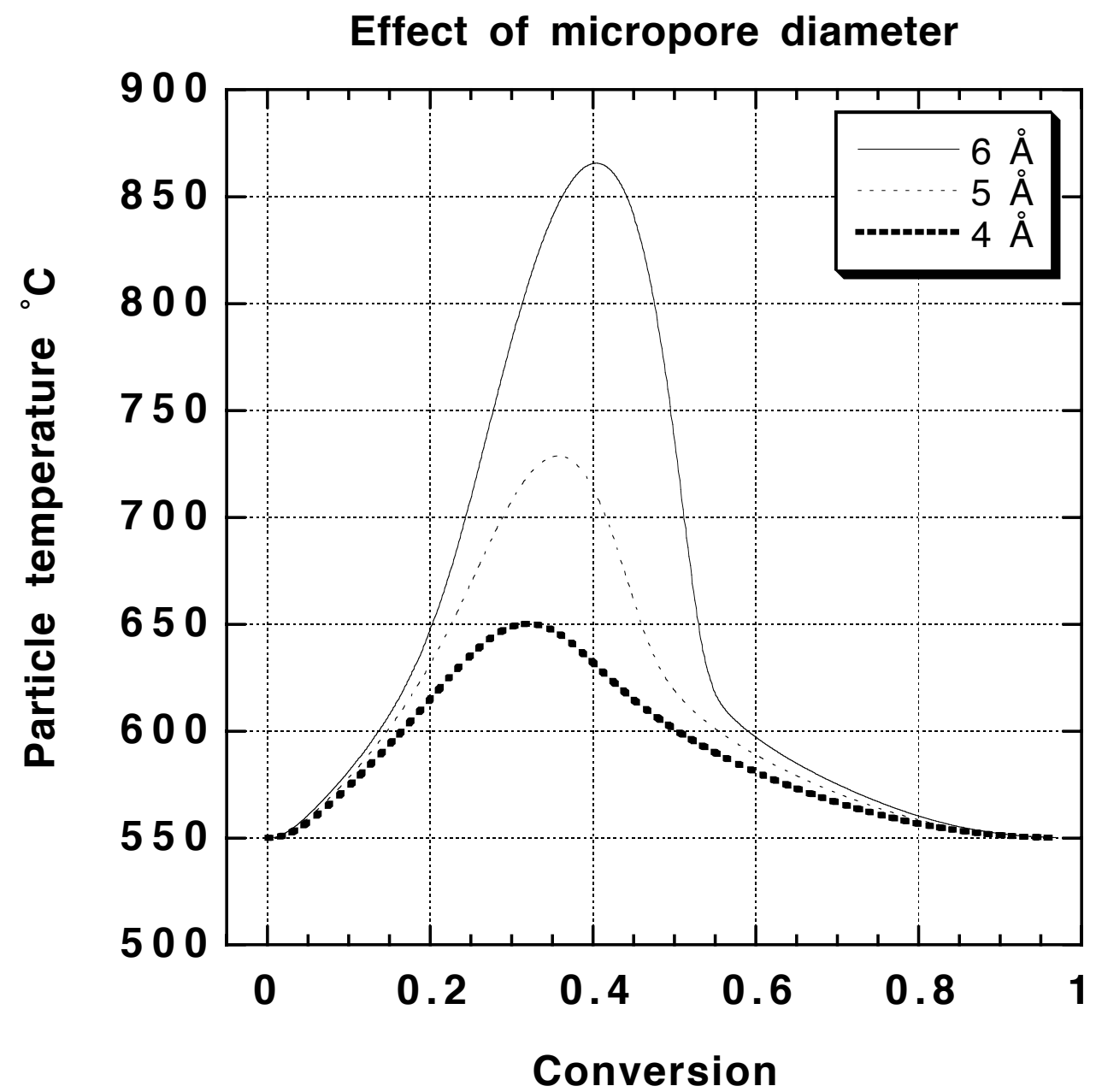

Figure 8.7: $\quad$ Effects of micropore diameter on char ignition behavior at $550{ }^{\circ} \mathrm{C}$ in $33 \% \mathrm{O}_{2}$. 


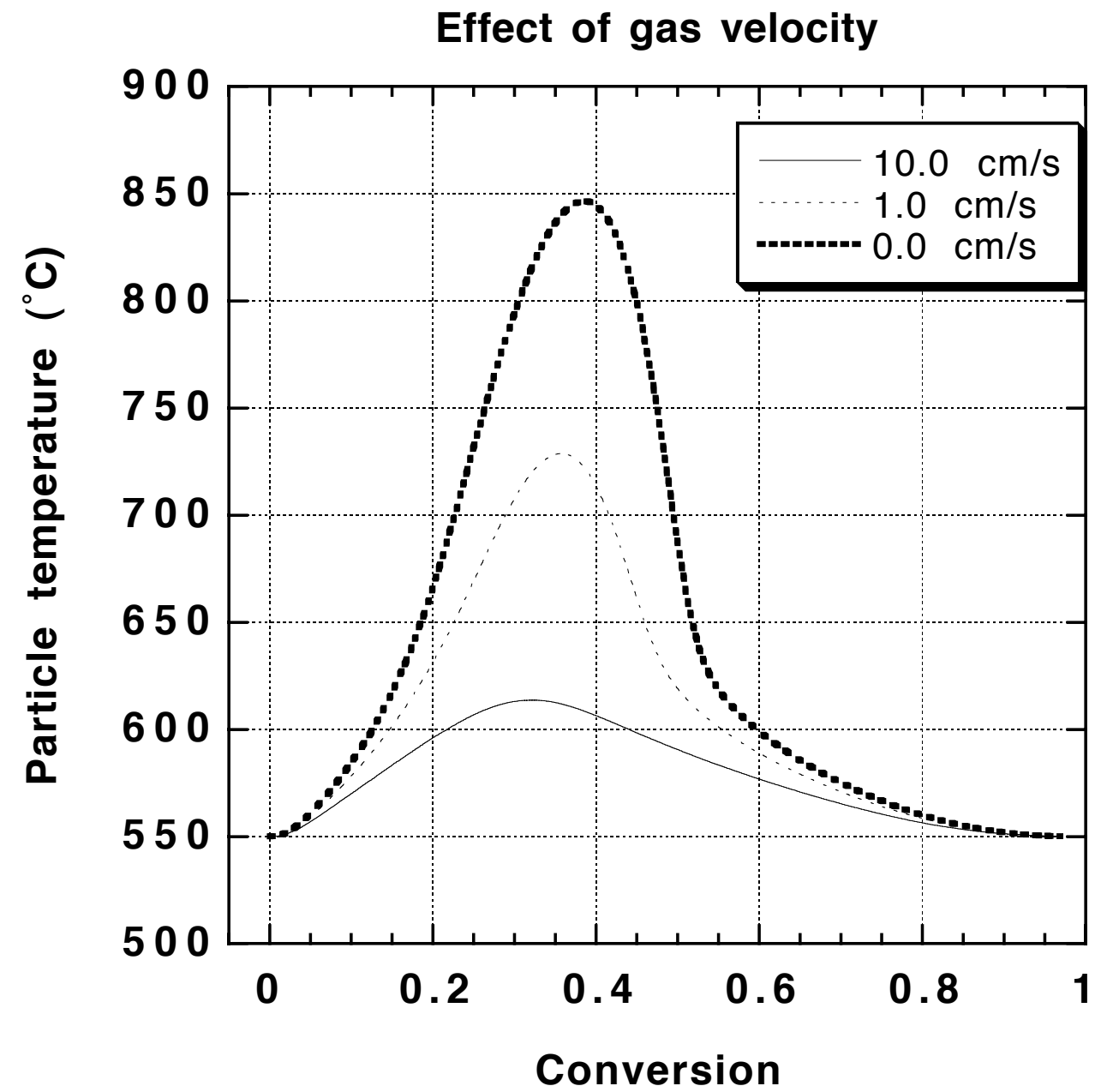

Figure 8.8: Effects of gas velocity on char ignition behavior at $550{ }^{\circ} \mathrm{C}$ in $33 \% \mathrm{O}_{2}$. 


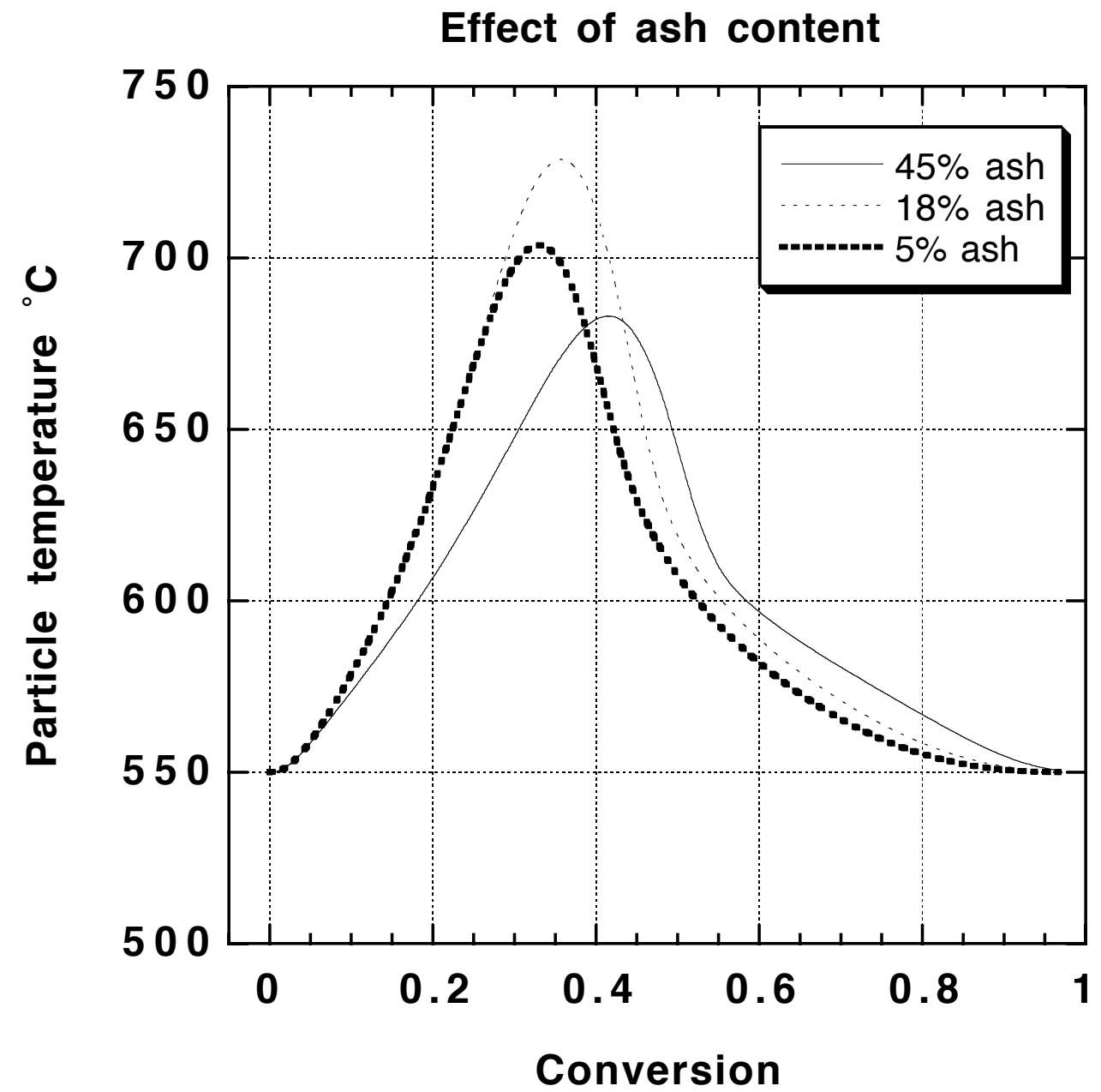

Figure 8.9: $\quad$ Effects of char ash content on char ignition behavior at $550{ }^{\circ} \mathrm{C}$ in $33 \% \mathrm{O}_{2}$. 


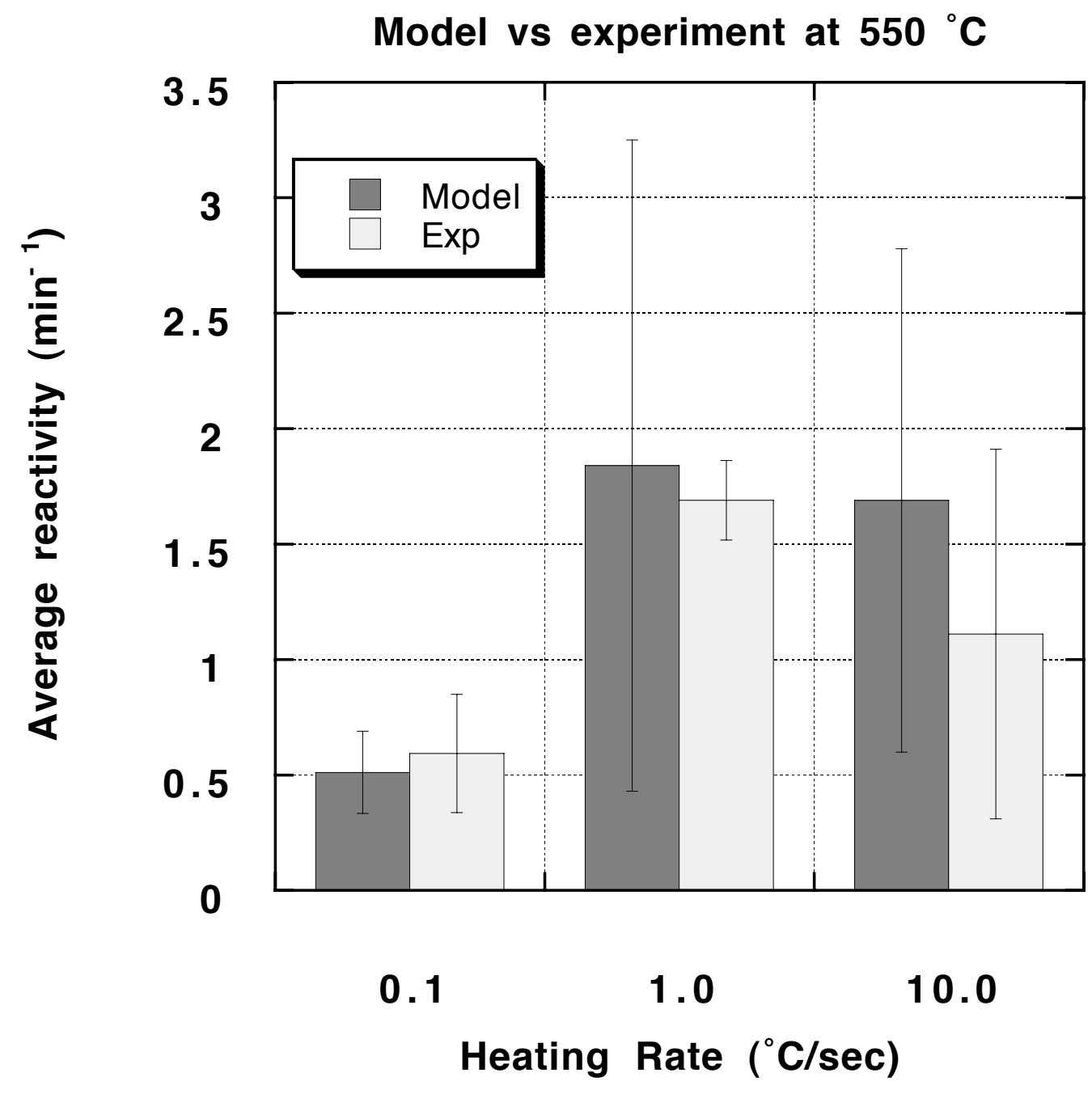

Figure 8.10: Comparison of average reactivity data between model and experiment at a combustion temperature of $550{ }^{\circ} \mathrm{C}$ and $33 \% \mathrm{O}_{2}$. 


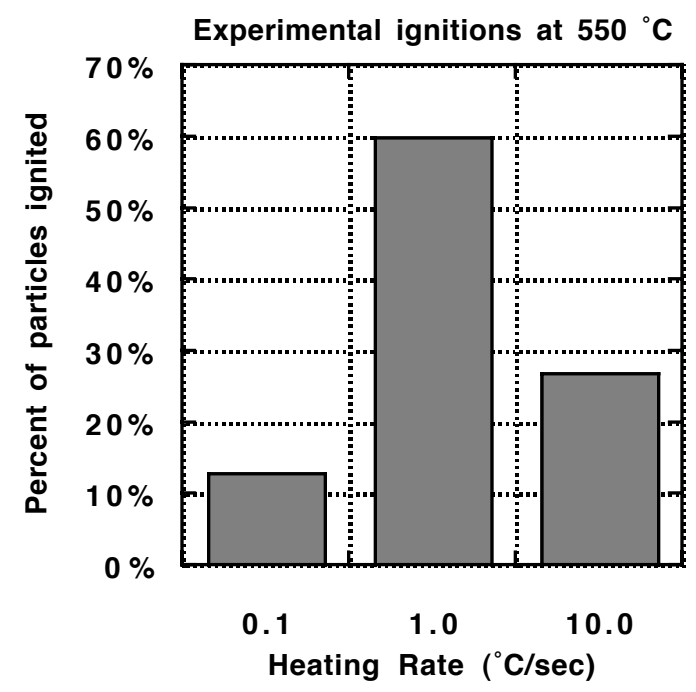

Figure 8.11a: Experimental data on particle ignitions at $550{ }^{\circ} \mathrm{C}$ and $33 \% \mathrm{O}_{2}$.

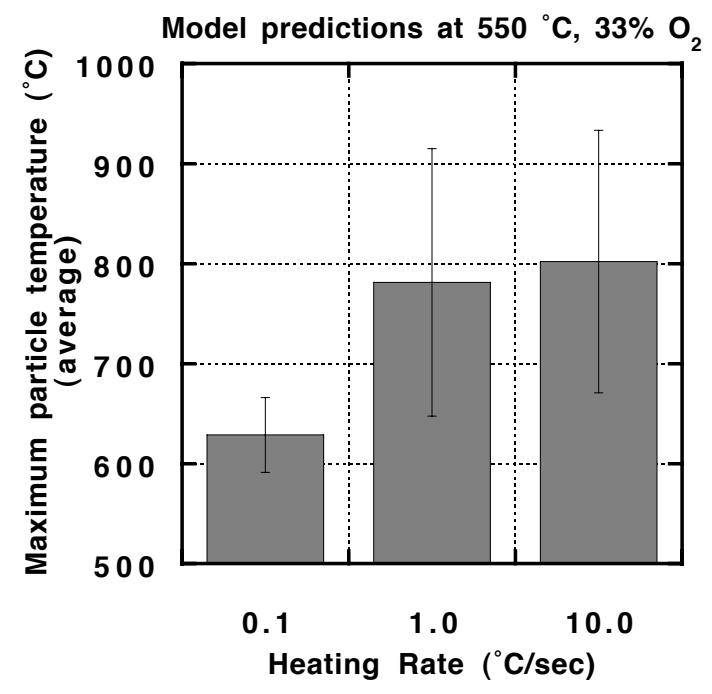

Figure 8.11b: Model predictions of maximum particle temperatures at $550{ }^{\circ} \mathrm{C}$ and $33 \% \mathrm{O}_{2}$. 


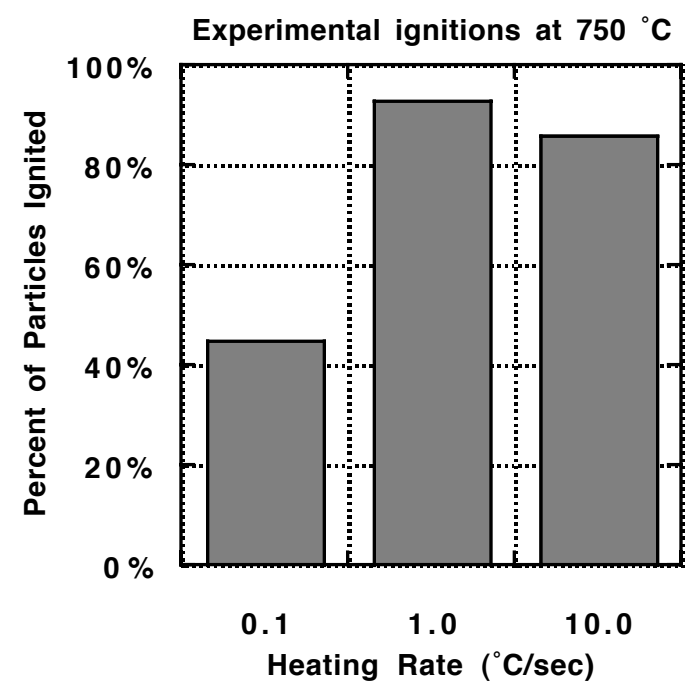

Figure 8.12a: Experimental data on particle ignitions at $750{ }^{\circ} \mathrm{C}$ and $33 \% \mathrm{O}_{2}$.

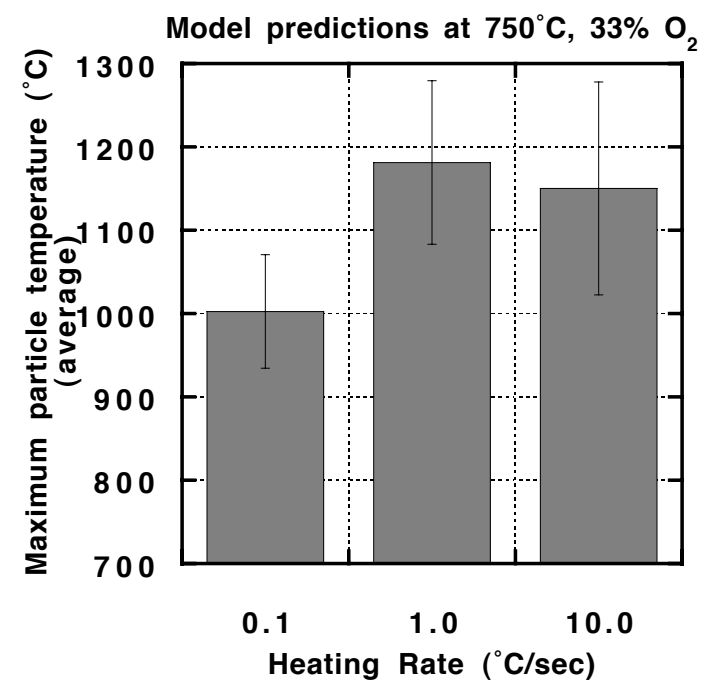

Figure 8.12b: Model predictions of maximum particle temperatures at $750{ }^{\circ} \mathrm{C}$ and $33 \% \mathrm{O}_{2}$. 


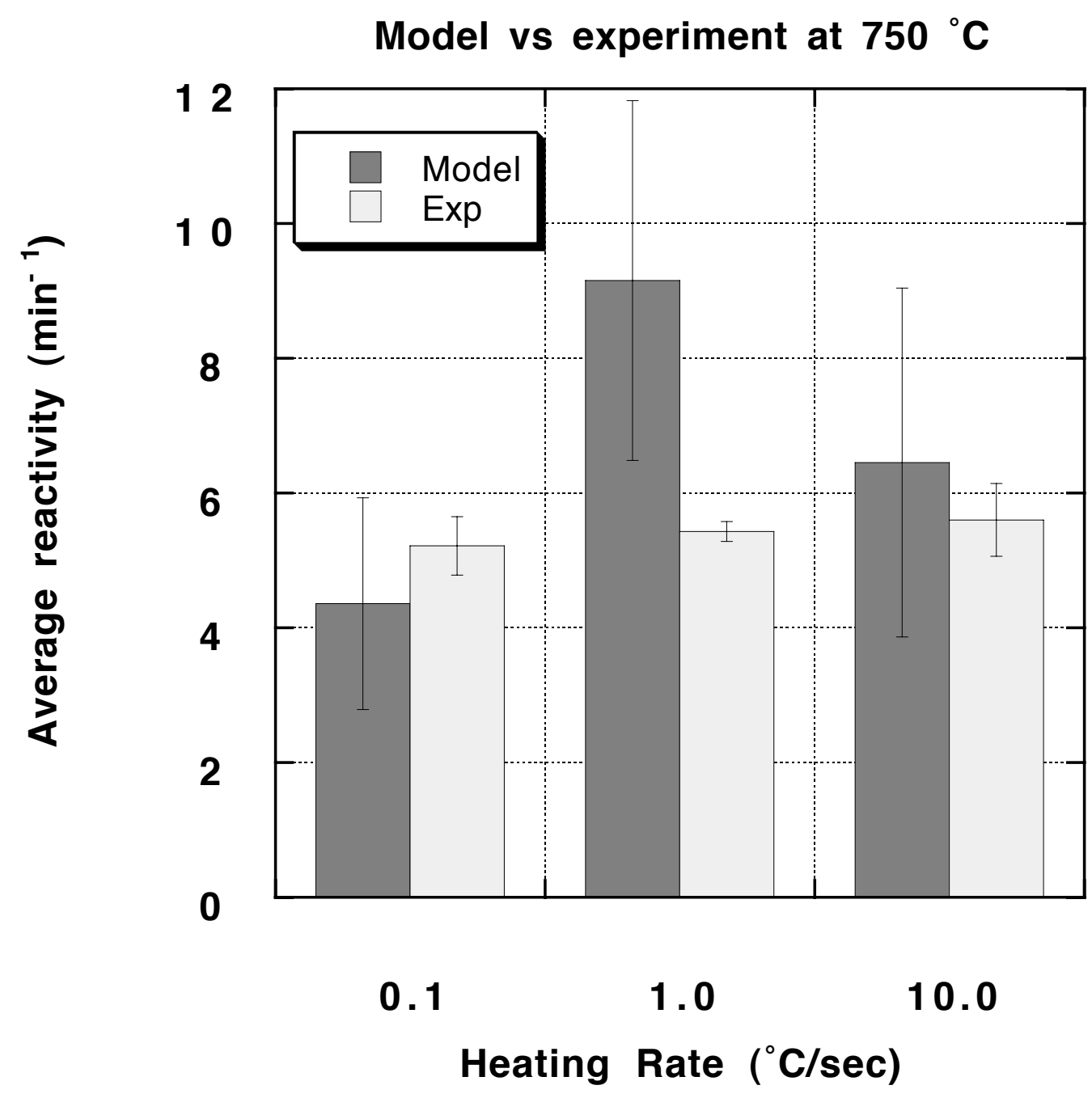

Figure 8.13: Comparison of average reactivity predicted by the model and measured experimentally at a combustion temperature of $750{ }^{\circ} \mathrm{C}$ and $33 \% \mathrm{O}_{2}$. 